\title{
Satellite Power System (SPS) \\ Resource Requirements \\ (Critical Materials, Energy, and Land)
}

October 1978

\section{U.S. Department of Energy}

Office of Energy Research

Satellite Power System Project Office

Washington, D.C. 20545

Under Contract No. EG-77-C-01-4024

\section{DOE/NASA}

SATELLITE POWER SYSTEM

Concept Development

and

Evaluation Program 
Avallable from:

National Technical Information Service (NTIS)

U.S. Department of Commerce

5285 Port Royal Road

Springfield, Virginia 22161

Price: Printed copy: $\$ 7.25$

Microf Iche: $\$ 3.00$ 


\section{Satellite Power System (SPS) Resource Requirements (Critical Materials, Energy, and Land)}

October 1978

Prepared by:

Allan D. Kotin

Allan D. Kotin Economic Consultants

Los Angeles, California 90024

for the

PRC Energy Analysis Company

McLean, Virginia 22102

Prepared for:

U.S. Department of Energy

Office of Energy Research

Satellite Power System Project Office

Washington, D.C. 20545

Under Contract No. EG-77-C-01-4024

\section{DOE/NASA}

SATELLITE POWER SYSTEM

Concept Development

and

Evaluation Program 


\section{NOTICE}

This report was prepared as an account of work sponsored by the United States Government. Neither the United States nor the United States Department of Energy, nor any of their employees, makes any warranty, express or implied, or assumes any legal liability or responsibility for the accuracy, completeness, or usefulness of any information, apparatus, product, or process disclosed, or represents that its use would not infringe privately owned rights. Reference herein to any specific commercial product, process, or service by trade name, mark, manufacturer, or otherwise, does not necessarily constitute or imply its endorsement, recommendation, or favoring by the United States Government or any agency thereof. The views and opinions of authors expressed herein do not necessarily state or reflect those of the United States Government or any agency thereof. 
The author acknowledges the following people for their review of the first draft of this white Paper:

Dr. Meridith S. Crist

Assistant Professor of Finance and

Business Economics

Graduate School of Business Administration

University of Southern California, Hoffman Hall 700

Los Angeles, California 90007

Dr. Alton J. Frabetti

Applied Resources, Inc.

1 Benton Road

Somerville, Massachusetts 02143

Dr. Robert Herendeen

Research Assistant Professor

Energy Research Group

Office of the Vice-Chancellor for Research

University of Illinois Urbana-Champagne

Urbana, IIlinois 61801

Professor John Mixon

Bates College of Law

University of Houston

Cullen Boulevard

Houston, Texas 77004

Jack Yagoubian

Partner

Dames \& Moore

1100 Glendon Avenue, Suite 1000

Los Angeles, Calif. 90024

Bernard Bienstock

Space Scientist

Hughes Aircraft Company

2060 East Imperial Highway

E1 Segundo, California 
This study reveiws the resource impacts of the proposed satellite power system (SPS). Three classes of resource impacts are considered separately: critical materials, energy and land use. The analysis focuses on the requirements associated with the annual development of two five-gigawatt satellites and the associated receiving facilities.

CRITICAL MATERIALS

A review of SPS materials literature reveals several problems, including:

a narrow definition of the universe of materials to be considered; (2) an absense of consistent summarization; (3) inadequate definition of materials with respect to purity, special applications, or physical dimensions; and (4) no distinction between raw materials requirements and manufacturing capacity needs.

A highly simplified screening model is developed and applied to determine which of the 22 materials listed for the SPS could pose potentially significant supply problems. The results of this explicitly illustrative effort indicated that with both silicon and gallium photocell array options, there were two items, mercury and tungsten, which appear to pose such problems. Under the gallium option, two more materials, gallium and silver, qualified as potential or definite problems. Additional manufacturing capacity may be a problem for: hydrogen, synthetic sapphire, arsenic, and graphite.

A three-phase approach to critical materials evaluation is proposed. The first phase is explicitly a screening mode. The brief second phase subjects initially unclassifiable materials to necessary additional primary research. The third phase is an in-depth evaluation of the surviving "critical" materials. Requjrements for initial screening include: expanded definition of the materials universe; better definition of materials; a systematic approach involving both quantified and judgmental thresholds; and sensitivity analysis. The in-depth evaluation effort should cover: projections of supply and reserves; analysis of current and projected non-SPS demands and potential for substitution; potential technological change; and price elasticity.

More refined estimates of materials requirements are not needed in the initial screening state especially if uncertainty tolerances are given. Better definition is probably more important.

\section{ENERGY ANALYSIS}

Estimating the energy requirements of the SPS is an exercise in what has come to be called energy analysis or energy modeling. Single-valued figures of merit e.g., net energy ratios, are of 1 imited value without a detailed treatment of the amount and types of component energies required. The major methodologies are: process analysis; input-output analysis; eco-energetics; and "hybrid" process and input-output analysis which is the indicated choice for the SPS. The methodology selected for the SPS should permit straightforward comparison to other energy technologies. SPS energy requirements may be an important public and legislative issue, despite the lack of consensus on methodology or philosophical validity. Significantly, this is the only resource area which has been 
studied by experts unrelated to the SPS design-evaluation effort.

The earliest of three published studies of SPS energy requirements (PRC) is based solely on input-output analysis and demonstrates the problems in using broadly defined economic sectors. The two other studies (Herendeen and JPL) rely heavily on energy-intensity estimates, though of rather different types. Accounting for indirect energies is acknowledged to be a significant problem. This literature review points up four important issues: (1) the "dynamic" consequences of the SPS program in which, though each individual plant has a high positive energy ratio, high initial energy requirements create a protracted energy drain during the initial years of operation; (2) for the SPS the "fuel-included" energy ratio and the "fuel-excluded" ratios are the same, while for all fuel technologies the fuel-included energy ratio is always less than 1 ; (3) the joint problem of uncertainties in energy-intensity estimates and in SPS performance estimates; and (4) the need to translate target cost reductions in dollar terms for key SPS components into projected energy cost reductions.

Detailed primary process analys is is recommended for elaborate and/or high technology elements of the program, e.g., solar cell fabrication. Use of published material energy-intensities or specific energy data is recommended when the process analysis has progressed to the point where further analys is relates to homogenecus materials and well studied processes. Policy decisions are needed with respect to the treatment of uncertainties, the modularization of the energy analysis, and the integration of critical materials and energy analyses.

LAND USE

The primary impact of SPS operations on land use will be the massive land requirements for 60 rectenna sites. Each site will require approximately $200 \mathrm{~km}^{2}(80$ square miles). This estimate includes a microwave buffer zone for which no definitive size has been established. The major problem is not how much land rectennas will use but where they can be located since there are so many constraints on the siting of rectennas.

Siting studies to date apply a set of criteria in a constrained mapping exercise to identify specific candidate locations. A sharply contrasting approach is used in this paper to identify and measure "eligible areas" rather than to locate candidate sites. In coordination with the Rice University Initial Identification of Eligible Areas study, computer mapping techniques are used to display and measure different combinations of example exclusion criteria. Among those variables which appear significantly to limit the eligible area are: flyways of migratory wildfowl, land in or suitable for cultivation, thunderstorms, latitude north of $40^{\circ}$, and seismic hazards. Comparing the distribution of eligible areas to 1985 power demand and energy imports suggests that the North Central and Northeast regions of the U.S. will be substantially underrepresented. Several key siting issues in need of resolution include: better data on microwave effects, potential for offshore siting, rigidity of costs, several climatological issues, and the need for some further examination of the purely local siting criteria. 
INTRODUCTION

I. CRITICAL MATERIALS

I-1. INTRODUCTION 3

Background and General Purpose 3

Redefinition of Study Scope 3

Organization of the Report 4

I-2. OBJECTIVES OF THE REDEFINED STUDY 4

I-3. METHOD OF APPROACH AND LIMITING ASSUMPTIONS

Use of Simplified Classification

Focus on Current Production and Resources 5

Universe of Materials Limited to July 13 Reference
Concept

Other Major Limitations $\quad 6$

I-4. CURRENTLY AVAILABLE RESEARCH ON SPS MATERIALS 6

Pre-1978 Sources 6

PNL "Solar Technology" Study 6

Recent JP! Study of the SPS Materials 8

$\begin{array}{ll}\text { Other Recent SPS References } & 9\end{array}$

Additional Recent Data on SPS Requirements $\quad 9$

I-5. PROTOTYPE MATERIALS CLASSIFICATION SCHEME 10

Selection of Data Base for Comparison $\quad 10$

Categories of "Criticality" 10

Special "Non-Gradient" Categories 11

Summary Results of Screening Analysis 12

Silicon Option $\quad 12$

Gallium Option $\quad 12$

$\begin{array}{ll}\text { Supporting Computations } & 15\end{array}$

I-6. REVIEW OF COMPONENT MATERIALS 20

Category 1 Materials: "No Apparent Problem" 20

Category 2 Materials: "High Demand - No Apparent
Problems in Expansion"

Category 3 Materials: "Possible Problem" 21

Category 4 Materials: "Real Potential Problem" 22

Category 5 Materials: "Definite Problem" 23

Category A Materials: "Apparent Problems in 23 $\begin{array}{ll}\text { Manufacturing Capacity" } & 23 \\ \text { Category B Materials: "Insufficient Data for Analysis" } & 24\end{array}$

Issues Raised in Classification Effort 25 
I-7. GENERAL FEATURES OF A PRACTICAL APPROACH TO CRITICAL MATERIALS Recommended Three-Phase Approach

I-8. PHASE 1: COMPREHENSIVE INITIAL SCREENING PROCESS 26

Expanded Definition of the SPS Materials Universe 27

Better Definition of Materials 27

Documented and Systematic Approach to Screening 28

Sensitivity Analys is of the Screening Model 28

I-9. PHASE 2: CLASSIFICATION OF INITIALLY UNCLASSIFIABLE VARIABLES

I-10. PHASE 3: IN-DEPTH EVALUATION OF SURVIVING CRITICAL MATERIALS

Suggested Elements of an In-Depth Analysis 29

I-11. NEED FOR BETTER SPS MATERIALS ESTIMATES 30

General Requirements for Critical Materials Analysis 30

Better Definition of Materials 30

Explicit Treatment of Quantitative Uncertainty 31

Deferral of Refined Estimating Efforts 31

REFERENCES TO SECTION I: CRITICAL MATERIALS 32

II. ENERGY ANALYSIS $\quad 35$

II-1. INTRODUCTION 35

Background and General Objectives $\quad 35$

Definition of Net Energy $\quad 35$

Key Issues and Organization of the Analys is 35

II-2. ENERGY ANALYSIS: DEFINITIONS, OBJECTIVES, AND VALIDITY 36

Definitions $\quad 36$

Objectives $\quad 39$

Validity Issues $\quad 40$

Philosophical - Methodological Issues 41

Energy Quality $\quad 41$

Boundary Problems $\quad 41$

Energy Measurement: Thermal vs. Electrical 43

Issues Involving the Treatment of Time 43 
TABLE OF CONTENTS

(Continued)

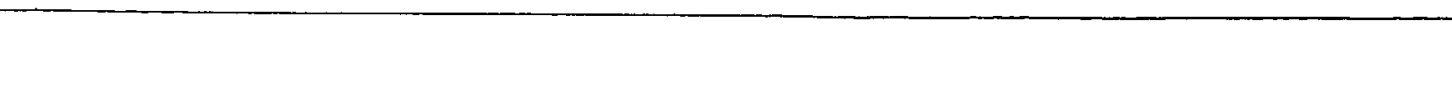

\section{II -3. ALTERNATIVE METHODOLOGIES}

Process Analys is

Input-Output Analysis

Page

Hybrid Analysis: Combining Process and Input-Output Analyses

Eco-Energetics

Summary and Implications for the SPS

44

44

45

48

49

50

II-4. PUBLISHED ENERGY ANALYSES OF THE SPS

An Initial Input-Output Approach: "A Survey of Satellite Power Stations"

A Materials-Energy Approach With Accompanying Uncertainty: The Herendeen Paper

A Different Materials-Energy Approach: The JPL "Resource Assessment"

Energy Requirements of Space Vehicles, Rice's PNL Paper

63

Implications of Extant Research

II-5. RECOMMENDED APPROACH TO ENERGY ANALYSIS FOR THE SPS 66

$\begin{array}{ll}\text { General Criteria for Selecting a Methodology } & 66 \\ \text { A Recommended Mixed Methodology Approach } & 66\end{array}$

A Recommended Mixed Methodology Approach

Design and Policy Prerequisites

66
68

Recommended Procedural Sequence

69

Task 1 - Module Definition

69

Task 2 - Prepare Materials List by Module

69

Task 3 - Identify Initial Candidates for Process Analys is

Task 4 - Establish Base for Comparison to Other Technologies

Task 5 - Assemble Key Energy Data Base Items 70

Task 6 - Perform First-Cut Preliminary Analys is $\quad 70$

Task 7 - Iterate and Refine Analysis 70

REFERENCES TO SECTION II: ENERGY ANALYSIS

III. LAND USE

III-1. INTRODUCTION

III-2. AN OVERVIEW OF SPS LAND USE AND SITING 76

Estimated Land Area Requirements $\quad 76$

The Problem of Inadequate Definition 70 
TABLE OF CONTENTS

(Continued)

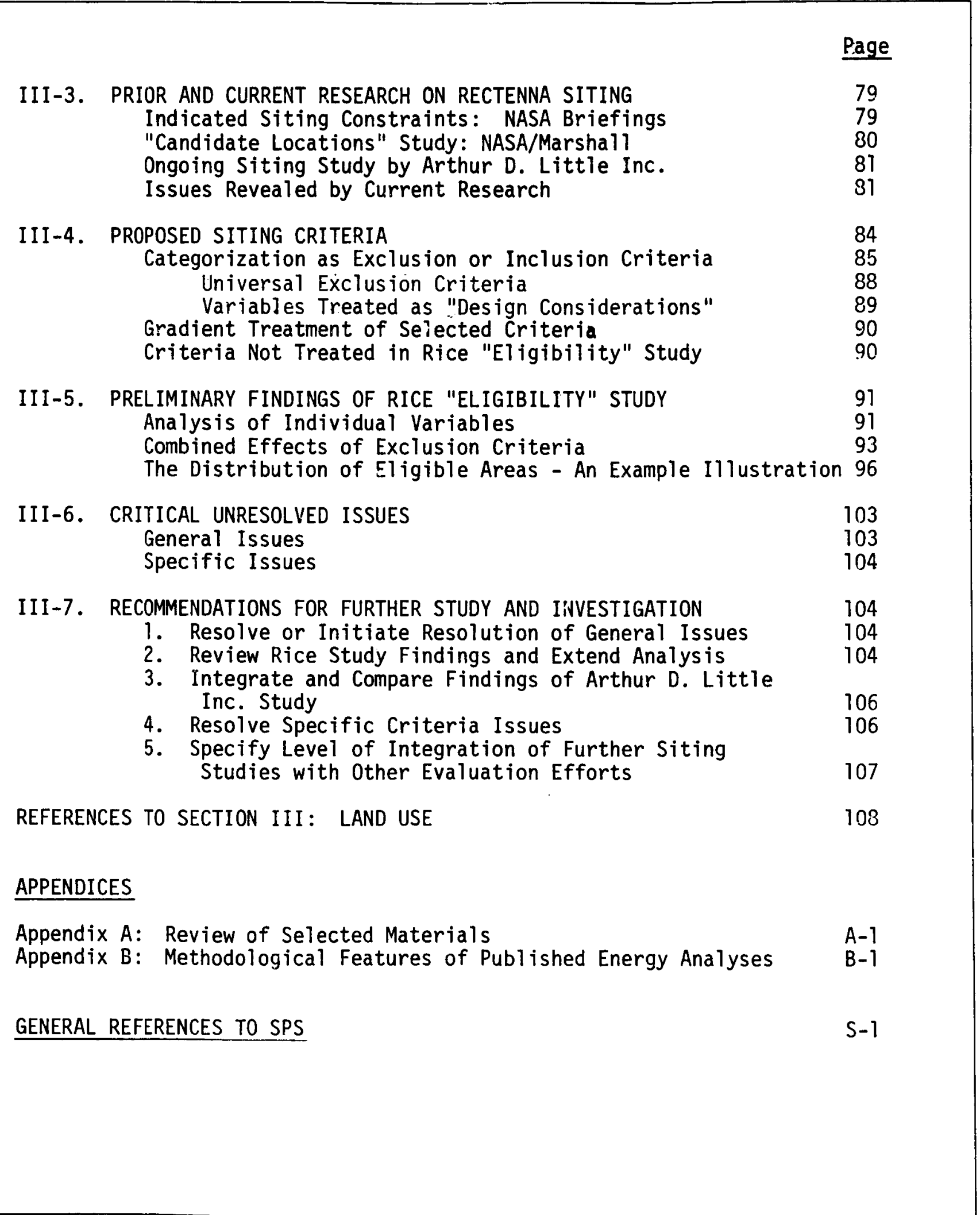


Exhibit

I-1

I -2

I -3

II - ]

II-2

I I -3

II -4

I I -5

II-6

III-]

III -2

III-3

II I-4

I I I -5

II I -6

II I-7

II I -8

I I -9

I I I - 10
Preliminary Classification of Potential Critical Materials for SPS: Silicon and Gallium Arsenide Options

SPS Materials Availability/Demand Analysis, Two 5 GW Satellites Per Year,Silicon (JSC) Concept

SPS Materials Availability/Demand Analysis, Two 5 GW Satellites Per Year, Gallium Arsenide (MSFC) Concept 18

Energy Flow Diagram and Commonly Used Energy Ratios 37

Capital Energies for SPS by Major Component

Input Variables Whose Uncertainties Are Taken Into Account: Herendeen

SPS Energy Ratios: Herendeen

Methodological Problems in Energy Analys is of Two Technologies: Herendeen

Energy Payback of 48 10-GW SPS Satellites: JPL 64

\section{Rectenna Site Concept}

Arthur D. Little, Inc. Rectenna Siting Requirements 82

Proposed Initial Siting Criteria

Area (and Percent of U.S.) Excluded by Each Mapped Variable

Incremental Exclusion Effects and Remaining Eligible Area 94

Census Regions and Geographic Divisions of the U.S.

Projected Regional Electricity Consumption and Total Energy Imports, 1985

Hypothetical Distribution of Sites

Regional Distribution ard Area Per Site for Five Basic Exclusions with Latitude Climate Variations

Specific Issues Requiring Resolution

105 
The U.S. Department of Energy and the National Aeronautics and Space Administration are investigating a potential new source of energy called the Satellite Power System (SPS). The SPS concept involves placing a satellite equipped with a large solar cell array in orbit around the earth. The arrays collect light energy from the sun, convert it to electricity and then to microwaves, beam the microwaves by a transmitting antenna on the satellite to a receiving antenna on the ground. The receiving antenna (rectenna) changes the microwaves back into electricity to be fed directly into the utility network. Both the satellite and the rectenna are on the order of $100 \mathrm{~km}^{2}$ in size and the system is designed so that each rectenna will provide 5,000 MW (5 GW) to the utility grid.

Inevitably, development of such a system will have far-reaching effects on society. This system can be expected to have substantial resource impacts. The large mass of the satellites themselves (36,000-50,000 metric tons), the large resource demands involved in launching the required materials into orbit and assembling the satellite, the production of satellite components, e.g., solar cells, on a massive scale, and the substantial land and materials requirements of the rectenna facility, will all contribute to these resource impacts. Space launch propellant requirements, much of the fabrication effort, and many of the materials to be used are highly energy intensive. Consequently development of the SPS will make significant demands on U.S. energy resources.

The subject of this paper is the resource impact of development of the SPS. In this context, resources are considered in three categories: critical materials, energy, and land. Not all of the materials required for development of the SPS wi17 be "critical." Notwithstanding the massive demands of this program, some materials are in sufficiently plentiful supply so that even the SPS program will not create shortages or production problems. The identification of which, among the many SPS materials requirements, may be considered as "critical" is itself a major effort.

The energy requirements of the SPS need to be estimated and then related to the energy output of the SPS. Such "net energy analysis" is mandated by law and may, under certain circumstances, provide a useful basis for comparing the SPS to other proposed power generation technologies.

The land use requirements of the SPS derive primarily from the need for large land areas for rectenna sites. The modest additional land requirements for space launch facilities are not considered as part of this study. A total of 60 sites for 5 -GW rectennas could require as much as $12,000 \mathrm{~km}^{2}$ (3 million acres) of land area. The apparent topographic requirements and potential problems created by extensive microwave transmission further exacerbate the problem by limiting the potential areas in which rectenna sites can be located.

\section{ORGANIZATION OF THE REPORT}

Each of the three classes of resources considered in this paper (critical materials, energy, and land) is treated in a separate section of this report. To some extent, these sections are independent sub-reports. For each of the three 
classes of resources, this white paper presents: (1) an introductory statement including organization of the study effort; (2) a review of recent literature on SPS impacts in the resource area considered; (3) a recommended approach to further systematic study of the problem; and (4) a list of references that apply specifically to the topic under study.

At the conclusion of the report a series of appendices are provided containing detailed information not included in the main text. These appendices are followed by limited set of general references which apply to the SPS as a whole and which were used throughout the report.

\section{ACKNOWLEDGEMENTS}

The project manager for the entire resources study effort was Allan D. Kotin. He also served as principal investigator in the areas of energy and land use. Meyer Levadie, Consulting Economist, served as principal investigator in the study of critical materials.

The Space Solar Power Research Program of Rice University began a related study effort of land use and siting during the preparation of this white paper. This parallel study effort deals with initial identification of eligible areas for rectenna siting. Preliminary outputs from this related study provide much of the substantive input to the discussion of land use and siting presented in this paper. Every effort was made to coordinate the two study efforts and the author wishes to particularly acknowledge the strong support and valuable assistance provided by James Blackburn, Project Manager for the Rice University study. 
I-1. INTRODUCTION

Background and General Purpose

The stated objective of this part of the study was to survey and summarize study efforts to date which treat the problem of SPS critical materials and to identify current research needs. To accomplish this study, the Statement of Work identified three tasks: (1) assemble and analyze relevant literature; (2) concurrently establish a list of questions that must be answered to determine the societal impact of the SPS; and (3) determine where unanswered questions exist and suggest an approach to answering them.

Initial analysis of these tasks suggested that there were five dimensions to the problem:

1. Defining (listing) the universe of materials to be evaluated.

2. Establishing the approximate annual requirements of the SPS program in a summary form suitable for comparison to published data on production, resources, and reserves.

3. Collecting or at least establishing the availability of published data on production, resources, and reserves.

4. Establishing, or defining how to establish, criteria for determining which materials are "critical".

5. Indicating a procedure or approach to further in-depth evaluation of critical materials.

Initially, it was hoped that the first two elements described above, e.g., defining the universe of materials and establishing SPS quantities, were already done and could be abstracted from the existing literature. Subsequent efforts could then be devoted to the last three items.

\section{Redefinition of Study Scope}

Initial efforts at assembling a list of candidate materials and approximate annual requirements were based on the two separate space center concepts presented in January 1978 (References S2 and S14). ${ }^{1}$ Just as the data assembly was completed, the partially-merged reference concept for the SPS was presented by the two NASA centers on July 13 (Reference S15). Shortly thereafter, the client indicated that there was a major parallel critical materials effort under way at Pacific Northwest Laboratories of Battelle Memorial Institute (Reference 9).2 On the client's instructions, further work on establishing the materials universe and initial quantities was postponed pending results from the Pacific Northwest Laboratories (PNL) effort.

1 References prefaced by an "S" are general references to the SPS which are listed at the end of the entire report.

2 Other references, identified with numbers only, are listed at the end of this section. 
Unfortunately, meaningful data from PNL on the SPS was not forthcoming. It became apparent by the end of July that any attempt to refine materials estimates in a form suitable for processing by the PNL computer model was clearly premature. The problems of approximation inherent in individual space center estimates of the reference concept for SPS were compounded in the merged concept presented on July 13. Subsequent discussion with PNL, Johnson Space Center, and the client indicated that more refined estimates would not be available within the time frame established for the white paper.

As a result of this development, the white paper study effort was redesigned to become an illustrative prototype of the initial criteria screening process. The primary purpose here is to focus on what is a general method of determining which SPS materials will be "criticai" and to identify, at least highly tentatively, some of the problems in classification.

Organization of the Report

The balance of this section of the report is divided into eleven parts. In Section I-2 immediately following this introduction, the objectives of the redefined study effort are presented. The method of approach and limiting assumptions are discussed in Section I-3. Currently available research on SPS materials requirements is reviewed in Section I-4.

A prototype materials classification scheme is presented and summarized in Section I-5, while Section I- 6 provides a review of individual component materials. The general features of a three-phase approach to this problem are described in Section I-7. The following three sections (I-8, I-9, and I-10) discuss the three phases of the recommended approach.

The concluding section of the report deals with the sensitive issue of the need for better materials estimates for the SPS.

\section{I-2. OBJECTIVES OF THE REDEFINED STUDY}

In addition to the literature review summarized later in this report, the primary focus of the study effort was to develop a prototype model. Six key objectives were established in the development of this prototype model:

1. A preliminary classification of criticality.

2. Identification of definitional problems.

3. Identification of particularly sensitive data problems.

4. An initial effort at segregating raw and bulk material considerations from considerations of manufacturing and processing capacity.

5. Identification and development of appropriate criteria for defining, in operational terms, various tests of "criticality."

6. Development of a framework for an expanded study. 
The development of a framework for expanded study encompasses several important elements. Perhaps the most important of these is to expand the universe of materials considered to assure that indirect materials requirements are also considered. The need for a staged approach to further study is another key element, as is consideration of what to do with those materials that are critical.

\section{I-3. METHOD OF APPROACH AND LIMITING ASSUMPTIONS}

\section{Use of Simplified Classification}

In the prototype SPS materials screening model, only five general categories have been developed. These are deliberately only quasi-quantitative. Neither the time or scope of the effort permitted the development of refined categories of the type used, for example, in the PNL study (Reference 9). Furthermore, refined categories may not be needed at the screening level. The major purpose here is only to illustrate a screening process. A generalized logical approach to increasing "criticality" is used rather than any precise gradient.

\section{Focus on Current Production and Resources}

The initial screen applied to each material was its relationship to current domestic production and/or shipments. There were several reasons for this. One obvious reason is that if the annual requirements of the SPS can be accommodated in present production capacities or represents a small proportion of current domestic shipments, it seems very unlikely that this would become a particular problem twenty-five years from now. Of course, this is to some extent contingent on reserves and resources. On the other hand, any careful consideration of reserves and the much less well defined category of "resources" is clearly beyond this analysis and is subject to a great deal of controversy. There is at least relative agreement on what constitutes domestic production and shipments.

Universe of Materials Limited to July 13 Reference Concept

In the NASA briefing of July 13 , a list of annual materials requirements was provided for the SPS based on two five-gigawatt satellites per year. This list showed materials needed for both silicon and gallium options. These options refer to two alternative designs of the solar (photovoltaic) cell array to be constructed in space, one using silicon as the primary element in the array and the other using gallium arsenide. The materials on these two lists comprise the materials universe to be considered in this prototype exercise.

Since the analysis is 1 imited to the July 13 briefing 1 ist, materials used during the design, development, testing, and evaluation phase were excluded. Furthermore, no treatment was provided in this list of secondary or tertiary requirements. In many cases the list was given in terms of the specific component elements rather than the bulk materials from which those elements are extracted. For the most part no attempt was made to estimate the indirect or bulk materials requirement. One notable exception to this was aluminum for which much of the analysis is done in terms of the primary resource ore, bauxite. Furthermore, no 
attempt was made to examine or disaggregate the categories identified on that list as "miscellaneous."

Other Major Limitations

Throughout this prototype analys is no consideration was given to either current or projected prices nor was there any attempt to examine price elasticity.

No extended or systematic effort was made to consider projections of either production or reserves through the time of initial SPS operations (approximately the year 2000). Some attention was given to future reserves in the context of where they were located. Import dependency in itself was not a critical parameter but import dependency on specifically sensitive countries is considered at a very generalized level.

\section{I-4. CURRENTLY AVAILABLE RESEARCH ON SPS MATERIALS}

\section{Pre-1978 Sources}

For the most part, resource and critical materials analyses developed prior to 1978 are largely irrelevant. The reference or "baseline" concepts developed prior to the beginning of this year differ significantly from the current reference concept. These variations are in such critical areas as the total number of satellites, the number of satellites and/or generating capacity to be installed each year, the start date, and the underlying technology or design. It is, however, interesting to note that most pre-1978 materials that did present materials lists had many serious problems. Some of these problems continue to characterize currently available sources on the SPS. Most notable is a lack of consistency in definition. In some cases, SPS materials were presented only for the satellite itself while in other cases all system components, including space transportation, rectennas, etc., were apparently considered.

Reference to back-up data, particularly back-up data used for the January 1978 briefing provided little if any enlightenment. In these much more voluminous sources the major problem was an absence of aggregation. While material quantities were frequently but not universally provided for individual system components and sub-components, they were nowhere summarized except in the briefing.

PNL "Solar Technology" Study

In March 1978, Battelle Pacific Northwest Laboratories published a study entitled "A Methodology for Identifying Materials Constraints to the Implementation of Solar Technologies" (Reference 9). This study, which was subsequently updated in July 1978, presents a highly sophisticated methodology for addressing materials requirements. This methodology is presumably based on extensive prior analysis and a voluminous and detailed data base. It employs a computer model which undertakes a form of process analysis to identify not oniy primary materials requiremerits but also secondary and tertiary materials requirements, carefully distinguishing between raw materials and bulk materials. 
While the PNL study may represent the state of the art in the application of materials analys is to solar technology, it is not clear that the PNL model is an appropriate tool for an initial screening analys is of the critical materials required for the SPS.

First of all, the paper deals essentially with terrestrial solar technology. It does treat in some depth the material requirements associated with photovoltaic solar processes, including an analysis of gallium cells. It does not, however, deal in any way with space transportation. Nor is it clear whether the gallium or silicon photocell technology discussed in the paper is the same as or even comparable to the technology proposed for the SPS.

Even if the scope of the PNL study were expanded to include all aspects of the SPS, there exist some important methodological questions.

The use of such an elaborate computer-based model may represent "over engineering" in the case of initial screening to define critical materials. A simpler methodology might represent a savings in time and effort. Furthermore, the acquisition, reduction, and evaluation of elaborate projective data is a time consuming and controversial process. It may be desirable to defer that process and apply it only to those materials that warrant it.

The somewhat mechanistic nature of the PNL computer model presents certain problems for the SPS analysis. Automatic and more or less universal assumptions are made with respect to the expansion of domestic production capacities (e.g., ten percent per year). Furthermore, comparably universal assumptions are made as to the relationship between current "known" reserves and future total "resources". Resources are assumed to be some multiple of reserves even in the absence of any published data. While historically, resources have turned out to be much larger than reserves of petroleum, for example, there is no assurance that the same relationship will apply to all or even most of the SPS materials.

Finally, the very nature of the PNL computer-based model forces all findings into a formal quantitative hierarchy. While it may be argued that this resolves the problem of "operationalizing" the definition of "critical", this is not necessarily desirable. There should be opportunity in any classification for the introduction of judgmental or logical elements that are not readily quantifiable.

The foregoing reservations with respect to the PNL model's applicability to the SPS apply primarily to its use in an initial screening process. It may well be that the PNL methodology is much more suited to the detailed evaluation of surviving materials, particularly if it is supplemented by some qualitative evaluation. Neither the scope of this white paper nor the expertise of its authors warrant any critical evaluation of either the assumptions or the data base implicit in the mode?.

The PNL study provided a very valuable supplementary data base and checkpoint for the prototype analysis developed in this white paper and the author wishes to 
acknowledge the substantial assistance it afforded.

Recent JPL Study of the SPS Materials

Jet Propulsion Laboratory, under contract to NASA Johnson Space Center, published a document entitled "Satellite Power Systems (SPS): A Preliminary Resource Assessment" (Reference 11) in August 1978. This document was received too late for extensive review and detailed incorporation into this white paper. Nevertheless, a brief review of the paper did provide the basis for certain observations.

Once again the problem of the changing definition of the SPS program rears its head. The "nominal system" used as an SPS reference concept in this report is taken from a 1976 NASA document prepared by the Johnson Space Center entitled "Initial Technical, Environmental, and Economic Evaluation of Space Solar Power Concepts". 3 The concept described in that reference differs in several important respects from the "reference concept" used in this study. The number of satellites was originally 112, scaled down to 48 . These were $10 \mathrm{GW}$ satellites representing a total capacity of $480 \mathrm{GW}$ as opposed to 300 in the reference concept. Although the annual rate of construction seems to have been about the same, i.e., $10 \mathrm{GW}$, this is not altogether clear since in the original 112satellite program, the annual rate would have been much higher. Furthermore, the JPL reference concept includes assembly in low earth orbit (LEO) rather than in GEO (geosynchronous orbit) as in the reference concept used for this white paper. Even a non-technical review of the numerous changes that have occurred in the reference concept since 1976 raises serious questions as to the applicability of the materials assessment derived from that era to the reference concepts being used now.

Notwithstanding this serious possiblity of inconsistency, there are several valuable features in the JPL analysis. This analys is is much more explicitly concerned with the joint treatment of resource requirements and energy requirements. The modular treatment of various system components in the JPL analysis is very clear and it does provide the crucial intermediate step of summarizing annual material requirements by major system components. One problem of a minor nature is that the summaries tend to be expressed in materials requirements per megawatt per year. It is not clear, without extensive further detailed analysis, whether these estimates can be converted on a per megawatt bas is to the current reference concept. Any attempt to convert these estimates to the present concept without further analys is would seem clearly unwarranted, given the substantial changes which may have occurred in the SPS concept. In addition, since the JPL analys is is based on the Johnson concept only, no consideration is given to materials requirements associated with the gallium option.

A brief review of this publication also indicates that is it primarily devoted to estimating requirements rather than to assessing whether those requirements

3 JSC 11568, Vol. I - Summary, NASA Lyndon B. Johnson Space Center, Houston, TX, August 31, 1976. 
are in some sense "critical".

Furthermore, the report itself acknowledges that "not all of the resources necessary for the production facilities were evaluated." This is similar to the limitation of much of the existing requirements data for the SPS in that it does not deal with secondary or tertiary effects.

Other Recent SPS References

A review of the SPS bibliography and inquiries with informed sources did reveal three other recent references related to certain aspects of the materials requirements of the SPS. One of the most notable of these was the recent study by Arthur D. Little Inc. entitled "Evaluation of Solar Cells and Arrays for Potential Solar Power Satellite Applications" (Reference 10). This publication, dated March 1978, is restricted primarily to a consideration of the solar cells but it does address in some detail the particular problems created by the gallium concept. These problems derive from the very limited production of gallium in relationship to the substantial requirements associated with the SPS.

One of the chief benefits of the Arthur D. Little study is in its treatment of the prerequisites for extensive solar cell development in the section entitled "Industrial Involvement in the Manufacturing of Solar Cells/Arrays for the SPS Program." This section provides virtually the only detailed analysis of the extraction and processing requirements associated with solar cell materials. Uniquely among the resources reviewed for this study, this report discusses present production capacity, reviews briefly the technology of production, identifies approximately the units in which production or extraction are likely to expand, and specifically references the national origin of critical materials. This reference proved invaluable in the current research in that it specifies the level of purity or type of an element. As noted below, it is almost useless to describe "silicon" without knowing the level or grade of silicon refinement required for the photocells. It may be that other references presume this knowledge but it is nowhere made explicit.

The coverage of the Arthur D. Little study is limited in that it does not deal with space transportation, space assembly, etc. On the other hand, this study, probably more than any other reviewed, provides a model of the type of information which should be provided in any attempt to screen the universe of materials requirements for those which are critical.

\section{Additional Recent Data on SPS Requirements}

Subsequent to the July 13 briefing in which the "merged" reference concept was presented, attempts were made to collect additional data from both Battelle Pacific Northwest Labs and Johnson Space Center on materials requirements. The only material received from Battelle dealing specifically with the SPS was based not on the merged concept but rather on the prior Johnson Space Center concept and was dated May 1978. It described a 10-gigawatt satellite program and referenced, rather curiously, a 1985 initial date. (See Reference 3.) For these and other reasons, this admittedly preliminary draft was not 
incorporated in this white paper. Not only was there no treatment of the gallium option but the author ( $R$. Watts) explicitly noted that most recent design changes had not been incorporated.

Efforts were also made to obtain more detailed materials requirements lists for the merged reference concept. The results of this effort produced a data submission by the Johnson Space Center (Reference 14) which suffered from problems typical of much of the prior information. Namely, the estimates were given in terms of per unit requirements of the various unit components such as the HLLV (Heavy Lift Launch Vehicle), the COTV (Cargo Orbital Transfer Vehicle), etc. Elaborate calculations with respect to use, $1 \mathrm{ife}$, and requirements per satellite were needed if in fact a reliable estimate of requirements per year were to be established. Since time was limited and parallel information was not readily available for the gallium option, it was decided to stay with the presumably mutually consistent 1 ists of materials provided in the July 13 briefing.

\section{I-5. PROTOTYPE MATERIALS CLASSIFICATION SCHEME}

Selection of Data Base for Comparison

This illustrative prototype classification scheme was designed to present a preliminary "screening" model for identifying which SPS materials were "critical". The initial and major premise in this analysis was that any material for which SPS annual requirements represented less than 10 percent of current production or shipments was presumably not a critical material. This presumption was qualified only with respect to the very high dependency on imports from sensitive countries.

This deliberately simplistic premise permitted the assembly of a minimally adequate data base within the available time. The data base was restricted primarily to domestic production or shipments with further information adduced as needed on domestic reserves and resources. The percentage of materials imported and the primary countries from which they were imported were also identified. To a large extent, the depth in which questions of import dependency and future reserves were considered was a function of data availability rather than a systematic attempt to treat all materials in the same detail.

The foregoing limitations of this data base and the approach used are themselves somewhat revealing. To the extent that materials can be screened out meaningfully with a limited data base, it may be quite desirable in minimizing the obviously extensive and controversial problems involved in establishing the "definitive" estimates for any material. This more arduous effort can be appropriately reserved for those materials which emerge as "critical".

Categories of "Criticality"

Theoretically, a critical material for production of the SPS is any material for which the annual and/or cumulative demands of SPS production, according to the current reference concept, would present a significant supply or production problem for the U.S. economy at the time of production. 
The foregoing definition has all the rigor and refinement of such bureaucratic terms as "reasonable and proper", "fair and just", etc. There is a need for some more operational definition of what constitutes a critical material. Initially, such definition should provide for different levels of criticality since it may not be obvious how "critical" a particular material is. Some sort of gradient is clearly needed.

To address this issue, the prototype analysis used five categories. The first of these, identified as "No Apparent Problem," reflects those materials for which SPS demands represent less than 10 percent of annual recent production or shipment levels.

The second category is designated as "High Demand-No Apparent Problem in Expansion." SPS annual requirements for materials in this category represent over 10 percent of recent annual production but the likelihood of a supply problem seems to be remote because of some combination of readily available imports, known changing technologies, or apparent potential substitution.

The third level or category used is simply identified as "Possible Problem." Materials in this category are ones for which SPS demand is not particularly large but the supplies are highly uncertain. Specifically, only arsenic and gallium for the silicon option appear in this category. Arsenic and gallium are required in sufficient quantities under the gallium option so that they are placed in a much higher category. The modest amounts needed for the silicon option, while they would strain existing resources production, do not appear to be a certain or even a real potential problem. The present data base is insufficient for a final determination.

There are certain materials for which a "Real Potential Problem" exists. This fourth category of "criticality" is basically defined as a failure to meet any of the tests for the three lower categories. At the same time, it is not the highest possible category because there would appear to be adequate reserves but potential supply problems could be created either by import sensitivity or inadequate extraction capacity at the present time. Materials in this class clearly warrant more detailed examination.

The fifth and highest category of "criticality" is "Definite Problems." In this category are those materials for which the SPS annual demand would tax some combination of the total known reserves and/or existing and projected extraction technology. There is only one such material in this category at this time and that is gallium.

Special "Non-Gradient" Categories

One of the most useful by-products of this preliminary analys is is the identification of certain materials for which the problem is not adequate supplies of the raw materials but rather limitations in manufacturing and processing capacity. These materials are assigned the special category identified as "A: Manufacturing Capacity Problem." 
In addition, there were a few materials for which the readily available data base was so inadequate, at least within the limits of this white paper effort, that no categorization could be made. Graphite and arsenic are the two items in this category "B" group. In these cases, there exists substantial uncertainty as to the substitutability of other final products (graphite) or the availability of adequate processing capacity (arsenic).

Summary Results of Screening Analys is

The results of this highly preliminary screening are summarized in Exhibit $1-1$. The results are presented separately for the silicon and gallium options since the materials requirements of the two are quite different. Subject to the qualification that this analys is is still highly preliminary, it appears that most of the materials required in either option are in the first two categories of "No Apparent Problem" or "High Demand-No Apparent Problem in Expansion."

In the original list of the materials provided in the July 13 briefing, there were 22 materials listed. Two of the materials 1 isted have been somewhat relabeled. Instead of aluminum, the exhibit refers to "bauxite (aluminum)" since the bauxite production is a critical parameter. Similarly for the material listed as "graphite epoxy," the exhibit shows it as "graphite epoxy (graphite)" to reflect the fact that graphite is the critical raw material. There is no apparent shortage of the manufactured material epoxy.

\section{Silicon Option}

Exactly half of the 22 materials are in the first classification of "No Apparent Problem" for this option. Another three materials, bauxite, oxygen, and silicon are in the second category of "High Demand-No Apparent Problem in Expansion."

Only four materials are in the "Possible" or "Real Potential Problem" categories. These are arsenic and gallium in the "Possible Problem" category and mercury and tungsten in the "Real Potential Problem" category.

Two of the materials in this option are better characterized as problems in expanding manufacturing capacities than as raw materials shortage (Category A). These are glass and hydrogen.

One material, yraphite, falls into Category B, "Data Sources Inadequate." Gallium Option

In general, the gallium option is characterized by a lesser number of "noncritical materials. Ten of these materials are in the lowest category, "No Apparent Problem." One material, bauxite, is in the next lowest category, "High Demand-No Apparent Problem in Expansion."

For the gallium option, there are no materials in the "Possible Problem" category. The two materials in that category for the silicon option, arsenic and 

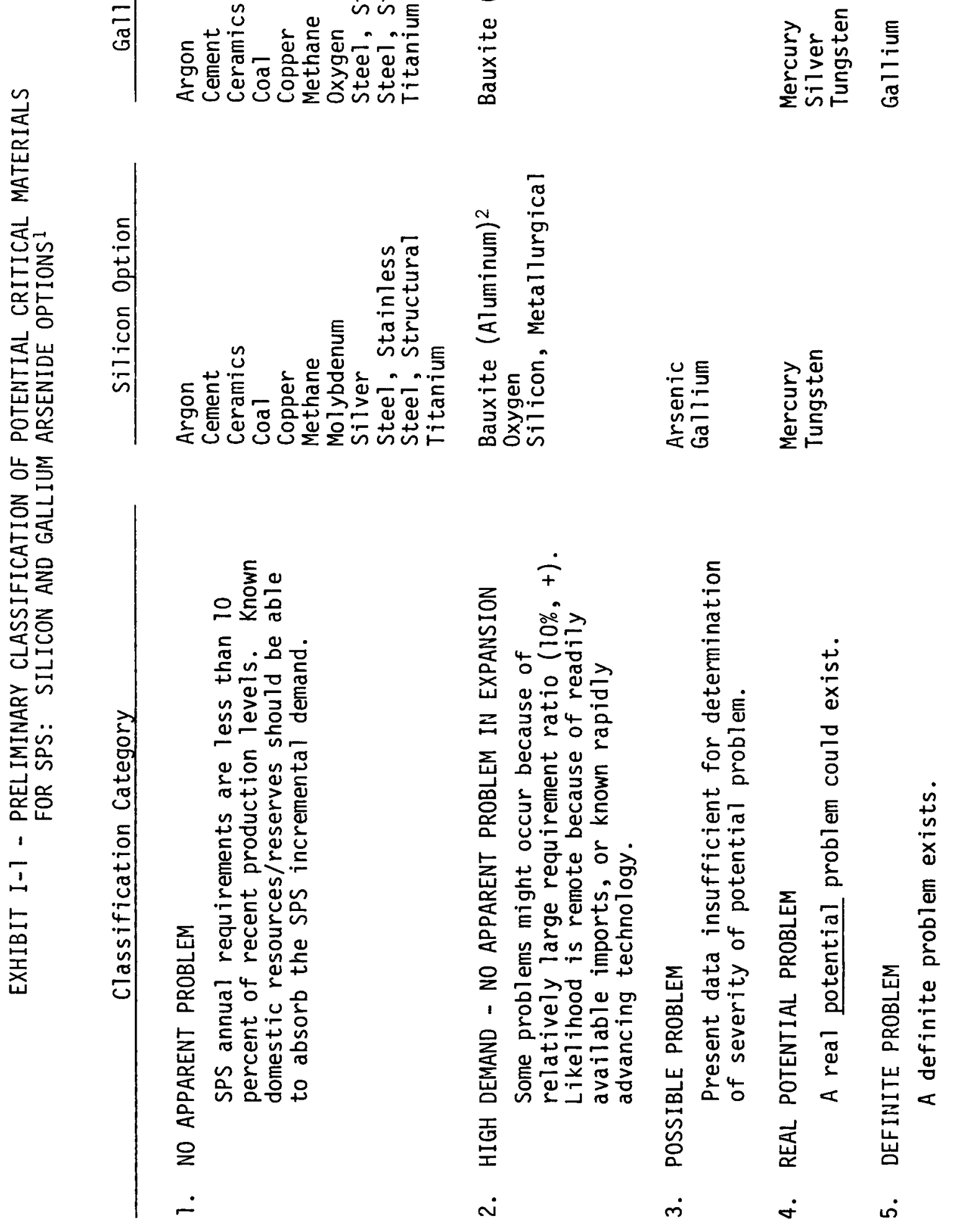


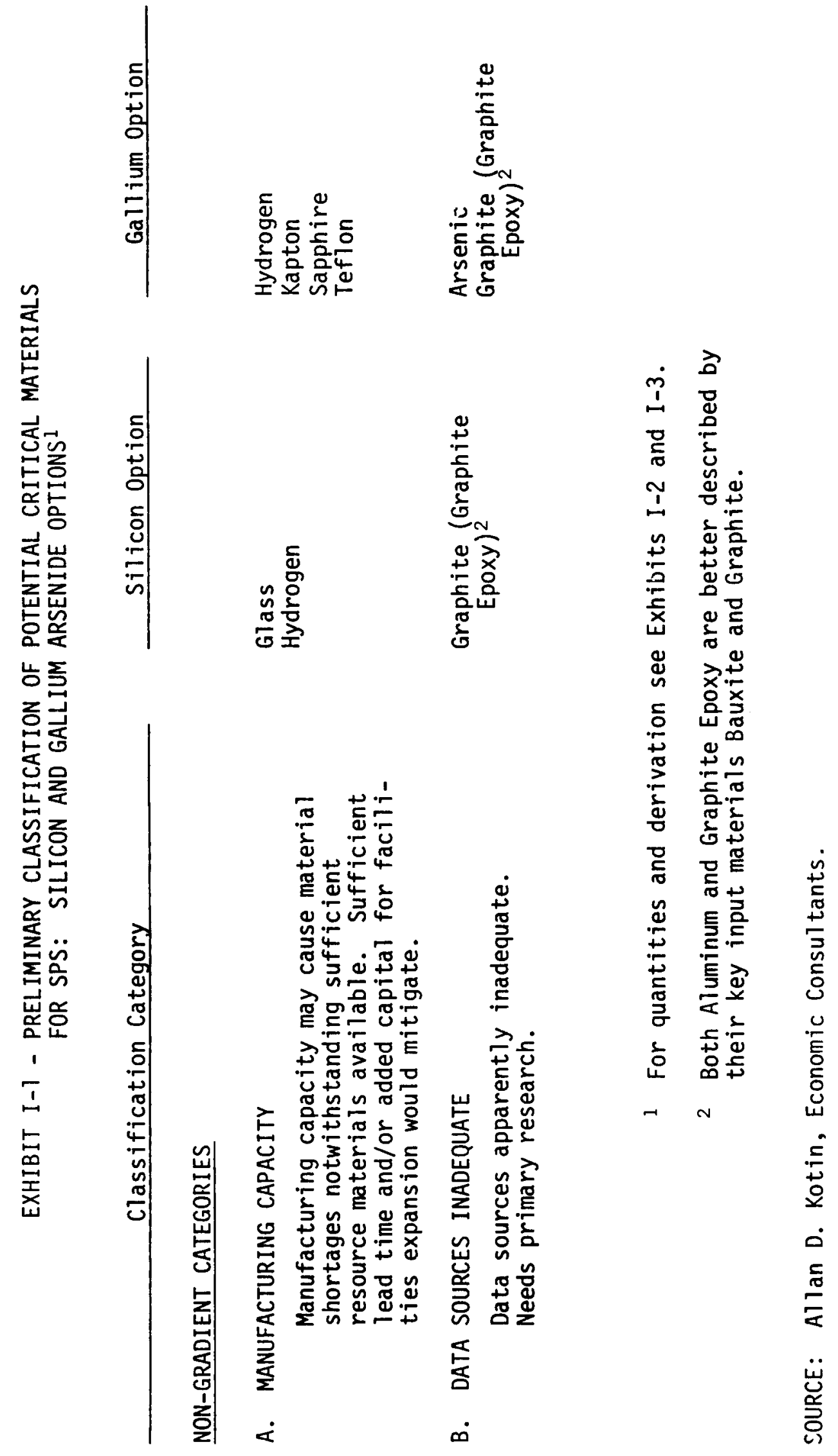


gallium, were considered as "Possible Problem" only because of the small amounts needed. With the gallium option, however, the amounts needed are much larger, and consequently, the level of severity is much greater.

Under the gallium option, mercury, silver, and tungsten are in the "Real Potential Problem" category and gallium in in the "Definite" category.

"Manufacturing capacity" problems would appear to apply to hydrogen, sapphire, teflon, and kapton under the gallium option (Category A).

Data sources are inadequate for the classification of arsenic as well as graphite. The reason for the change in the status of arsenic as between the two options is that the much larger quantities needed in the gallium option move it from the "Possible Problem" to the "Data Sources Inadequate" category. With the small amounts needed in the silicon option, there is less need for extended further research. The problem is basically of limited production related to limited demand. In the case of the gallium option, the problem may be restated as substantial demand in the face of 1 imited and uncertain supply.

\section{Supporting Computations}

The computations which support the foregoing classifications of materials are presented in Exhibit I-2 and I-3. The two exhibits are identical in format and construction. The silicon (Johnson Space Center) concept is summarized in Exhibit I-2 while the gallium arsenide (Marshall Space Center) concept is described in Exhibit I-3.

The annual requirements estimate is taken directly from the materials list in the July 13 briefing (Reference S15). The table provides for three data items on each material: domestic resources, domestic production capacity, and production/ shipments volume. Not all three are filled out for each material. In the case of highly processed materials, e.g., aluminum and argon, no resources estimate is given but instead reliance is placed on production and shipments data. In the case of raw materials which are converted to a final material, e.g., bauxite, resources and/or shipments data are given. All materials requirements assigned to one of the five categories are compared to at least one and, in most cases, two indices of current resources, capacity, and production.

In the final column, the "Criticality Rating" for each material is given as a number or letter corresponding to those used in Exhibit I-1. SPS annual requirements are expressed as a percentage of current (recent) production or shipments in the adjoining column. In some cases, a compound rating has been assigned, e.g., $B(4)$ for arsenic. This indicates that arsenic more appropriately belongs in the $B$ category of requiring further detailed research. If, however, it was necessary to make some very preliminary judgment on its "criticality" level without further research, that level would be Level 4, "Real Potential Problem." For purposes of the prior summary (Exhibit I-1), the non-gradient category was used. The gradient level is provided here only for reference. 
$\frac{n}{n}$

윤

㟧里

خ

$\exists$ 뚠

क

光岕 岁

W

光岳出

뚠중

$\sum^{\frac{1}{2}}$

象是

志 $\therefore$ 하영

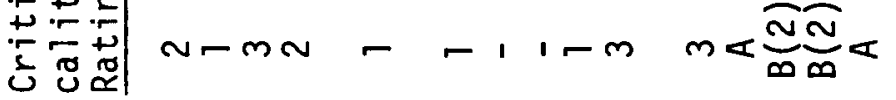

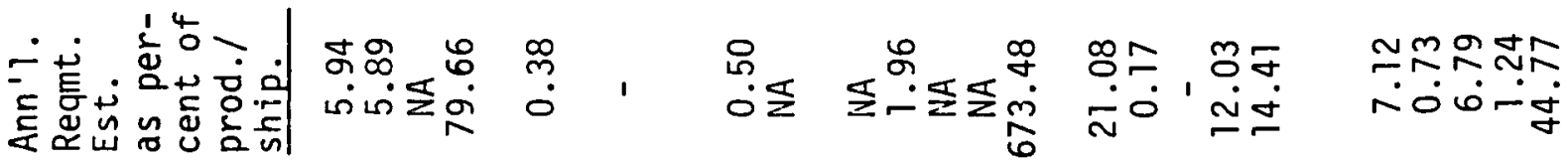

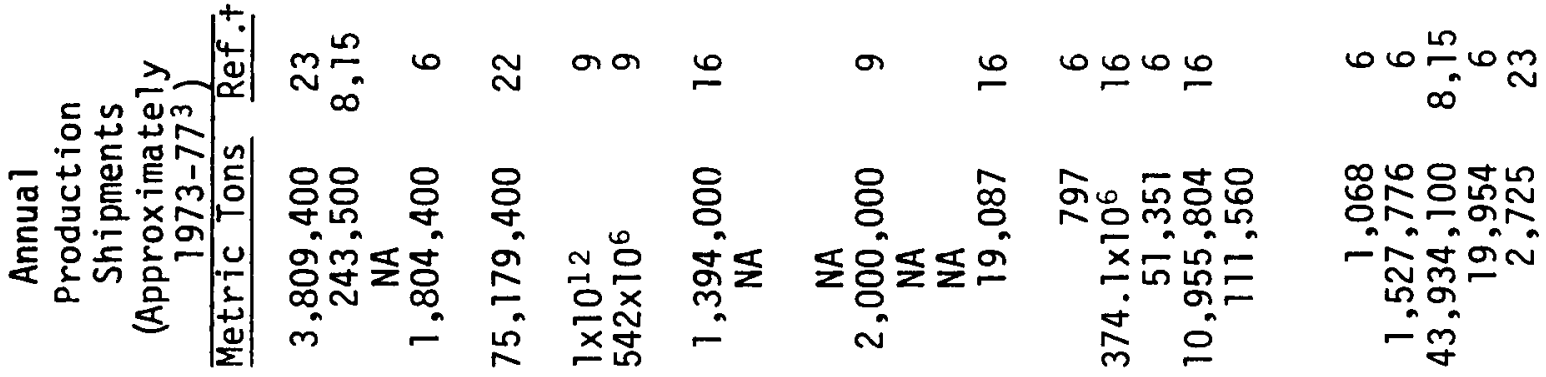
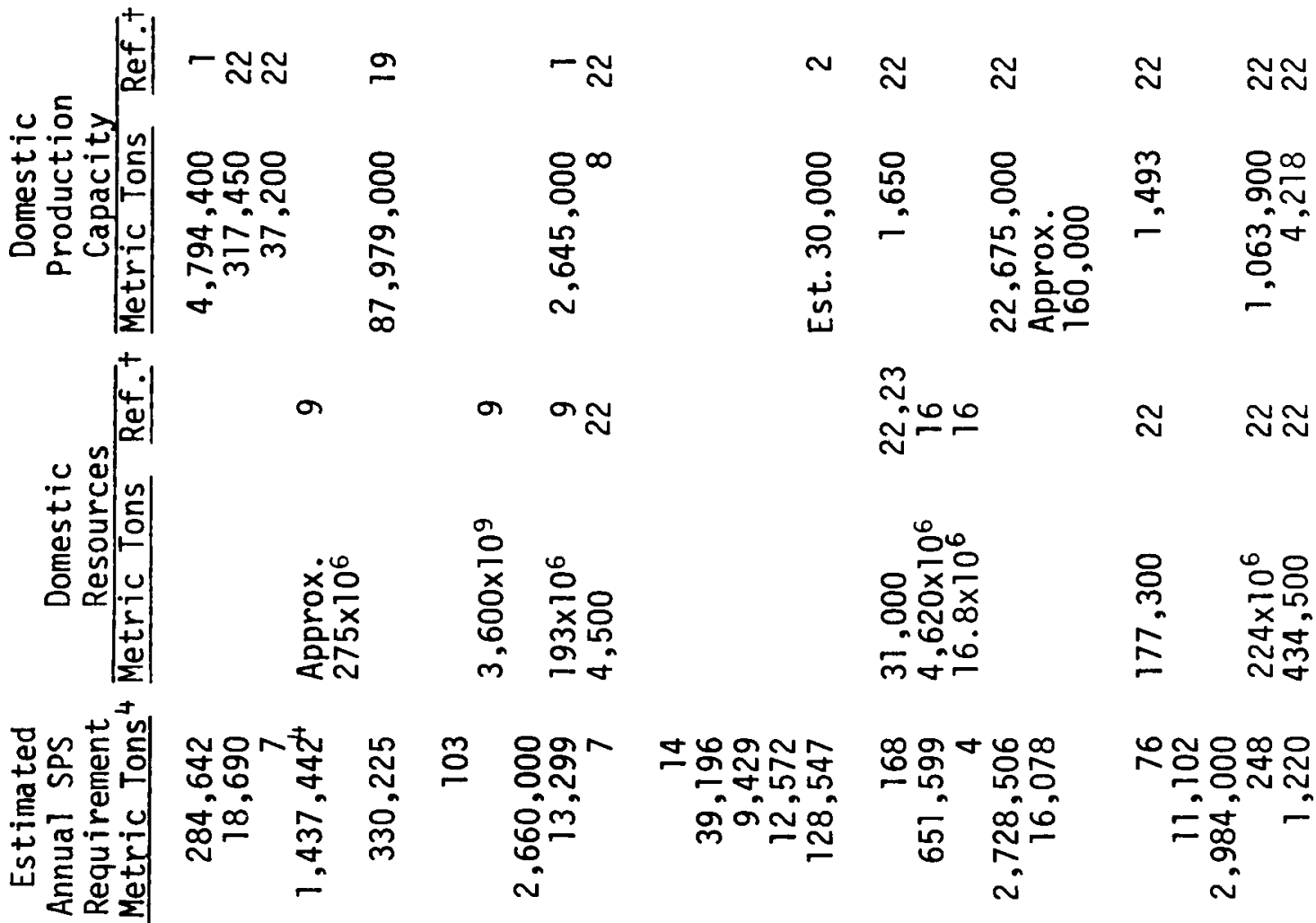

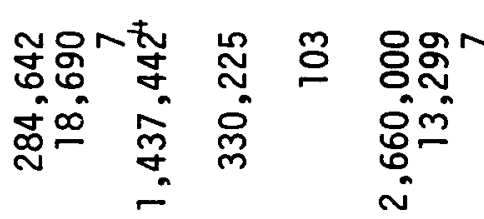

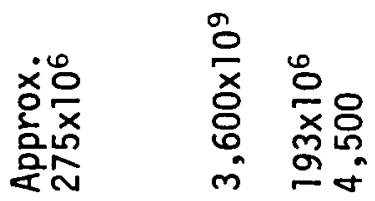

a $a N$

$\mathfrak{n}_{N}^{n} \mathscr{N}$

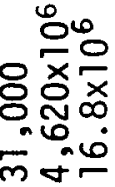

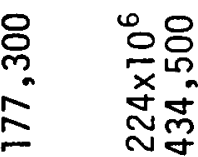

$\cong N \cong$

ㅇํำำ

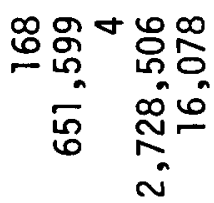

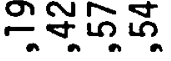
ஸ்

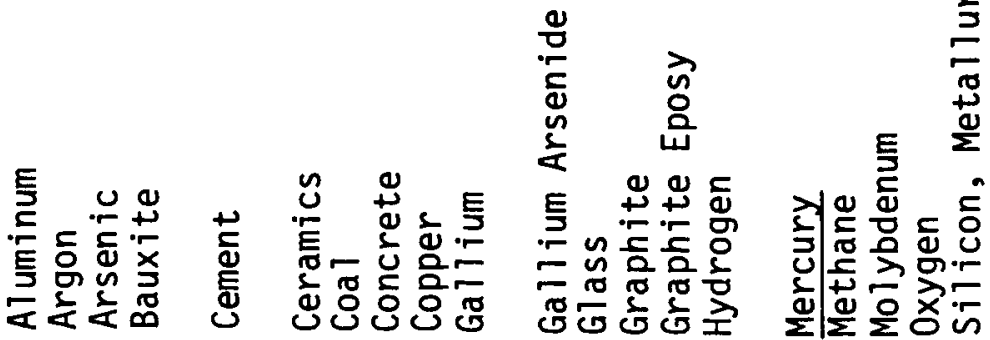

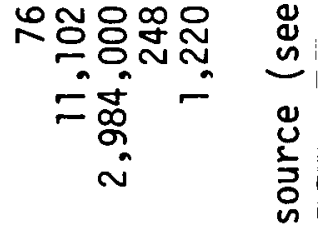

$\underset{7}{\mathbb{0}}$

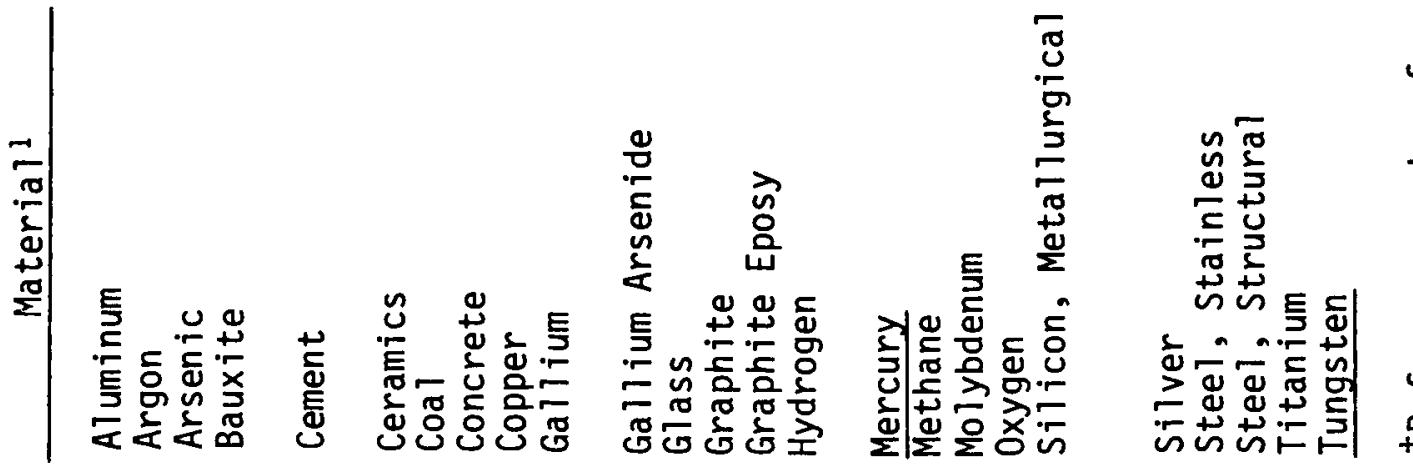




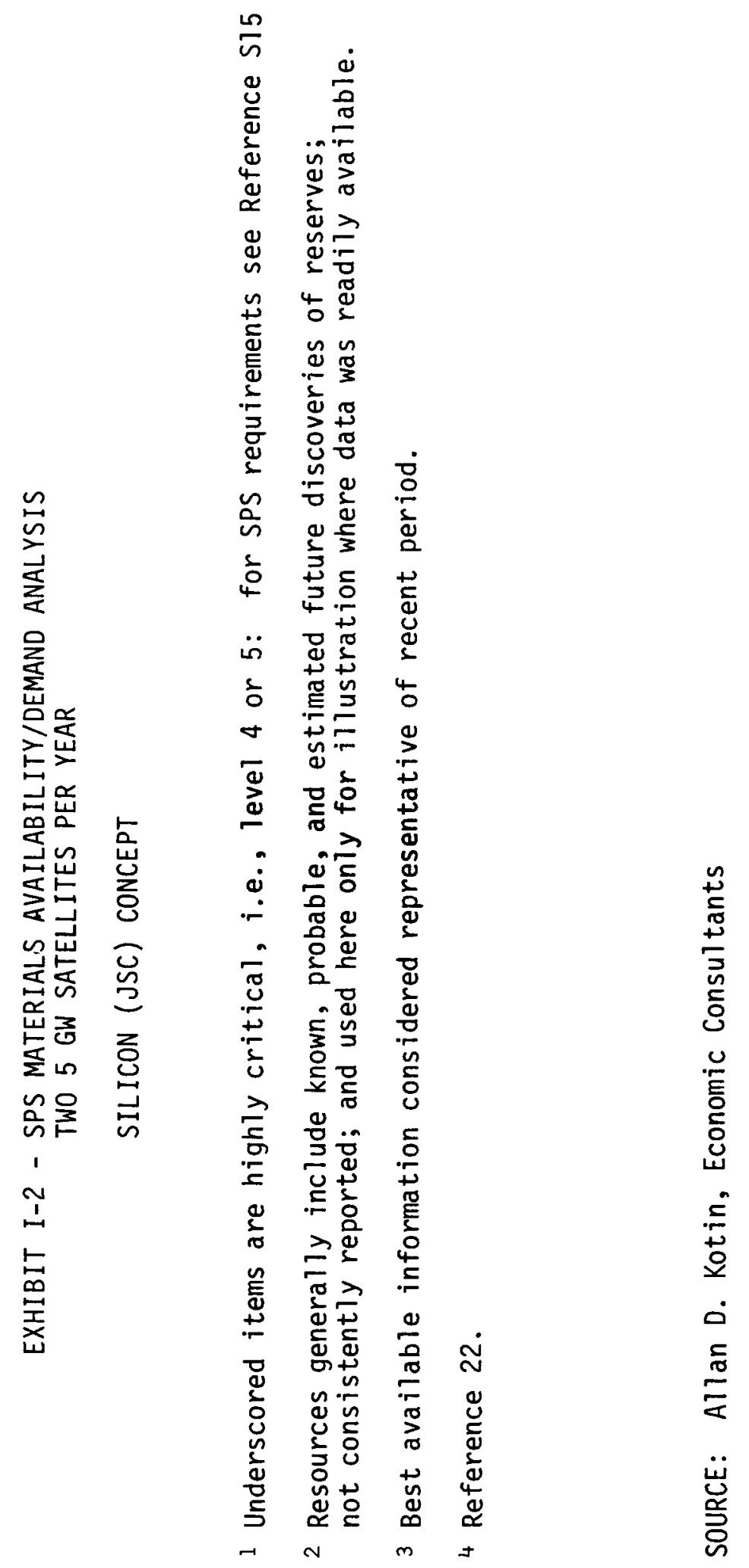



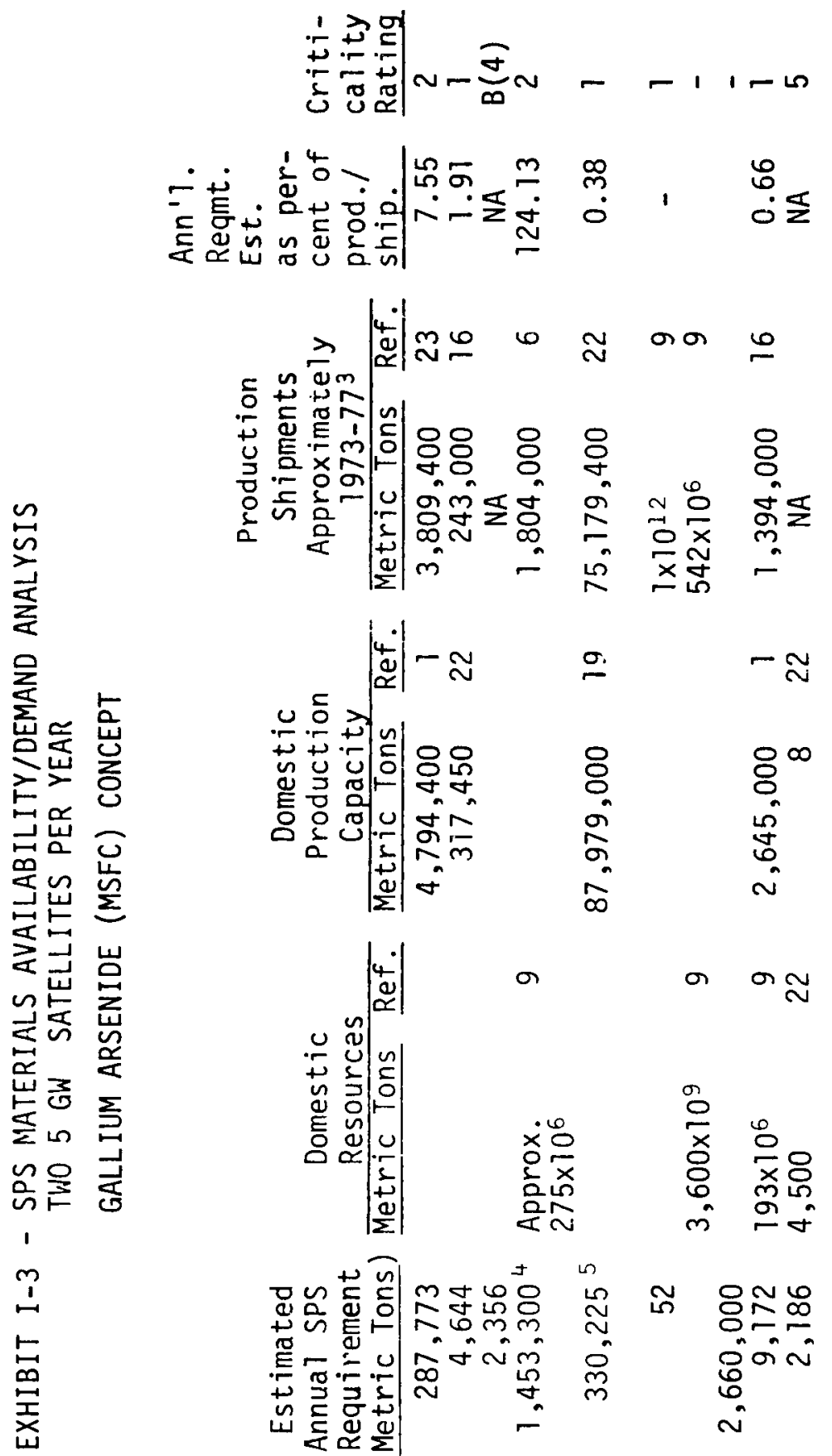

ผ ํํำ $\ll$

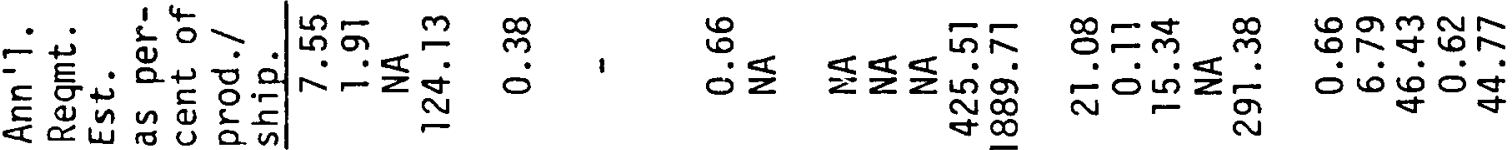
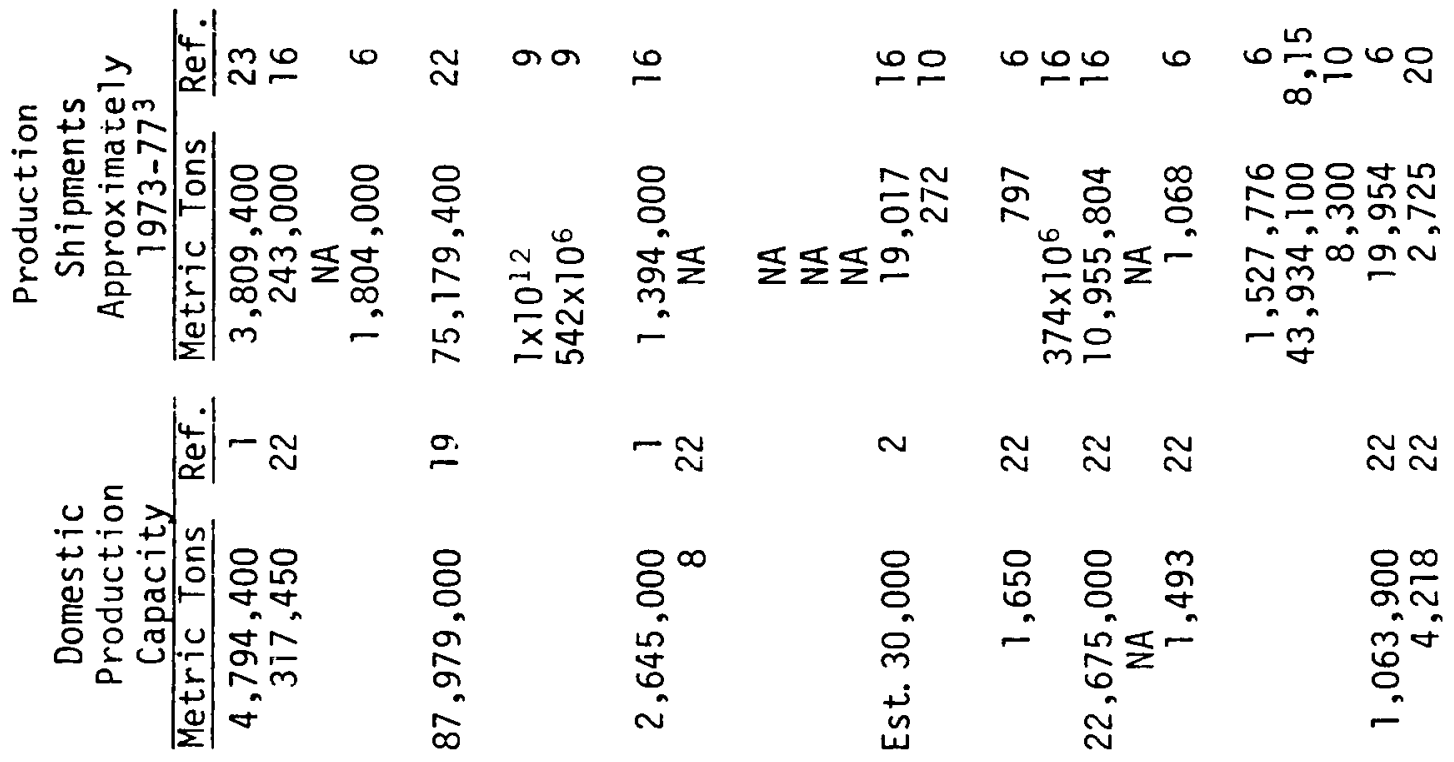

$N \quad N N$

$\approx N$

8
0
n
un

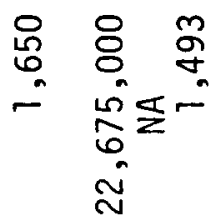
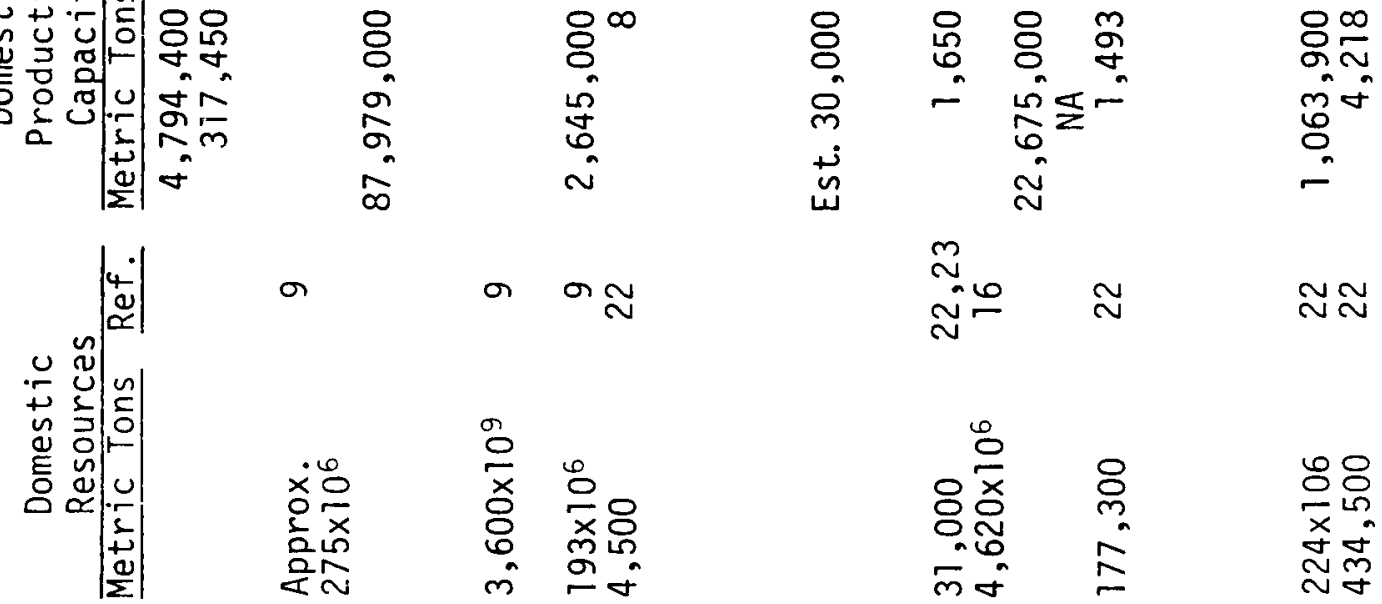

$\sigma$

a $a$

$m$

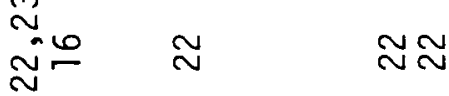
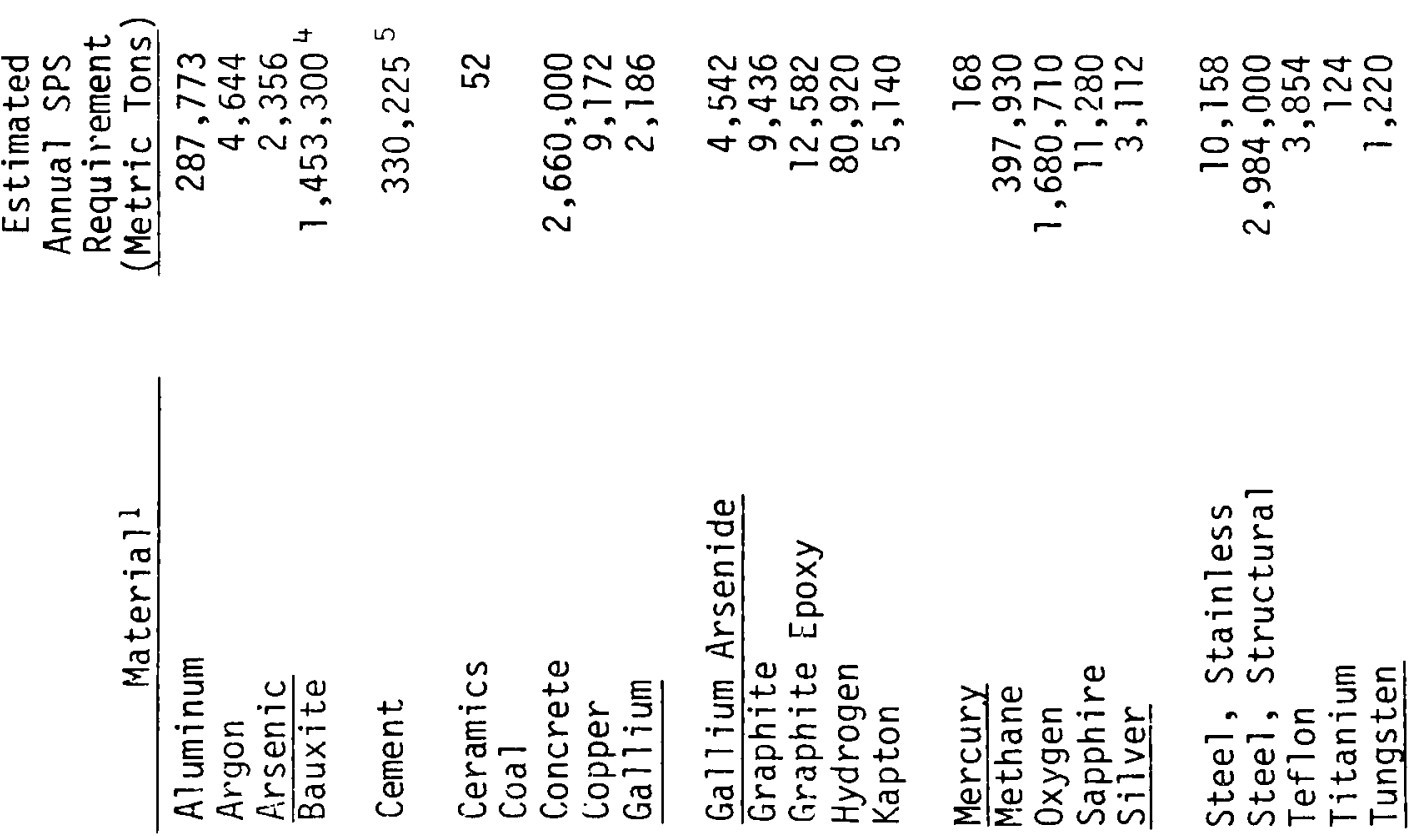


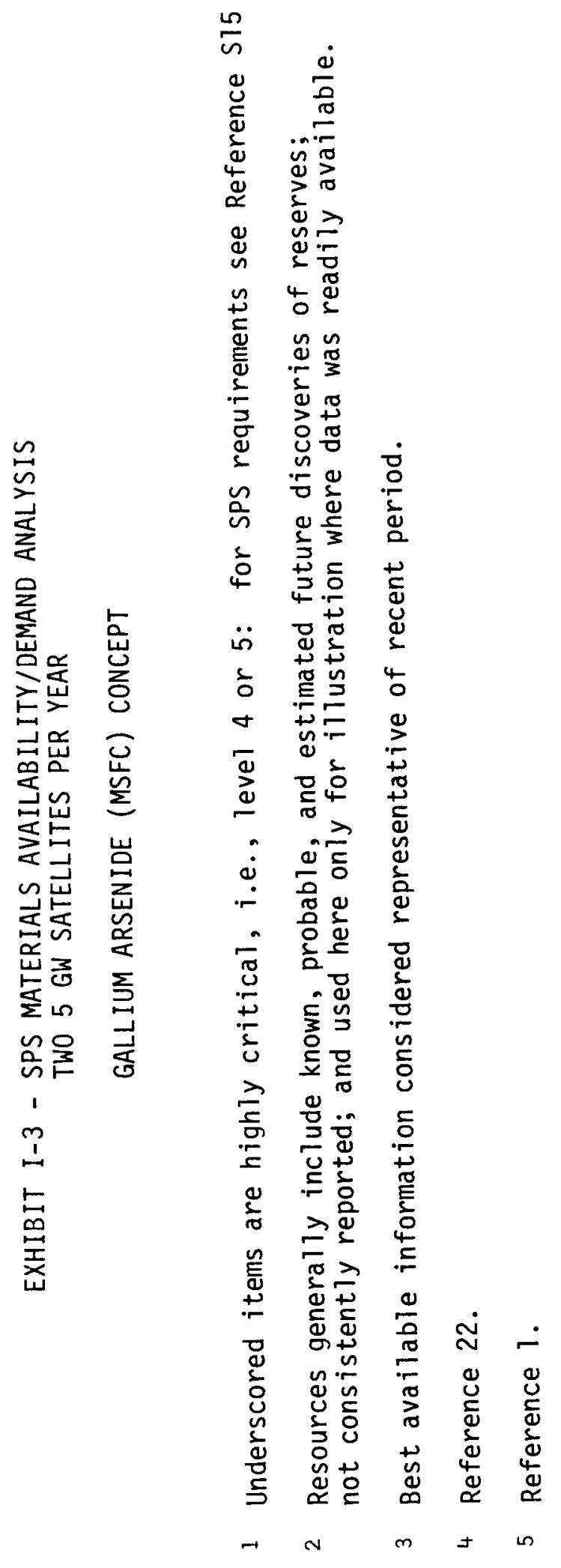




\section{I-6. REVIEW OF COMPONENT MATERIALS}

Even within the framework of this very limited analysis, numerous problems emerge with respect to data sources and classification of materials. It is therefore impossible to simply generalize about many of the materials. Specific comments on definitions and assumptions are required. For most of the sensitive materials, an expanded discussion of the assumptions, data sources, and problems in classification is provided in Appendix A entitled "Data Sources and Classification Problems with Regard to SPS Materials."

The discussion presented below, therefore deals only with the general nature of the problems noted, and technical details are noted in the appendix.

Category I Materials: "No Apparent Problem"

For the most part, the basis of classification and definition of these materials is self-evident. In at least three cases, however, there were significant definitional or derivation problems which had to be resolved before the materials could be classified.

The specifications given in the July 13 "merged" reference concept included concrete but not cement. Of the materials that make up concrete, i.e., sand, gravel, and cement, there would appear to be no shortage of the first two. Cement, however, has been periodically in short supply in the United States. Consequently, it was necessary to isolate the cement category.

"Ceramics" is not a single defined material. It represents a group of materials for which it was possible to get very generalized shipments estimates which are much larger than the SPS annual demand. It may be that further disaggregation could reveal some problems.

The materials list in the July 13 briefing specifies "structural steel." This definition, taken at face value, proves to be somewhat inadequate. There tends to be some semantic variations in what is described as structural steel in various reporting documents. In many cases, the estimates of structural steel production includes only major steel members such as those used in heavy engineering construction and heavy supporting columns for large buildings. A more specific definition of the type of structural steel required for rectenna construction was obtained from the American Iron and Steel Institute (Reference 8). Based on this source, it appears that the type of steel needed for SPS components is not in short supply and does not correspond to the narrow definition of structural steel used in the various reported data series. The larger question of sustained high domestic levels is outside the scope of this analysis.

Category 2 Materials: "High Demand - No Apparent Problems in Expansion"

For the silicon option there were three materials in this category, bauxite, oxygen, and metallurgical silicon. Only one of these, bauxite, was classified in this category for the gallium option. 
Bauxite is the preferred and, currently, virtually the sole material from which aluminum is refined. Not enough bauxite is mined in the United States to supply current needs for aluminum production. As a result, major import sources have been developed in the West Indies (particularly Jamaica) and in Australia. These sources of supply were, for purposes of this analysis, considered to be relatively stable. Tentative estimates of these countries' resources indicate that they are quite adequate to meet the expansion in demand required by the SPS program. The only conditions under which problems might arise would be if overseas shipments to the United States were interdicted or halted for some currently unforeseen political or military reason. At the present time, only about 15 to 20 percent of U.S. bauxite requirements are produced from domestic resources. It should be noted, that large scale experiments are under way to refine aluminum from materials other than bauxite. For example, kaolin, a clay found in abundant supply in the United States, contains a substantial proportion of aluminum. It is not now economical to extract aluminum from this source, but experiments are under way to improve recovery technology.

The estimated annual demand for oxygen, under the gallium option, is over 2.7 million metric tons. This estimate is not only we1l over 10 percent of current domestic production (11 million metric tons) but is also somewhat over 10 percent of estimated domestic production capacity (22.7 million metric tons). There should, however, be no problem in the raw materials for oxygen since it is freely available in a variety of sources. This element, arguably, should be placed also in Category A. In any case, however, it is clearly not a significant potential problem for the SPS.

Silicon was simply labeled as silicon in the list of materials requirements. This caused some definitional problems since the Arthur D. Little report (Reference 10 ) reveals that is was not just silicon but particularly high purity silicon that will be required. While there are massive raw material resources for silicon, the development of silicon from one state of purity to the next requires significant additional steps of refinement. It is apparent that the preparation of high purity silicon adequate for solar cells would require at least one step of refinement past that required for the manufacture of what is commonly known as "metallurgical silicon." The Bureau of Mines (Reference 18) estimates that it would take approximately three years to develop a plant

equipped to produce high purity silicon (solar grade) from metallurgical silicon. Thus, given enough lead time, the manufacture of adequate supplies should not present any problems.

Category 3 Materials: "Possible Problem"

No materials fell into this category under the gallium option. Under the silicon option, arsenic and gallium were classified in this group. Since both of these materials are classified elsewhere under higher levels of criticality, they are discussed below. 
Category 4 Materials: "Real Potential Problem"

Mercury and tungsten occur in this category for both silicon and gallium options. In addition, silver appears in this category for the gallium option.

In recent years, over 95 percent of domestic mercury needs have been supplied by imports. There is some indication, however, that imports have declined to about half their prior rate due to the recent opening of a major mine in Nevada. Spain is the primary current source of imported mercury. The recent dramatic changes in Spain's government may raise questions of long-term stability and dependable supply. Pending verification of further reduced dependence on imports, this material has been conservatively classified as a potential problem. Mercury is a fairly good example of the type of material which would survive an initial screening for "critical" status but might well be el iminated by further in-depth investigation.

The domestic production capacity of tungsten is extremely limited at approximately 4,200 metric tons per year as shown in Exhibits I-2 and I-3. The SPS requirement of approximately 1,200 metric tons annually would represent well over a quarter of this total capacity. It would also be almost half of recent shipment levels of 2,700 metric tons per year. Because of the high cost of mining existing domestic reserves, the vast majority of tungsten is imported to the United States (Reference 20). Only 31 percent of these imports come from either Canada or Mexico. Other major sources of supply include Peru, Bolivia, Thailand, the People's Republic of China, and Australia. Although several of these sources of supply can be considered both friendly and stable, not all of them fall into this category. Therefore reliability of supply 20-25 years in the future remains questionable and characterizes this material as a "Real Potential Problem." Once again, it should be stressed that this is an initial screening effort. Further, detailed examination of the distribution and quality of reserves might resolve this problem.

SPS silver requirements are trivial under the silicon but are quite substantial (3,200 metric tons per year) under the gallium concept. Gallium option demand would exceed current domestic production or shipments by a factor of almost three. The projected silver demands would be nearly equal to the combined mine production levels of a 11 three North American countries. Furthermore, the combined 30-year proposed program would consume approximately twice the "proven" reserves in 1974. In this regard, it should be noted that most domestic silver is recovered as a by-product of other mining, notably copper and to a lesser extent, zinc. Little silver is mined directly. The high demand in relation to current production is, in and of itself, reason for assigning this to the "Real Potential Problem" area. The failure of this study to consider the question of price and price elasticity may be particularly meaningful in this case. Further investigation might well reveal the fact that at significantly higher prices, the recovery of silver as a by-product and/or the expansion of direct mining would be highly feasible. 
Category 5 Materials: "Definite Problem"

Under the assumptions of the silicon option, there are no materials which fall into this category. Under the assumptions of the gallium option, however, gallium itself becomes the sole Category 5 material. The best discussion of gallium recovery and its potential expansion is provided in the Arthur D. Little report (Reference 10). Gallium itself is a by-product of the production of refined aluminum and zinc. The gallium recovery rate from bauxite (primary aluminum source) has been estimated to range from approximately .002 to .004 percent. At the lower level of extraction, the amount of bauxite refining required to generate annually the 2,200 metric tons of gallium needed for the SPS program would be almost 10 times the volume of bauxite refined in the United States today.

Preliminary review of the literature indicates that to achieve the higher rate of recovery (.004 percent) adds significantly to recovery costs. Consequently, even at the higher rate of recovery, supplies would be clearly inadequate from existing bauxite processing and might, in addition, impose what could be a prohibitive tax on the refining capacity of the aluminum industry.

The foregoing analys is of gallium is based in part on the assumption that it will continue to be available only as a by-product. No cost-effective alternatives have yet been identified. Mineral resources are, however, often developed only in response to explicit needs. Thus far there has been little need for gallium beyond what can be economically produced as a by-product of aluminum refining. clearly, the gallium concept would require extended further research into the supply of this mineral.

Category A Materials: "Apparent Problems in Manufacturing Capacity"

There are a total of four materials which fall into this category: hydrogen in both options; glass in the silicon option; and sapphire and teflon in the gallium option. In all four cases, materials cannot be assigned to a gradient category with respect to the potential scarcity of constituent raw materials.

In the case of glass, the problem is one of definition. Total glass manufactured (annualiy) in the United States exceeds, by several orders of magnitude, the requirements of the SPS. The particular kind of glass needed for the SPS, according to the Arthur D. Little study (Reference 10) is high purity borosilicate glass. Current production levels of this borosilicate glass are approximately 29,000 metric tons per year. Under the silicon concept, SPS annual requirements of 39,000 tons per year would exceed the total domestic production by 25 percent. Clearly, substantial expansion of this manufacturing capacity is required.

There would seem to be no particular shortage of the raw materials for this or any other kind of glass. There is, however, an interrelationship between this type of glass and the need for high purity silicon which is one of its major ingredients. 
The transportation fuel requirements of the SPS program indicate a need for either 81,000 metric tons per year of liquid hydrogen (gallium option) or 129,000 metric tons per year (silicon option). Both these numbers are substantially higher than both the current estimated production capacity of 30,000 metric tons per year and the current estimated annual production of approximately 19,000 tons per year. In the numerous references to specialized or new manufacturing requirements for the SPS, e.g., photocell fabrication, launch vehicle manufacture, etc., no mention is made of hydrogen production or potential improvement in that technology. It is not clear whether it is assumed that current technology can be used to increase production at the same or lower cost. This is an issue for further research.

Synthetic sapphire is required in very large amounts for the gallium arsenide option (over 11,000 metric tons per year). Preliminary research revealed no data source for synthetic sapphire production at this time. Clearly it would be inappropriate to take more generic statistics on synthetic gems and apply them to this need. The Arthur D. Little study (Reference 10) provides limited information on the fabrication of this material. The basic constituent material is purified aluminum trioxide $\left(\mathrm{Al}_{2} \mathrm{O}_{3}\right)$. Apparently, this material is available only from a single source in Switzerland, which produces whatever small quantities are required for use in the micro-electronic industry. The process of producing synthetic sapphire is very material and energy intensive. Production of synthetic sapphires in the quantities needed for the SPS program would exceed known world capacity by several orders of magnitude. Given sufficient lead time, American technology should, with an assured market, be able to develop sufficient domestic capacity for the production of $\mathrm{Al}_{2} \mathrm{O}_{3}$ and subsequent fabrication of synthetic sapphires.

Teflon is a proprietary product manufactured by DuPont. The substantial expansion of teflon requirements is indicated by the fact that under the gallium concept, the 3,000 metric tons per year requirement is over 46 percent of current production $(8,300$ metric tons). There appear to be no particular raw material problems associated with this except that one of the ingredients, fluorspar, is almost entirely imported.

Category B Materials: "Insufficient Data for Analysis"

Graphite and arsenic fall into this category. Arsenic is in this category only for the gallium concept, since the amounts required for the silicon concept are quite small.

Graphite is estimated to account for approximately 75 percent of the graphite epoxy material for the SPS. Based on this assumption, something in excess of 9,400 metric tons per year would be required for either of the SPS options. This would be a very large, but not overwhelming, proportion of the approximately 79,000 metric tons of graphite imported from all sources in 1977 . There is essentially no source of domestic graphite at this time. The whole question of import dependency may be moot since technology has been developed recently for synthesizing graphite epoxy from rayon fibers (Reference 4). If these fibers are heat treated (baked), the fibers align in the same direction and the synthetic 
material may in fact provide better control of grain regularity than with natural graphite fiber. The technology is relatively new and the extent to which it can be expanded to fill SPS-generated demand has not yet been determined. If synthetic processing is adequate to meet the needs of the SPS program, there would be no raw materials problem since the basic raw material, rayon, is a forest fiber product. Without further research into the adaptability of this technology, this material cannot be classified as to its criticality.

The arsenic manufacturing problem appears to be more political than technological. According to the Arthur D. Little study (Reference 10) there is presently only one facility in the United States which produces the high purity arsenic that will be needed for manufacture of gallium arsenide. This production, which is currently in relatively small quantities, is based on a by-product process of copper smelting. There has also been considerable environmental resistance to expansion of the output and/or use of arsenic. Changes in those attitudes would probably be a prerequisite to significant further by-product extraction or manufacturing capacity expansion in this country. Since very large quantities of arsenic are required under the gallium option, this has been classified as needing further primary research. Arguably, it could also have been classified as an area in which manufacturing was the major issue.

Issues Raised in Classification Effort

Several methodological and definitional issues have been raised in the attempt to classify SPS materials. These include:

1. Definition as related to purity: arsenic, glass, graphite, siiicon.

2. Definition as related to components of materials listed as compounds: gallium arsenide.

3. Definition of materials identified by generic or proprietary name: ceramics, concrete, glass, kapton, tefion.

4. Resource materials produced as a by-product of other mineral refining processes: arsenic, gallium, silver.

5. The problem of separating manufacturing requirements from raw material requirements: arsenic, glass, hydrogen, kapton, oxygen, sapphire, teflon.

The foregoing list is obviously only partial. Many materials appear on more than one list. The important thing here is that these dimensions or aspects of component materials should be much better defined if further critical materials evaluation is to be systematic and accurate.

\section{I-7. GENERAL FEATURES OF A PRACTICAL APPROACH TO CRITICAL MATERIALS}

The foregoing research, despite its limited scope, provides some insights into the requirements for an effective approach to identifying and evaluating critical materials. To be effective, any approach must deal with the problem that, considered in its broadest sense, the critical materials issue could be 
investigated in infinite detail. A practical approach to critical materials evaluation should be as cost effective and timely as possible. To accomplish this, such an approach should:

1. Be as broad as possible in the initial definition of the universe of materials to be examined.

2. Minimize elaborate data collection and reduction efforts until screening is completed and the number of candidate materials is reduced.

3. Provide specifically for non-quantitative judgments as well as quantitative criteria; but, only with a standardized format for presentation of such judgmental criteria.

4. Generate useful results even in the absence of more detailed or "harder" estimates of SPS materials.

5. Recognize explicitly the flexibility and potential for change in materials reserves and the technology through the year 2000.

6. Specify in advance the form and content of subsequent analys is of "critical" materials which survive initial screening.

7. Allow, in the intial screening process, for the possibility that some materials may be impossible to classify without additional primary research.

\section{Recommended Three-Phase Approach}

If critical materials evaluation is to be achieved prior to real "hardening" of the SPS design, it should proceed in several phases. The first phase should be a screening phase in which a generous or broad definition of potential "criticality" should be used to isolate those materials requiring further evaluation and eliminating those for which the demand will be trivial in the context of current and future production.

To accomplish this, a three-phase approach is recommended, specifically recognizing the separate nature of the screening process and the subsequent in-depth evaluation process. The three major phases proposed are:

Phase 1: Comprehensive initial screening.

Phase 2: Classification of initially unclassifiable materials.

Phase 3: In-depth evaluation of surviving "critical" materials.

\section{1-8. PHASE 1: COMPREHENSIVE INITIAL SCREENING PROCESS}

The major elements of the first phase of the proposed approach to critical materials evaluation are presented below in outline form. These are intended to represent a set of general parameters for such an investigation rather than a detailed procedure. 


\section{Expanded Definition of the SPS Materials Universe}

SPS materials evaluations have so far been based on a mass analysis of the system components and required propellants. Hastage, additional materials required in processing, materials required for secondary and tertiary resource materials are all omitted. While it may be argued that any systematic mass analysis would capture these indirect mass requirements, there is too much variation in methodology to simply trust this to the judgment of the analyst. For example, the Battelle PNL methodology does in fact deal with secondary "bulk" input materials to the process, e.g., cryolite and carbon for aluminum. It is not clear, whether it deals with materials required for significant expansion of manufacturing capacity.

It is important in this regard also to distinguish raw materials in their natural or extracted form from processed materials. Secondary or tertiary materials should be identified in all cases, perhaps using the PNL methodology. The emphasis here is on identification rather than quantification. Once a list of secondary and tertiary materials, including those required for substantial expansion of the manufacturing process, has been established, then an intersectional or reinforcement analys is should be undertaken to show where several different materials or processes make demands on the same resource.

Where such intersections or reinforcements occur, this material should be added to the list of candidate materials for screening. This analysis of indirect demands could be based on economic input-output analysis, the PNL "resourcestree" analysis in their computer model, or other available techniques.

At the end of this process there should be an expanded universe of materials for examination.

\section{Better Definition of Materials}

The most critical aspect of better definition concerns purity or special types of materials to be used. As already noted, the definition of "structural steel", "silicon", and "glass", all had to be researched even at this primary level of classification. There may be other materials of similar specialized purities or applications which are not evident from their simple definition.

It is probably also important to segregate, as early as possible, those materials for which the raw materials are more or less "universally available" and for which the real constraint is manufacturing capacity. Examples of these materials include: hydrogen, oxygen, synthetic sapphires, ceramics, teflon, kapton, etc.

The development of the SPS will necessarily involve creation of a great deal more manufacturing capacity in several different areas. New rocket fuel plants, fabrication of space vehicles, fabrication of the solar cell array, and a wide variety of other system requirements will create whole new industries. At this time, it would seem inappropriate to segregate required additions to hydrogen 
or glass manufacturing capacity from these other system requirements. Obviously the economic evaluation of this project should include a consideration of the additional manufacturing capacity required. Arguably, such an evaluation should also include potential positive benefits on the national economy of this expansion. In any case, the increase in manufacturing capacity required as a function of the SPS program should be treated as a separate issue from materials availability.

Documented and Systematic Approach to Screening

The key characteristics of a systematic approach to screening which is costeffective would contain the following elements:

1. The approach should be based on the available and, insofar as possible, consistent data snurces.

2. There should be quantified thresholds, e.g., percent of current production, percent of current and projected reserves, percent of imports.

3. Quantified thresholds may in fact be mixed functional relationships, e.g., percentage thresholds of domestic production may be changed as a function of the percentage of raw materials imported.

4. The model should provide for judgmental input in such areas as potential substitution of other materials, import sensitivity and prospects for technological change.

5. Judgmental or other non-quantified factors should be treated in the standard format and classified for all but the most trivial cases. They should not be introduced only on an ad hoc basis.

6. Per unit and total annual energy requirements for each material should be identified and compared to some pre-established critical energy threshold, e.g., one percent of SPS annual energy output (Joint task with further energy analysis efforts recommended in Section II).

The requirements for "available and consistent data" presents an interesting issue. It is probably preferable that the "need for further primary research" be an output of the initial screening process rather than a prerequisite to it. It is almost inevitable that classification of one or more materials based only on published data will be impossible and there will be a need for further primary research. Postponing this primary research until after the screening process has been completed is probably desirable for two reasons. First of all, materials requirements may change. Secondly, smaller-scale focused research studies in these areas might well be easier to control and be more cost effective.

Sensitivity Analysis of the Screening Model

The initial screening model should be subject to some sensitivity analysis to determine how much the number of materials classified as "critical" would change in response to shifts in either the quantitative or judgmental thresholds employed. It might be very useful to know how many more materials would be critical if a threshold was raised or dropped. 


\section{I-9. PHASE 2: CLASSIFICATION OF INITIALLY UNCLASSIFIABLE VARIABLES}

Given the parameters set forth above for Phase 1 of the evaluation process, it seems quite likely that some materials will emerge from this process as being unclassifiable without further primary research. This second phase of the process is designed to accomplish that primary research but only after having an opportunity to review the characteristics of the other materials. This review would, to some degree, harden the definition of what constituted a "critical" material. This in turn would permit a better statement of how far to go in such additional primary research.

\section{I-10. PHASE 3: IN-DEPTH EVALUATION OF SURVIVING CRITICAL MATERIALS}

The scope and format of the subsequent in-depth evaluation of those materials determined to be critical should be set at the earliest possible date. In fact, it is almost mandatory that the requirements of this in-depth analysis be set forth even before the screening process begins. In the absence of this, it would be difficult to avoid "reinventing the wheel" or going back over the same ground once a material has been defined as "critical".

Suggested Elements of an In-Depth Analys is

The following highly tentative list of $i$ tems has been developed for such in-depth analysis:

1. Detailed projection of domestic, North American, and world supplies: supply in this context to mean known reserves, probable reserves, and some hiqhly tentative estimate of "resources", with further classification by country of origin for those in which some specified percentage of reserves is outside North America.

2. Detailed analysis of projected increases in demand for non-SPS uses; and the potential for materials substitution in these other uses. One example would be increased use of aluminum in automobiles.

3. Evaluation of potential technological changes to improve recovery of the final material from raw material sources, including but not limited to use of: new source materials, e.g., kaolin instead of bauxite for aluminum, improved mining, improved processing, and refining.

4. Explicit consideration of whether providing an equivalent amount of power with pre-selected alternative technology, e.g., coal, nuclear, would use significantly less of the material in question.

5. Explicit treatment of current prices, recent price trends, projected price elasticity, and ultimate impact on the total cost of the SPS.

Obviously, for any materials classified as genuinely "critical", there should be a high degree of interaction with the design effort for the SPS. Specifically, this interaction shouid involve a thorough investigation of the potential for substituting alternative materials for the one designated as "critical". This investigation of substitution should consider both the technological problems 
and the cost impact. The cost impact in this context should be expressed both in absolute terms and in relation to the estimated cost impact of the material in question as revealed in the analys is of price elasticity.

I-11. NEED FOR BETTER SPS MATERIALS ESTIMATES

General Requirements for Critical Materials Analys is

There is an inevitable and unavoidable tension between the need for precise quantity estimates for this process and the inherently preliminary and undefined nature of a "reference concept" design of the SPS. This section of the white paper, focuses on those aspects of materials estimates refinements that can be achieved within the framework of a "reference concept" design. Perhaps one of the most important general requirements is that materials requirements be summarized. Except for the briefings, the general literature on the SPS presents only the unit requirements per vehicle, per launch, per square meter of solar cell area, etc. While information is often given on the number of launches, the size of the solar array, the transformation of the materials estimates for several different components into a total system requirement is a complex process best undertaken by the people who prepare the initial estimates.

Another generic problem concerns the universe of materials. Unfortunately, the briefing documents do not indicate how broad the scope of the materials analysis is. It appears in most cases only to relate to the mass of the satellite and the mass of the transportation vehicles and required fuel. It is often unclear whether estimates include command and control systems, ground support systems and launch facilities, etc. The terms of reference should always be clearly stated including tining considerations where annual requirements are not uniform.

The foregoing comments with respect to the terms of reference should not be taken as a requirement to account for even the most minor materials. What is more important is that the terms of reference clearly state what is being accounted for and what is being excluded. The reason for the exclusion should be given, possibly in the form of a total mass or the simple assertion that these are standard components readily available.

Better Definition of Materials

A better definition of the material items is probably even more important than better quantitative estimates. One critical result of this research has been to indicate how important it is to state purity, special applications, and even, in some cases, the physical dimensions of the material.

A parallel and equally critical issue is the separation of materials as between those which depend ultimately on raw material availability and those which depend on manufacturing and processing. A clear indication of which materials are or could be synthetic is critical. 


\section{Explicit Treatment of Quantitative Uncertainty}

Recognizing the difficulty involved in coming up with precise materials quantities, it would seem that this problem could be dealt with by specifying the levels of uncertainty. This type of uncertainty treatment is characteristic of many forms of similar analysis, e.g., energy requirements, etc. Tolerances for each of the materials quantity estimates should be given. With these tolerances, a quantitative estimate of uncertainty could be established and reflected in the initial screening model. Obviously, surviving "critical" materials would, in the third and final phase of the evaluation process, be scrutinized to reduce the tolerance. One of the key by-products of the approach is that it could focus the need to refine quantity estimates on only those materials which present a potentially critical problem. At the present time, the problem is often stated as giving better estimates for all materials when better estimates for all materials are not really needed.

\section{Deferral of Refined Estimating Efforts}

As noted above, it would appear that any attempts to significantly refine material quantity estimates can reasonably be postponed until a later stage in the evaluation process at least from the point of view of critical materials evaluation. Only when those materials that are potentially critical have been identified is the arduous and often highly judgmental exercise of assigning specific numbers to unspecific concepts really warranted. 
1. American Bureau of Metal Statistics Inc., Non-Ferrous Metal Data, 1976, (New York, New York).

2. Barber M., General Manager, Union Carbide Company, Linde Division, Ontario, California, personal communications, August 1978.

3. Battelle Pacific Northwest Laboratories, Bulk Material Requirements and Raw Material Requirements for Silicon, $N / P$ Single Crystal (Satellite Power System), draft materials based on NASA/JSC concept, provided by R. Watts, dated May 24, 1978.

4. Bienstock, Dr. B., Hughes Aircraft Company, El Segundo Division, personal communications, August 1978.

5. Commodity Research Bureau Inc., Commodity Yearbook, 1977, (New York, New York).

6. Fairchild Publications, Metal Statistics, 1978, (New York, New York).

7. Hoffman, Frank, President, F.E. Hoffman and Associates, Glendale, California, personal communications, August, 1978.

8. Jeffries, M., Manager, American Iron and Steel Institute, Engineering and Environmental Committee, Washington, D.C., personal communications, August 1978.

9. Litchfield, J.W., R. Watts, et al., A Methodology for Identifying Materials Constraints to Implementation of Solar Technologies, Battelle Pacific Northwest Laboratories, Richland, Washington, March 1978. (Revised Ju1y 1978)

10. Little, Arthur D., Inc., Evaluation of Solar Cells and Arrays for Potential Solar Power Satellite AppTications, (report to National Aeronautics and Space Administration, Lyndon B. Johnson Space Center), March 31, 1978.

11. Livingston, Floyd R., et al., Satellite Power System (SPS) Prel iminary Resource Assessment, $9 \overline{00-805}, \overline{R e v . ~ A, ~ J e t ~ P r o p u l s i o n ~ L a b o r a t o r y, ~ C a l i f o r n i a ~}$ Institute of Technology, Pasadena, California, August 7, 1978.

12. Lyday, Travis, Graphite Specialist, U.S. Department of the Interior, Bureau of Mines, Division of Non-Metal1ic Minerals, Washington, D.C., personal communications, August 1978.

13. The Mitre Corporation, Metrek Division, Proceedings of Workshop on the Evolving Structure of the Electric Utility Industry, papers and edited transcripts from workshop held by The Mitre Corporation, Metrek Division, McLean Virginia, March 9 and 10, 1976, (sponsored by Division of Policy Research and Analysis, National Science Foundation), MTR-7193, March 1977. 
14. NASA, Lyndon B. Johnson Space Center, "Preliminary Materials Definition for the Silicon Solar Power Satellite," (letter from H.E. Benson), July 31, 1978.

15. Nash, Janet, American Iron and Steel Institute, Statistics Department, Washington, D.C., personal communications, August 1978.

16. Predicasts Inc., Predicasts Basebook, 1977, (Cleveland, Ohio).

17. World-Product-Costs, 1977, (Cleveland, Ohio).

18. Schottland, Fred, Physical Scientist, U.S. Department of the Interior, Bureau of Mines, Division of Ferrous Metals, Washington, D.C. personal communications, August 1978.

19. Snider, Linda, "The Fundamentals are Changing in Cement," Fortune, August 28, 1978.

20. Stafford, Phillip, Tungsten Specialist, U.S. Department of the Interior, Bureau of Mines, Division of Ferrous Metals, Washington, D.C., personal communications, August 1978.

21. United Nations, Department of Economic and Social Affairs, U.N. Statistical Yearbook, 1976.

22. U.S. Department of the Interior, Bureau of Mines, Mineral Facts and Problems, 1975, (Washington, D.C.).

23. , Bureau of Mines, Commodity Data Summaries, 1977, (Washington,

24. , Bureau of Reclamation, Concrete Manual, (Washington, D.C.).

25. Valenzuela, J., Assistant General Manager, Big Three Industries, Carson California, personal communications, August 1978. 


\section{ENERGY ANALYSIS}

II-1. INTRODUCTION

Background and General Objectives

The stated objective of this part of the study is to review and summarize prior study efforts which treat the problem of the energy required to develop and operate the SPS. The statement of work identifies three general tasks:

(1) assembly and analys is of relevant literature; (2) establishment of a list of issues and questions that must be resolved; and (3) identification of unresolved issues and unanswered questions together with recommendations of an approach to dealing with them.

The estimation of energy requirements is a new and emerging discipline, referred to variously as "energy analys is," or "energy resource accounting." "Net Energy Analysis" is a related but more narrowly defined process. Some initial methodological review is critical if SPS energy requirements are to be compared to those of alternative power generation technologies.

\section{Definition of Net Energy}

The Federal Non-Nuclear Energy Research and Development Act of 1974, PL 93-577 $5(a)(5)$, stipulates that "potential for production of net energy by the proposed technology at the state of commercial application shall be analyzed and considered in evaluating proposals." As noted in one recent overview of net energy analysis, this law, "does not define net energy and, to date, efforts of many analysts to arrive at a unique definition have failed. The continuing debate over the merits of net energy analys is and the ambiguity involved in its application result in an interesting challenge of determining how to adinere to the requirements of (the 1aw)." (Reference 11.) 1

It is clear that the basic premise is that "it takes energy to get energy." A working generalized definition of net energy analysis would be the comparison of the energy produced by a system to the energy required to create and operate it.

Key Issues and Organization of the Analysis

The typical output of net energy analys is is a net energy ratio which expresses the energy generated by a process (after subtracting the energy required to create and operate $i t$ ) as a proportion of the total energy output of the process. This concept of net energy analysis has been challenged on several grounds. There are many who question whether it is worthwhile to even undertake it. Many experts feel that it adds nothing to and may be redundant to economic analysis. Even among the sponsors of energy analys is, there is a growing tendency to de-emphasize use of a single "net energy ratio" number. Many feel it is a poor representation of a complex and heterogeneous set of component requirements.

1 References identified with numbers only are listed at the end of this section. 
The immediately following section of this report (II-2) deals with objectives, and validity of energy analysis. The term "energy analysis" is used deliberately instead of net energy analysis to indicate the expanded and more disaggregated concept. Some philosophical and methodological issues of energy analys is which apply to the SPS are considered.

Section II-3 reviews alternative methodologies and attempts to summarize their weaknesses and strengths. This summary includes again an attempt to relate them specifically to the SPS. The status of energy analys is of the SPS, including a review of its rather limited existing literature, comprises Section II-4.

A recommended approach to energy analysis for the SPS is discussed in the following section (II-5), and the report concludes with a brief review of some specialized issues that apply to the SPS.

\section{II-2. ENERGY ANALYSIS: DEFINITIONS, OBJECTIVES, AND VALIDITY}

\section{Definitions}

Exhibit II-1 presents a theoretical energy system labeled as an "energy recoverypower generation system." The central box on the chart includes (fuel) extraction, (fuel) processing, transportation, and conversion (to electricity), which apply to most existing generating systems. Throughout the analysis, references are made to power generating systems although most of the concepts are applicable to any energy using/energy producing process.

In the diagram in Exhibit II-1, energy flows into the system from some primary direct energy resource (fuel). The energy content of this resource either becomes direct energy input to the system (DEI) or is unrecovered and is resource energy lost (REL), e.g., coal pillars left in underground coal mines. The energy del ivered into the system (DEI) undergoes a conversion process in which inevitable thermodynamic losses are encountered. These losses are identified as energy losses in conversion (ELC) and the useful energy produced by the process is called energy output-total (EOT). Part of this total output may be used to power the extraction-processing-conversion process, in which case it is identified as energy output returned (EOR). The balance of the energy output it available for use and constitutes energy output-final (EOF).

In order to make this process operate, energies are extracted from the economy as a whole. These energies, identified as energy subsidies, can take two forms: (1) energy subsidy direct (ESD), such as the power required to mine, clean, or transport coal; or (2) energy subsidies embedded in materials (ESM), such as the steel and concrete used in the power plant and generators, the trucks required for transport, etc. These energy subsidies derive in turn from primary energy resources in the economy (PER), e.g., coal, 0il, hydro, or nuclear. The direct energy resource (DER) is usually of the same type as other primary resources but is distinguished from the indirect resources which operate through the subsidies (ESD, ESM). 
(Unrecovered)

Resource

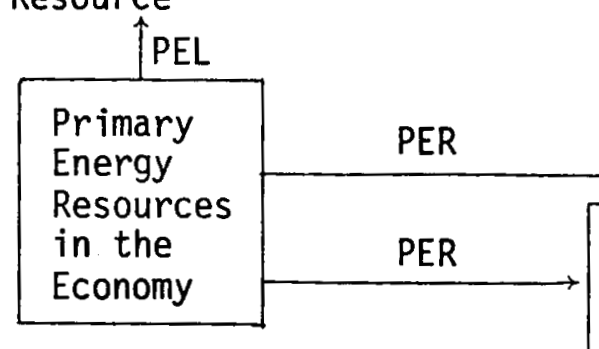

Energy

Subsidy

Direct

(e.g., Fuels,

Electricity)

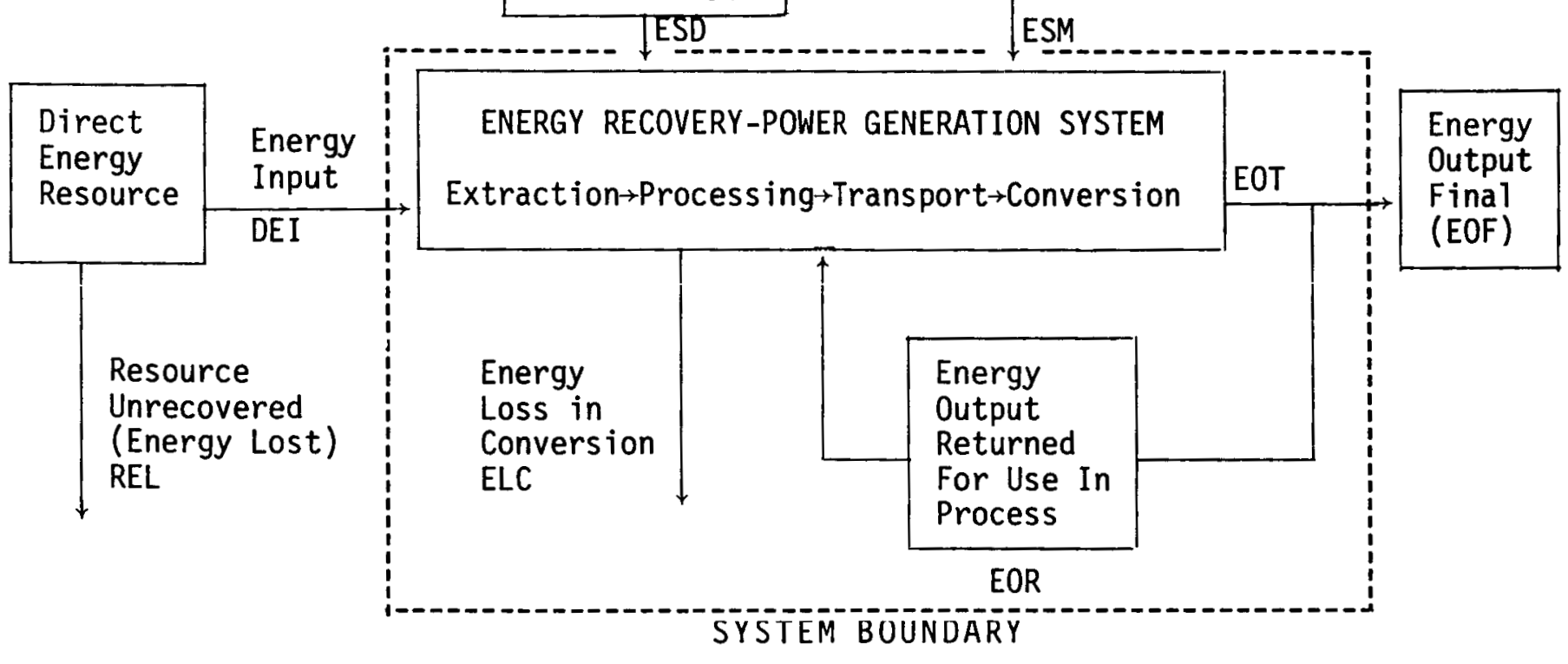

(1) Net Energy Output

$=E O F-(E S D+E S M)=E O T-E O R-(E S D+E S M)$

(2) Energy Subsidy

$=\frac{E S D+E S M}{E O F}=\frac{E S D+E S M}{E O T-E O R}$

(3) "Net" Energy Ratio (Fuel Excluded)

$=\frac{E O F}{E S D+E S M}=\frac{E O T-E O R}{E S D+E S M}$

(4) "Net" Energy Ratio (Fuel Included)

$=\frac{E O F}{D E I+E S D+E S M}=\frac{E O T-E O R}{D E I+E S D+E S M}$

(5) Thermodynamic Efficiency (As Usually Applied to Conversion of Fuel to Electricity)

$$
=\frac{E O T}{D E I}=\frac{D E I-E L C}{D E I}
$$


The boundary of the system, as shown by the dotted line, is critical. This boundary is drawn in such a way as to exclude direct energy inputs (DEI) and tt also includes the energy returned to operate the process (EOR).

One formal definition of "net energy" is provided by C.W. Bullard (Reference 2) as follows, "The term 'net energies' refers to the output of an energy production system determined by taking full account of the energy required for inputs to the process. Energy used directly as well as indirectly must be considered. Examples of direct energy include that used to power oil wells and energy consumed in refining processes. Indirect energy uses include that used to manufacture the steel and pipes for refineries, pipelines, tankers, etc." In this definition, the direct and indirect uses described correspond to the energy subsidies (ESD, ESM) described in Exhibit II-1. The term "energy subsidy" seems somewhat more appropriate here since there is a confusion between direct enargy as fuel input to the process and energies withdrawn from the economy to operate the process. The term "energy subsidy" is a central concept in the early work of Development Sciences, Inc. (References 6 and 7).

The net output of the system is shown in Equation (1) on Exhibit II-1. Total energy output (EOT) is reduced by both types of energy subsidies (ESD \& ESM) and by the energy returned to the system (EOR).

A11 equations presented in Exhibit II-1 represent the entire energy output and all energy requirements over the system's lifetime.

Energy subsidy is usually expressed as a number of subsidy energy units (Btu's) per Btu of final output and is calculated as shown in Equation (2).

The most frequently used ratio is the "energy ratio" shown in Equation (3). This ratio is often called the net energy ratio (abbreviated " $N$ " or "NER"). This ratio expresses final energy output as a multiple of the total energy required to generate that output. The term "fuel excluded" indicates that only the energy subsidies are considered and not the energy input. This is the key ratio associated with the so called "energy limit." If this ratio is near or below 1.0, then the energy system produces less energy than it consumes in its creation and operation, even excluding the fuel it consumes. This ratio is typically quite high for most power generation technologies.

A second and much less widely used ratio is the "energy ratio (fuel-included)" shown in Equation (4). In this equation, the final energy output is divided by the sum of the energy subsidies plus the direct energy input. Due to the laws of thermodynamics, this ratio will always be less than one, since it is impossible to recover all the energy content of a fuel. The distinction between the fuel-included and fuel-excluded ratio is particularly significant, since, for the SPS, the two ratios are the same. Only if the sun is considered to be a depletable fuel resource, which is clearly outside the scope of any current time frame, could the fuel-included ratio be any different than the fuel-excluded ratio. This is not to say that the energy ratio for solar systems could not be less than one. This would occur, however, only if the energy subsidies exceeded final energy output. 
The term "net energy analysis" may, in the narrowest sense, be attached to the computation of the net energy ratio as in Equation (3). There is a widespread and growing consensus among energy analysts, that this single-valued approach is, at best, incomplete and, at worst, misleading. Many anaiysts propose a broader approach to the problem, identified as "energy accounting" or "energy resource accounting." The objective then is not the computation of any specific ratio, but rather simply the estimation of the primary energy requirements embodied in the energy subsidies. These primary energy resources (PER) are, as shown in Exhibit II-1, the ultimate sources for the energy subsidies (ESD \& ESM). The emphasis here is on the simple estimation of the primary energy resources required per unit of final energy output, e.g., the coal, oil, nuclear resources required per kilowatt hour.

There are two measures of primary energy resources used in energy resource accounting. The general convention is to measure primary energy resources, e.g., coal, crude 0il, and natural gas, as they are extracted from the earth. More elaborate treatments deal with "resources in situ," including the unrecovered resource left in the ground. Estimates of primary energy resources in situ include both extracted energy resources and those left in the ground as unrecovered (PER plus PEL). Similarly, direct energy resources (in situ) represent the sum of those extracted and those left unrecovered (DEI plus REL).

The "energy payback period," usually expressed in years, is the time required to generate final energy output equal to the intial energy expended in creating the generation system. The equation for this is shown below:

$$
\text { (6) Energy Payback (in years) }=\frac{E_{\text {initial }}{ }^{+E S M_{\text {initial }}}}{\text { EOF }_{\text {annual }}-\left(\mathrm{ESD}_{\text {annual }}{ }^{\left.+\mathrm{ESM}_{\text {annual }}\right)}\right.}
$$

The computation of an energy payback period requires the separation of total energy subsidy (ESD and ESM) into two components, initial subsidies required to create the system and annual operating subsidies. Final energy output (EOF) is also expressed on an annual basis in this equation.

\section{Objectives}

A variety of objectives have been ascribed to energy analysis. In the extended literature of controversy on this subject, there are three general objectives frequently ascribed to energy analysis:

1. Evaluation of alternative energy generation (conservation) technologies.

2. Insight into and/or direct projection of the energy resource impact of alternative courses of action.

3. Description of the energy components, direct and indirect, of proposed systems, policies, etc.

Although the founder of energy analysis, Sir Frederick Soddy, did imply an energy theory of value somewhat analogous to the Marxist labor theory of value, this 
position is not all all widely held. Most energy analysts disavow any attempt to use energy ratios or energy resource accounting as a sole or even primary basis for evaluating alternative systems or policies. Rather, they see it as a supplement to economic analysis and other forms of policy analys is.

With respect to its predictive values, the opponents of energy analysis ascribe to it claims that are made by few, if any, of its practitioners.

The descriptive function or objective of energy analysis is the one most universally endorsed. The basic assumption is that additional information can be valuable in decision making and policy setting processes. To the extent that it is consistently measured and accurate, information as to the energy impact of different technologies, systems, and policies can enhance our understanding of the universe. In this last regard, energy resource accounting specifically emphasizes the need to know not only how much energy is required to produce energy but also what kinds of energy are needed. The qualitative differences in energy are often more important than the total amount of energy required.

\section{Validity Issues}

A variety of philosophical and methodological objections to energy analys is have been raised. The controversy has been extensively documented and frequently summarized in the literature (References $5,8,10,11,17,19,20,22,27,28$, and 30$)$. To some extent, the statutory requirement for net energy analys is makes the question of its validity irrelevant. There are, however, two issues in particular which have some bearing on the SPS.

Some critics claim that energy analysis, by whatever name, adds nothing to economic analysis. The following reply stresses the importance of descriptive analysis:

It should be clear that, without behavioral hypothesis, both energy accounting and thermodynamic analys is are purely descriptive exercises. Webb and Pearce (Reference 30) assert that, as such, both are of no use. By way of analogy one might ask whether Webb and Pearce would recommend that all cartographers and surveyors cease work as they provide mere descriptions. The important point is, of course, that mere description is a necessary input to evaluation and prediction....

Returning to the analogy of cartography, it can be noted that the topographicai conditions always show up in economic conditions without concluding that is is always a redundant exercise to draw relief maps. (Reference 5.)

A second and potentially much more damaging criticism of energy analysis is made by Gerald Leach in a paper appropriately entitled "Net Energy Analysis - Is It Any Use?" (Reference 17.) While the author admits that net energy analys is has never claimed relevance to many of the issues on which it is criticized, he 
asserts that the component to which it does address itself - the indirect inputs of energy to supply technology - is relatively insignificant. It is his feeling that this component, i.e., the energy subsidies (excluding fuel), are at or near the noise level created by uncertainty and data inaccuracies. The abstract notes, however, "though analys is might have some value in checking the 'net returns' of very rapid large technological shifts, to date they have not identified any significant effects when the whole energy system is taken into account." (Reference 17.)

A review of the literature partially supports this view. Energy subsidies are often low, e.g., 15-25 percent of output, particularly in relationship to the actual fuel consumption. Whether or not this represents "noise" is arguable. In the case of the SPS, however, initial energy subsidies to create the system are unusually high and there is no direct fuel consumption (Reference S16). 2 In addition, SPS is exactly that type of program which represents a "very rapid and large technological shift." For all of these reasons, this objection may not apply to the SPS.

Philosophical - Methodological Issues

Energy Quality

There are several general issues in energy analysis that apply to all methodologies used. The "valuation" or "disaggregation" issue concerns the non-equivalence of different types of energy. Energies differ widely in quality. In this context quality can refer to the thermodynamic quality of the energy, its envi-

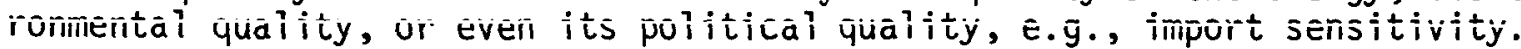
Whatever methodology of energy analys is is employed, the results should, insofar as possible, be disaggregated from the total energy requirements into the different primary source components, e.g., coal, oil and gas, nuclear, etc. The different qualities of energy almost require disaggregated estimates in energy analysis and significantly reduce the value of single-valued energy ratios.

\section{Boundary Problems}

Perhaps the most perplexing problem in energy analys is is establishing what constitutes an appropriate boundary for the system under study. This boundary problem has several different manifestations.

One of the simplest aspects of the boundary problem concerns the use of the energy output of a generation system to provide power to the system itself (EOR in Exhibit II-1). A coal-fired power plant requires energy for the mining and processing of coal prior to its conversion to electricity. In a mine-mouth coal power plant, this energy could be supplied by the generator itself or externally. The final energy output (EOF) is defined as total energy output (EOT) less the energy output returned for operation (EOR).

2 References prefaced by an "S" are general references to the SPS which are listed at the end of the entire report. 
Exhibit II-1, Equation (3) shows:

$$
\text { "Net" Energy Ratio }=\frac{\text { EOT-EOR }}{\text { ESD+ESM }}
$$

If the boundaries were drawn more tightiy so as to exclude the energy returned, the net energy calculations might be quite different. In that case, the energy returned (EOR) would be zero, final energy output (EOF) would equal total energy ouput (EOT), and there would be a higher energy subsidy (ESD) to account for operating energies previously supplied internally through EOR. The net energy ratio would be significantly lower. If, on the other hand, all direct energy subsidies (ESD) were provided by the power generated (an increase in EOR), the net energy ratio would be extremely high. In all these cases, the net energy output of the system is unchanged. This aspect of the boundary problem points up the need for explicit component estimates rather than reliance on singlevalued ratios.

The general issues of where one separates energy supplies from energy demands and how far one goes in measuring indirect energy are clearly described by Leach:

Net energy analys is is plagued by the problem of what external inputs should legitimately be counted, which is the same as asking where one draws the boundary between energy supply and demand. The solution adopted depends, in part, on the availability of data, but mainly on which of two very basic and contrasting ideological assumptions one makes....

The first approach to the boundary or counting problem is to draw the boundary between the energy supply system of facility being analyzed and the rest of GNP.... This boundary is drawn automatically if all inputs are counted using inputoutput methods since these are also consistent with the conventional definition of GNP.

This approach may seem reasonable at first sight. However, as Bullard has argued, it rests on the fundamental assumption that all activities within GNP are intrinsically "good" and that so long as there are not external costs and future costs and benefits have properly discounted, the flow of materials and energy through GNP should be maximized since it is not intrinsically "bad" thereby to deplete resources stocks....

Naturally, this view is strongly contested. At the concrete level, gas stations, new towns, etc. would not be required but for the existence of the energy sector and therefore are not "good" but "costs" to be included in the energy (subsidy) 100p.... (Reference 17)

Considerations of expediency and data availability would appear to resolve this issue. Input-output analysis will be needed to establish energy requirements for many of the generalized aspects of SPS development. Therefore, the first GNP approach identified by Leach will be used and the larger philosophical issues involved in whether GNP is "good" or not will be left open. 


\section{Energy Measurement: Thermal vs. Electrical}

The choice and consistency of units is a problem in energy analys is of alternative power generation systems. The output from such power generation sytems is typically expressed in kilowatts (electrical). On the other hand, most of the energy inputs are expressed in terms of thermal energy, i.e., Btu's (British thermal units). The "enthalpy" or energy value of a kilowatt (electrical) is 3,413 Btu's. This simplistic conversion can create misleading comparisons, since it requires 10,000-10,500 Btu's of coal, 011 , or gas to produce one kilowatt (electrical) as most power generation systems are only 30-35 percent efficient in conversion. In dealing with fuel energy inputs and electrical energy output, a conversion convention must be adopted. This conversion problem can be avoided if: (1) the SPS is compared only to other electrical generating systems; and (2) the energy requirements are expressed in the thermal units of primary resources, e.g., coal, oil, etc.

Issues Invoiving the Treatment of Time

Development and operation of any energy generating system involves: (1) initial energy subsidies, in both direct energy and energy embodied in capital equipment; and (2) annual operating energies for the power plant itself and for extraction and processing of fuel resources. One of the most distinguishing characteristics of the SPS is that the initial energies of developing the system are very large relative to the operating energies (Reference S16). For many fossil fuels and nuclear technologies, there is a large ongoing energy cost involved in fuel extraction processing and transportation. Traditionaliy, there has been no attempt to discount future energies to some present vāiue. Encrgj' cost, in most energy analysis, is treated as having the same value whenever it is expended. Discounting future energy costs would favor high operating energy needs relative to startup requirements; it would make systems which require substantial initial energy subsidies, such as the SPS, less attractive. Most energy analysts agree that some distinction should be made at some level between initial and operating energies, but that any discounting should be left to the discretion of the reader.

A different time issue is raised in considering a program involving several power plants instead of an individual power plant. This form of "dynamic" energy analysis of total energy output in relation to total energy input to the program as a whole often shows large energy deficits during the initial development period, particularly if the energy system is capital intensive. The SPS represents just such a program. Even if each unit itself shows a low energy subsidy and/or a reasonably rapid payback, the program as a whole may represent a net energy drain on the economy for a long period of time. Any complete energy analysis of the SPS program should not only consider the energy requirements per five-gigawatt sateliite, but also the energy flows represented by the whote program. 


\section{II-3. ALTERNATIVE METHODOLOGIES}

A review of the literature suggests that there are four general approaches to energy analysis for power generation technologies:

1. Process Analys is

2. Input-output Analysis

3. Hybrid Analysis, e.g. a Mixture of Process Analysis and Input-output Analys is

4. Eco-energetics.

Process and input-output analysis are, technically speaking, techniques of analysis rather than overall methodologies. Eco-energetics may use both input-output analysis and process analysis. It differs from the typical forms of energy analysis primarily in terms of its scope. Eco-energetics attempts to include energy flows from the natural environment and incorporates concepts from ecology and system dynamics.

A recent review of issues in net energy analys is prepared by Pacific Northwest Laboratories of Battelle Memorial Institute (Reference 11) provides a useful tabulation on all of the various methodological features associated with the energy analysis models used by various experts in the field. This tabulation, which is reproduced as Appendix $B$ to this report, categorizes each model or approach by "type of analysis". This categorization parallels the fourway classification presented above.

Two aspects of this summary are worthy of additional comment. First of all, none of the models is exclusively a process model. Although a few rely almost entirely on input-output analysis, the majority of models that are not ecoenergetics, are in fact "hybrid" models. None of the literature summarized deals with the SPS. For the most part, the solar applications cited are those involving decentralized heat applications of solar energy.

\section{Process Analysis}

"Process Analysis consists of tracing production input back through the economy in stepwise fashion to calculate the energy requirements of each input". (Reference 25)

"It begins with an assessment of the direct inputs of coal, oil, electricity etc. to the production process.... Next, the direct energy inputs to the production of all nonenergy inputs are tabulated. This process proceeds ad inifnitum until all direct energy and indirect energy inputs to the production (process) are counted." (Reference 2) Clearly, this analysis must be truncated because of the infinite number of steps that would ultimately be involved.

Process analysis has its origin in engineering analysis and it is best applied to highly qualified technical personnel specifically familiar with the actual 
design. Even so, the tracing of indirect energy inputs becomes a time consuming and counterproductive effort once the first two or three levels of input are exhausted.

For many materials there is published data on the unit energy requirements of production, e.g. BTU's/pound or Joules/kilogram. When process analys is quantifies the input of a homogeneous material, e.g. aluminum of a certain specification, the analyst can then use the published data on the energy intensity or specific energy requirements of that material. Energy intensity or specific energy estimates may not always account for all indirect energy inputs to the manufacturing process. Another problem is that such estimates may not disaggregate the energy inputs by resources, e.g. coal, oil, electricity, etc.

To some extent, use of published energy-intensity data represents this "process analysis by proxy." Many forms of mineral extraction and refinement, notably including copper and aluminum, have been studied exhaustively. In those instances where the initial process analys is leads quickly to the unfabricated but refined mineral, it may be desirable to use energy-intensity data rather than continue the process analysis.

There still remains the question of how to account for the rest of the inputs. For example, in tracing back the fabrication of a launch vehicle, it might well be possible to proceed in a relatively small number of steps to the component aluminum, titanium, etc. This would, however, account for only a portion, albeit a potentially large portion, of the total energy input to the finai iaunch venicie. One treatilient of the remining energy inputs is to ignore them, on the grounds that the primary materials, particularly if they are energy-intensive, account for the vast majority of the total energy required. A second, and often more desirable approach, is to use input-output analysis to estimate the remaining energy inputs.

\section{Input-Output Analysis}

Input-output analysis was developed in the early 1940's by Wasily Leontief for the study of the U.S. economy. In applying this technique, a national or regional economy is broken down into a series of sectors corresponding to the various industry groups, final demand, the government and international trade. The flow of goods, services, and money between these sectors is then analyzed. Through the application of matrix algebra techniques, coefficients can be generated for each sector identifying the impact that a change in unit output for that sector will have on the economy as a whole or on any other specific sector.

The application of input-output analysis to energy analys is was pioneered by Clark Bullard and his associates at the Center for Advanced Computation (CAC) at the University of Illinois. Using the 1963 input-output table developed by the Bureau of Economic Analysis of the U.S. Department of Commerce, CAC undertook to determine the energy component of each sector's purchases. 
Relying primarily on data provided by the Bureau of Mines and other energy data sources, they were able to determine the amount of energy (direct and indirect) associated with a dollar of output from each sector. This measurement, typically expressed as BTU's per dollar, may then be used as proxy for the energy requirements of production. A detailed dollar budget should make it possible to estimate the total direct and indirect energies required for that system. Each dollar component is classified by economic sector and the energy intensity associated with each dollar output of that sector is identified. The sum for all sectors of energy intensity times dollar cost by sector is the total energy requirement in the simplest application of this approach.

Working with Robert Herendeen, among others, Bullard and the CAC team subsequently refined their analysis using the 1967 input-output tables. In subsequent development of this approach, CAC has also changed the format of the input-output table so that for the energy sectors themselves, e.g., coal, crude oil, gas, electricity, the units are not BTU's per dollar but rather BTU's input for final BTU's output.

The best reference to this methodology is in the handbook prepared by Bullard (Reference 4). In this document, the author reviews several of the major sources of uncertainty associated with input-output analysis. Price level changes can occur without corresponding changes in physical quantities of energy costs. Another source of uncertainty is change in the structure of the economy. A particularly significant source of uncertainty is change in the technology of producing goods and services, particularly as regards the amount of energy required per unit of output. Another significant source of uncertainty is due to sector aggregation. "Ideally, each product would be a unique output of a BEA (Business Economics Administration) sector, and therefore would have a unique energy coefficient." (Reference 4). This is clearly not the case and in many instances the particular product associated with a plant or system may represent only a small proportion of sectoral output and may not be typical in its energy requirements of the sector as whole.

Presented below is a brief list of the limitations of input-output analysis from the same reference together with a brief statement of the manner of adjus tment:

1. Price level changes. Use published sectoral deflator.

2. Technology changes. Updated energy intensities not yet available.

3. Aggregation of typical and atypical products in a single sector. For some sectors, but not all of them, CAC has developed a table showing the approximate mix of the major components within the sector so that the user can determine whether a particular product or service is typical of the sector as a whole.

4. Producers' versus purchasers' price. Since purchase price includes profit margins, transportation costs, distribution costs, and insurance, CAC has attempted to develop estimated margins for these various "nonproduction" components of price for selected sectors. 
5. Uncertainty in base year data. CAC provides error tolerances (percentage of the mean) for a subset of 90 sectors so as to be able to estimate the uncertainty associated with the energy/dollar intensities provided in the table.

Clearly, the priricipal benefit of input-output energy analys is is the ability to trap all indirect effects with a single energy coefficient rather than having to follow through an elaborate process analysis. Offsetting this powerful advantage, are the major problems of aggregation and timeliness. The sectors are admittedly very coarse approximations for most analysis. Furthermore, the use of a data base, no matter how elaborately adjusted or corrected, that reflects the U.S. economy in 1967 must be suspect. The problem of timeliness arises from the long lead time (approximately four years) for BEA to develop the input-output table from its data collection efforts. Additional time is required for CAC to convert this into an energy input-output matrix. For example, the 1972 inputoutput table for the U.S. economy will not be available as an energy input-output table from CAC untii some $i$ ime in eariy 1373 (Reference 12). Even then, the energy-dollar flow relationships will not reflect the technological and price changes associated with the energy crisis in 1973-74. It seems unlikely that input-output energy analysis that reflects the impact of the energy crisis will be available until sometime in the early to mid-1980's.

To some extent, the uncertainties associated with aggregation can be offset by pursuing process analysis until the required input is sufficiently homogeneous and/or sufficiently characteristic of its sector to minimize the potential errors of angregation.

Because of the large elements of uncertainty associated with input-output energy coefficients, there are many people who feel there is very little additional accuracy obtained by using the input-output coefficients for a particular sector. Instead, they would propose an approach in which the process analysis would be carried to the point where all major energy-intensive components had been identified and then for the remaining indirect energy, the simple ratio of energy per dollar of the total GNP can be used instead of individual sector ratios (Reference 20).

One intermediate position, already noted above, is to use process analysis up to the point of identifying primary raw materials, e.g., aluminum or steel; and then use energy intensities as produced by the input-output table in lieu of published engineering data on specific energies. The advantage of this is that it assures that all indirect energies used in fabrication are accounted for. The disadvantage is that the results may be distorted due to the time uncertainties that characterize input-output analys is in general (References 12, 13, and 14). 
In summary, input-output analysis provides a conceptually elegant technique for capturing all indirect and direct energies at the same time. It is plagued by the problems of uncertainty and timeliness. These problems may be reduced by pursuing process analysis to the point where the economic sectors considered are both effectively homogeneous and stable over time. This leads to the concept of a hybrid methodology which involves both process analysis and input-output analysis.

Hybrid Analysis: Combining Process and Input-Output Analyses

Most of the energy analysts employing input-output analysis actually use the hybrid approach since process analys is is clearly necessary to determine the direct energy components of final fabrication, direct energy input to the operating process, and specialized aspects of fabrication or construction not adequately dealt with in highly aggregated input-output sectors. This is the approach used by Bullard, Herendeen, Development Sciences Inc., Melcher, Pilati, and others (References 2, 3, 6, 7, 8, 12, 13, 14, 22, and 25).

The maior benefit of hybrid analysis is that process analys is can be confined to those major visibly energy-intensive components of a process. The components of the process left out can be dealt with by input-output coefficients to capture both direct and indirect energy.

Process analysis in this context can deal with both direct energy inputs to a process, either the primary process or second or third level processes, and material input. As the direct energy flows are accounted for and tabulated, the materials required can be accumulated and traced back in turn to component materials and energy. Presumably at some point in this process one reaches a sufficiently homogeneous or standardized definition of materials so as to be able to use either the input-output energy coefficient for that material sector or published (engineering) specific energy estimates.

Two remaining operational questions concern: (1) when to stop using process analysis and resort to the input-output data; and (2) whether, when the analyst stops using process analysis presumably because he has traced the process back tc homogenous materials, he should use the publichsed "process" data on materials energy-intensities or the input-output data on energyintensities for that material.

With respect to the first question of when to stop the process analysis, Bullard (Reference 4) suggests successive testing of uncertainty. The CAC input-output tables provided error tolerances by sector which can be supplemented by the particular analyst using the tables. It is possible at each successive iteration to generate an estimate of the uncertainty in the final estimate of energy. According to this approach, a target level of uncertainty is set, e.g., $\pm 10 \%$, and process analys is and/or disaggregation of component sectors is pursued until that stated target is reached. 
In the most elegant application of this uncertainty analysis, the underlying uncertainties in the basic data inputs are combined with the error tolerances of the energy-intensities to develop an overall estimate of uncertainty. In the case of the SPS, the large uncertainties associated with the inputs would preclude ever reaching any refined estimate on this basis. Nevertheless, the uncertainty reduction approach to determining the appropriate limits of data refinement may help to target those areas in which process analysis should be pursued.

Either input-ouput energy coefficients or other published energy-intensity data may be used for presumably homogeneous materials. This does not pose a problem if the two estimates are reasonably close. Where the two estimates differ, the analyst must pick the estimate which appears to best reflect the current state-of-the-art on an ad hoc basis. There will always be some presumption that the energy-intensities as derived from the input-output table will be higher than those derived from purely direct process analys is simpiy because indirect energies are always included in input-output estimates.

\section{Eco-Energetics}

"Eco-energetics differs from other methods in net energy analysis primarily by the inclusion of energy flows to the process from the natural environment. It also accounts for the indirect energies embodied in goods and services provided by society to the process in a different manner than process analys is or inputoutput analysis." (Reference 11). Eco-energetics was developed by Dr. Howard Odum of the University of Florida at Gainesville. "In the definition of net energy held by Odum and followers, the bioiogicai sysieliis' tehiavior is used as an analogy for human systems' behavior and become a normative quide for energy use as well. If once the premise is granted that human systems can and should be modeled after lower order biological systems, then net energy boundaries for analysis are open wide to include geological time scale, energy to run human communities, including human labor, and the opportunities foregone by using the resource in a less "efficient way'.... The human system which uses the least energy to accomplish survival will have the best chance to survive and flourish in the long run. Eventually this premise, definition, and conclusion become a moral model for organized social action." (Reference 8).

Deriving largely from this different philosophical framework, eco-energetics differs in several methodological respects from other techniques:

1. Energy flows from the natural environment are used, e.g., the energy value of the vegetation that could otherwise be grown on the land required for the system or process under investigation.

2. The use of a single energy per dollar ratio for all indirect input, e.g., the number of Btu's per dollar GNP in the United States.

3. The use of energy quality factors to differentiate different types of energy where the quality factor represents the relative usefulness 
(ability to perform useful work) of the energy source, e.g., oil would be a higher quality energy than wood or coal.

4. Explicit consideration of the time dynamics of the system, e.g., the increase in prices associated with particular systems and the subsequent changes that they may effect in the distribution of energy in the future.

Several key objections have been raised to eco-energetics. Perhaps the most important of these is the unusually long time frame implied by the analogy of human energy consumption to biological species survival (References 5,8 , and 17). Another critical objection relates to the use of vegetation energy content as a proxy for the energy cost of pre-empting land for other uses.

"The question remains: 'Is the value of society of the lost vegetation really equivalent to the useful energy content?" (Reference 11).

While some consideration of the environmental changes involved in energy consuming or producing systems is clearly needed, many experts express reservations as to whether they can be meaningfully treated by the use of energy content proxies. For this and other reasons, the eco-energetir.s approach is perhaps more relevant to social planning or philosophical debate, and has not achieved widespreadacceptance as a formal analytic approach. An abstract of one of Dr. Odum's publications states that "examination of energy systems can be vital and of good quality for human existence. Sharp changes in public viewpoint and public policy are to be expected soon." Dr. Odum goes on to say, "we hope these overviews will provide a general way for all of us to understand the place of humanity in nature, the responses of our system, and a way to predict the future." (Cited in Appendix F of Reference 8).

\section{Summary and Implications for the SPS}

Hybrid analysis, involving the use of both process and input-output analyses, clearly emerges as the methodology best suited to the SPS. Primary reliance on process analysis is difficult at best and certainly not warranted at the present early state of the SPS. On the other hand, input-output analysis, taken by itself, is characterized by numerous uncertainties even when applied to present technologies. When applied to the unconfirmed and rapidly evolving SPS technology, these uncertainties would be further compounded.

The hybrid approach offers the opportunities to pursue process analysis through a few initial steps and then to use input-output analys is to capture indirect effects. In this context process analysis can be considered as: purely primary process analysis in which the actual energy and material inputs to specific SPS components are examined; or secondary process analys is in which material energy-intensity data is collected and then applied at appropriate points in the analys is.

Eco-energetics would not appear to provide an easily applied or widely accepted framework for energy analys is of the SPS. 
II-4. PUBLISHED ENERGY ANALYSES OF THE SPS

There are only three published analyses of the energy requirements of the SPS that are even partially comprehensive. In the briefing literature and support documentation provided by NASA and its contractors, there are periodic references to energy requirements or "energy payback." These references are either explicitly incomplete or so generalized and inadequately documented as to prevent any evaluation of the methodology or data base used.

The first of three published analyses is to be found in "A Survey of Satellite Power Stations" (Reference S16). This approach, which adapted the input-output methodology for measuring energy' subsidies used by Development Sciences Inc., was admittedly a first cut approximation based exclusively on the dollar allocation of projected SPS costs.

The second published analysis, and the only one done by someone not involved in the SPS design or evaluation effort, was performed by Robert Herendeen, of the Center for Advanced Computation at the University of Illinois. This anaiysis appeared in two forms, first as a report submitted to the Committee on Science and Technology of the U.S. House of Representatives in connection with their hearing on H.R. 12505, a bill relating to the SPS research and development program. The same material, in a slightly different form, was presented at a recent symposium on energy modeling and net energy analys is sponsored by the Institute for Gas Technology. In this latter format, it was one of two technologies described in a paper entitled "Two Technologies Near the Net Energy Limit: Gasohol and Solar Power Satellite Power Stations" (References 13 and 14).

The third and most recently published energy analysis was performed by Jet Propulsion Laboratory for NASA/JSC (Johnson Space Center) as part of an overall study entitled "Satellite Power System (SPS) Preliminary Resource Assessment" (Reference 18).

All three of these analyses are based, to one degree or another, on obsolete SPS reference concepts. In addition, the two more recent studies refer only to a silicon photocell solar array, with no reference to the gallium arsenide concept. The applicability of the energy requirements estimates in any of these published reports to the current reference concepts for the SPS (either option) is therefore highly questionable. The following discussion is intended to identify key analytic problems and not to present actual energy estimates for the SPS.

An Initial Input-Output Approach: "A Survey of Satellite Power Stations"

In September 1976, PRC Systems Sciences Company completed a survey of power satellite systems for the Energy Research and Development Administration (ERDA). At the request of the client a brief energy subsidy analys is was included (Reference S16). To meet this key requirement within the limited time frame available and given the very minimal information on SPS design at the time, the input-output methodology was selected. It was then and still remains the 
quickest approach, particularly if the only data available is an estimated budget. Development Sciences Inc. (DSI) had recently completed an evaluation of several alternative power generation technologies (Reference 7). In this report, they had employed the input-output methodology developed by the Center for Advanced Computation (CAC). The DSI approach involved suing input-output analysis to generate estimated energy subsidies for each of the technologies considered. The DSI analysis was actually a partial hybrid in that energy pathways were defined for the extraction, processing, and conversion of fuel to electricity and direct energies were identified. For the most part, however, all materials input and much of the indirect energies were inferred through the use of the input-output energy tables.

Virtually the only readily available data on the SPS at the time was an estimated dollar budget by major system components that had been prepared by ECON as part of a prior evaluation of the SPS for NASA. In the PRC survey, the DSI methodology is applied in a very approximate fashion to the budget items set forth in the ECON cost estimate. Several of the classic uncertainties associated with input-output analysis applied. First of all, there was a high degree of inappropriate aggregation in the sectors. For example, the substantial volume of aluminum proposed for use in space construction was adapted directly from the aluminum forming sector in the input-output table. Similarly, the large klystron or amplitron tubes used to convert current to microwave radiation could nowhere be directly identified, and energy requirements were simply inferred from a mixture of primary nonferrous metal, e.g. copper, and electron tubes.

These and other approximations are shown in Exhibit II-2 which is a summary of the computation of capital energies. In this context capital energies refer to those initial energies expended to launch the SPS and build the rectenna site. The only items excluded are those involved in operations and maintenance which appear to be quite small.

The table itself shows reasonably clearly the methodology by proceeding from cost item to dollar cost to allocation by sector to energy requirement by type of energy. These data are taken directly from the original reference.

Error tolerances and the resulting variance in total energy requirement have been added as the final columns to Exhibit II-2. They are presented in order to show which sectors contribute most significantly to the uncertainty of the final estimate. The most significant error tolerance is not from the CAC reference but rather arbitrarliy imposed by the consultant on the solar cell blanket component of the solar array. The untested technology, substantial need for quality control, and other factors suggest that the initially supplied value is probably not even this accurate. Other error tolerances are taken from CAC data (Reference 4).

Even without considering the uncertainties in the data or the problems of aggregation, there could be as much as a 12 percent error. In addition to the solar array, other sectors which contribute significantiy to this uncertainty include aluminum forming, inorganic chemicals (used as a proxy for liquid gas fuels), and new construction (utilities). 


\section{EXHIBIT II-2 - CAPITAL ENERGIES FOR SPS BY MAJOR COMPONENT ${ }^{1}$ (5-GW Satellite-1976-Gallium)}

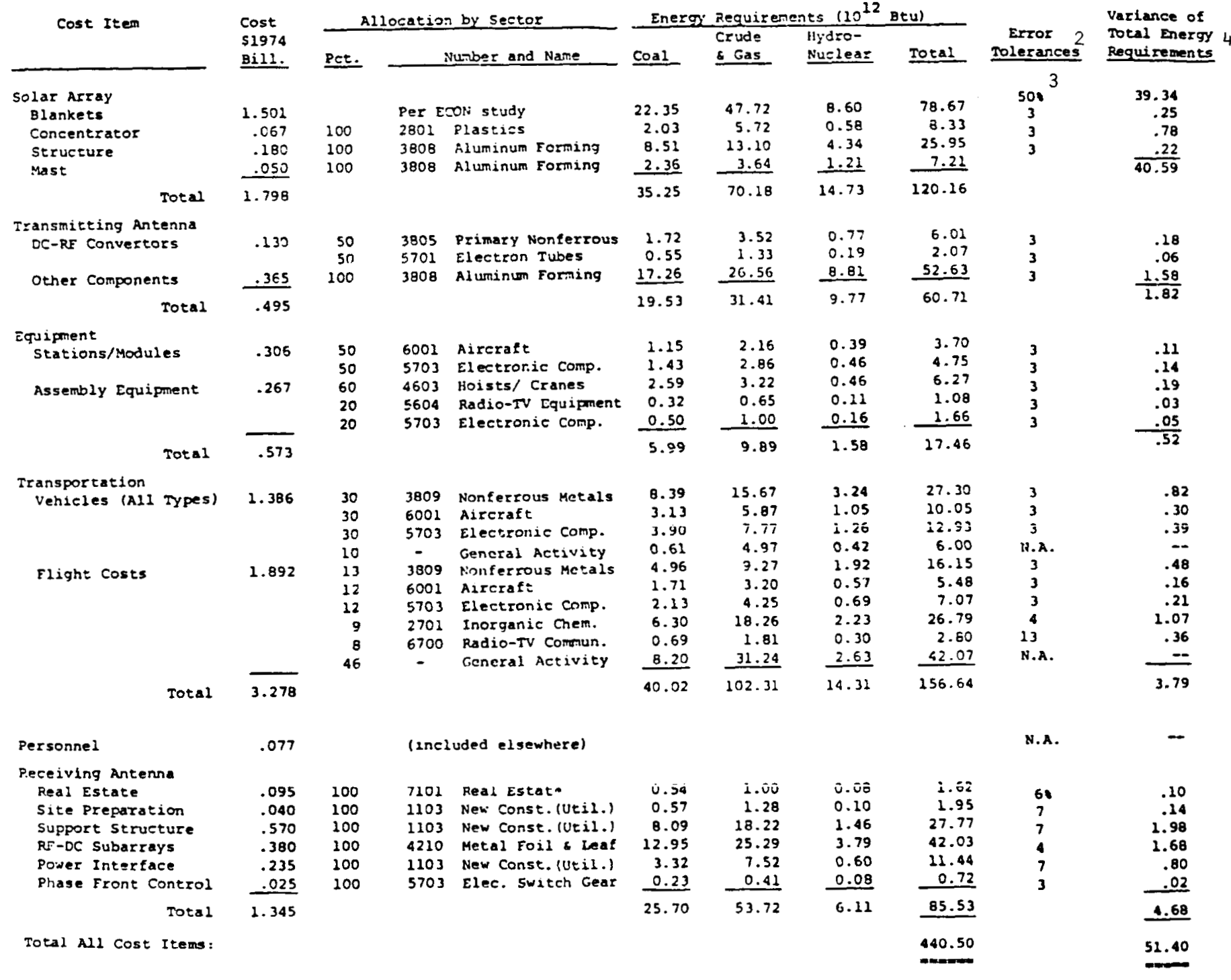

Note: N.A. indicates not available

$$
\text { -- indicates not applicable }
$$

${ }^{1}$ All data, unless otherwise noted, from Reference S16, Exhibit 46.

${ }^{2}$ Taken directly from: Clark, W. Bullard, Peter S. Penner, and David A. Pilati, Net Energy Analysis: Handbook for Combining Process and Input-0utput Analyses, Center for Advanced Computation, University of I7linois at Urbana-Champaign, (CAC Document No. 214), October 1976, Table A-7 (Total Primary), pp. 65-66. If specific SIC code not shown, figure for more general SIC code used.

${ }^{3}$ Allan D. Kotin, Economic Consultants estimate.

${ }^{4}$ Computed as product of energy requirements, total and error tolerances. 
Other problems revealed by this analysis include the high degree of aggregation and occasionally inappropriate allocations of cost items to specific sectors. The use of aircraft and electronic components as proxy for space stations and modules; the use of hoist cranes, radio equipment and electronic components for space assembly systems, are only two examples of the type of gross approximation that was required.

In summary, this analysis indicated that some type of comparison can be drawn in a relatively short time from a budget. At the same time, however, the coarseness of the budget input and its inapplicability to the sectors in the input-output table, seriously limit the accuracy and reliance which can be placed on the conclusions.

This highly abbreviated input-output based analys is concluded that the SPS required an energy subsidy of approximately 15.9 percent. This compared favorably with estimates developed by DSI for most competing technologies. The only technologies with lower energy subsidies were geothermal and strip mined coal with a mine mouth power plant.

Two problems were encountered in the final comparisons presented in the PRC study. In the DSI analysis of electrical generating systems, a 20-year 1 ife is assumed. The SPS concept is predicated on a 30-year life. Since initial (capitai) energies are greater in the SPS than in most other generation technologies, the lifetime over which to amortize these is particularly critical. For example, the energy subsidy for the SPS increases by almost 25 percent if the capital (initial) energies are amortized over 20 rather than 30 years. This points out the need for a common time frame or a rational basis for using different time frames if power generation technologies are to be compared as to their energy requirement.

A second and closely related problem concerns plant or load factor assigned to each power plant. In the DSI methodology and in most power plant evaluations, load factors of 80 percent or less are used. At the time of the PRC survey, the "nominal" load factor for the SPS was 95 percent. Subsequent research into occultation effects and maintenance requirements indicate a load factor of 92 percent.

\section{A Materials-Energy Approach With Accompanying Uncertainty: The Herendeen Paper}

The two published references covering this research explicitly state that the findings are only preliminary in character, that the research is continuing, and that the number of inputs to the analysis is arbitrarily limited in the interest of expediency. (References 13 and 14). Dr. Herendeen further reinforced these important qual ifications in subsequent personal communications. He went on the stress that the presentation of the SPS, along with the gasohol technology for enriching gasoline with grain alchohol, was selected for presentation at the IGT symposium only because they appeared to represent examples of technologies that approached the energy limit, i.e., could require more 
energy than they produce. At the presentation of his paper, Dr. Herendeen modified his findings and partially reversed himself on the question of whether or not the SPS actually approached the energy limit.

The actual energy ratios are to some extent irrelevant in any case. What is particularly significant about this paper is the types of assumptions that the author had to make, his treatment of uncertainty, and the special problems he encountered in attempting to apply his methodology to the SPS.

The following quotation provides an overview of both the methodology employed and some of the problems encourntered:

The SPS....has been studied at a low level since its proposal in 1968 and was the subject of congressional hearings in April, 1978. It has the obvious advantage of almost completely uninterrupted insolation in its geosynchronous orbit. Design concepts are ambitious: typically one talks of 5-10 GW capacity, with an array size in space of $100 \mathrm{~km}^{2}$ and a receiving antenna (rectenna) of $100-$ $200 \mathrm{~km}^{2}$. It goes without saying that any design data are somewhat uncertain.

I have attempted an energy analysis based on available publications. Because of data uncertainties I have used a rather aggregated approach in which the SPS is characterized by five 'modules' (for example, transportation to orbit) each requiring 10 materials (for example, silicon for solar cells) and whose overall requirements or performance are governed by eight parameters (for example, half life of solar cells in space).

Besides fuzzy data material requirements, because the project is so far in the future the energy intensities of these materials are also very fuzzy....given this, the only response is to perform an elementary error analysis....(Reference 14).

A careful review of this paper, combined with subsequent discussions with the author, reveal the following elements in his analys is:

1. The energy analysis is based exclusively on the energy requirements of key materials; materials energy intensive are taken from the CAC input-output analys is and include indirect energies.

2. Not all materials involved in the SPS are considered

3. The SPS concept evaluated is the silicon concept, since there is no mention of gallium.

4. The reference concept for this analysis was the 1976 Johnson Space Center concept involving 10-GW satellites to be constructed at the rate of 2-4 per year for a total development plan of 112 satellites.

5. The analysis is specifically and appropriately concerned with performance characteristics of the satellite, notably the degradation of the solar cells in orbit. 
This last point is of some concern since the author's estimate of the degradation of the solar cells is his own and does not reflect the current reference concept efficiency parameters. In the current design, the SPS output capacity will actually be somewhat oversized initially and the solar cells will be periodically repaired through a special annealing process. The average output to the utility grid of the SPS system should therefore be maintained at its design level throughout its 30-year lifetime.

This is but one of several problems raised by $\mathrm{Dr}$. Herendeen's strong emphasis on uncertainty analysis in the energy analys is of the SPS. Exhibit II-3 reproduces a list of input variables whose uncertainties were taken into account in Dr. Herendeen's analysis. Two of the items on this list are already implicit in his treatment of output degradation (items 1 and 6 , solar cell half life and cell attrition). The variations in the rectenna area and the solar cell thickness are themselves somewhat problematic. Solar cell thickness has an extremely powerful effect on materials requirements and, indirectiy, on transportation requirements.

The uncertainties associated with energy intensities (Items 6 through 17 on the Table) are more appropriately the concern of the energy analyst than some of the performance parameters of the SPS. Even here, however, there are several areas in which additional research is manifestly needed. The use of a single "energy intensity" for electronic parts for a project this heterogeneous clearly poses a problem of aggregation. Similarly, the wide ranges in energy intensity associated with silicon, liquid hydrogen and argon should be reducable through further research. Admittedly, this was only an initial approximation and no attempt was made at refinement.

The final item on the list of uncertainties is particularly significant because it again deals with the amount of credibility that should be given to the reference concept. In subsequent conversations, Dr. Herendeen indicated that the range of 1-2 assigmed to "material quantity" really applied to the amount of material that would have to be lifted into orbit and were used then as proxies for variation in the highly energy intensive fuel requirements of launch and interorbital transportation.

There is a real question as to whether large uncertainties, or any uncertainties for that matter should be assigned to "target" parameters or design specifications in the reference concept. Attatching error tolerances or "range values" to key performance parameters of the SPS can have an extremely powerful effect on the results of any energy analysis. Such performance uncertainties, particularly when compounded, create credibility problems even for an illustrative energy analysis of the SPS.

The problem of compounding uncertainties was acknowledged by the author. At the presentation of this paper, he presented a refinement of his analys is in which the uncertainty range was narrowed. Instead of assuming that all the worst values would apply concurrently or that all the best values would apply 


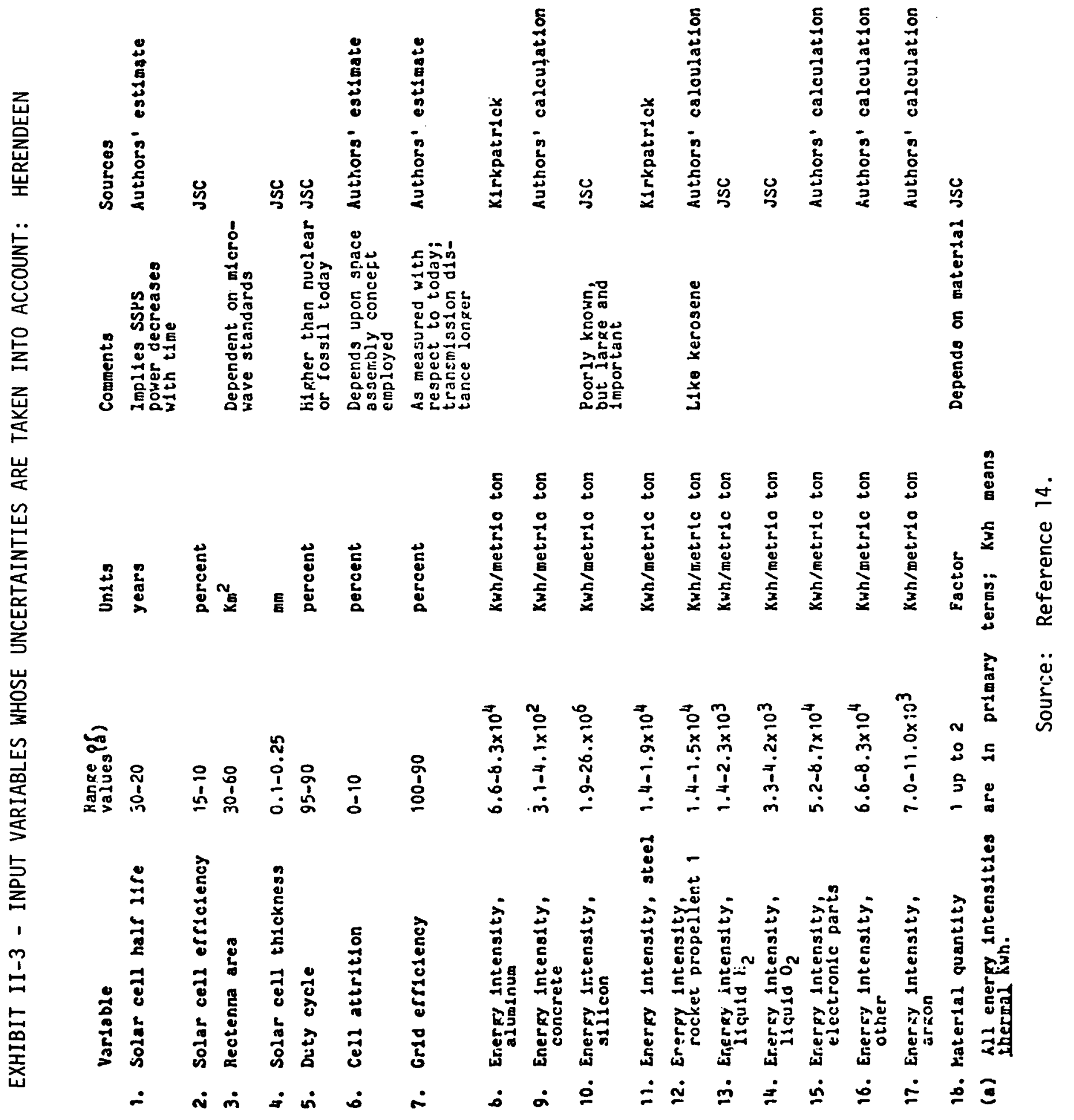


concurrently, he applied a random simulation (Monte Carlo) technique to generate a mixed distribution.

The summary results of the paper, together with the changes effected by the Monte Carlo treatment of uncertainty, are shown in Exhibit II-4. The "energy ratio", defined on the table, applied to the entire lifetime of the SPS. In his initial estimates, this energy ratio varied from 0.5 to 9 . After application of the Monte Carlo technique simulating a random distribution of extremes, the range narrowed to 0.7 and 3.9 .

Energy ratios are presented on a "fuel-included" and a "fuel-excluded" basis. For solar systems, there is no difference between "fuel included" and "fuel excluded" ratios. Therefore, the SPS energy ratios on a "fuel included" bas is are substantially higher than all the other technologies which are, by thermodynamic law, significantly under 1.0. Which of the two ratios is better is a policy decision, but even this brief analysis suggests that both ratios should be presented.

The second major definitional problem reflected in the author's analysis concerns the equivalent energy value of electrical output. The "free energy" content on enthalpy of kilowatt hour (electrical) is 3413 Btu. It therefore appears technically accurate to present energy ratios for power by 3413 and comparing this product to the energy requirements as expressed in Btu's. There is, however, potential problem associated with this apparently straightforward conversion. Converting to electricity typically requires the expenditure of approximately 10,000 Btu per kwh since the thermal efficiency of energy conversion in fossil fuel power plants is, at best, approximately $35 \%$. In the course of his presentation, Dr. Herendeen acknowledged this potential inconsistency and restated his energy ratios to account for the fact that the energy requirements were all measured in thermal values whereas the energy output, without subsequent adjustment, was measured in the thermal equivalent of electrical values. The resulting change, as shown in Exhibit II-4 raises the SPS energy ratios to a range of 2.1 to 17.7 with an intermediate value of 6.6. The same increase by a factor of three also applies to the energy ratios used for other energy technologies. Unless the outputs of the processes being compared are not commonly defined, e.g., kwh (electrical) or kwh (thermal), this definitional issue creates severe problems.

In his presentation of two very different technologies, the SPS and gasohol, Dr. Herendeen took the opportunity to address several other problems in energy analysis by contrasting the two processes under examination. In one instance he compared selected aspects of the two systems under study including their size, cost, regional suitability, and vested interests. In another part of the analysis he reviewed the methodological problems associated with applying energy analysis to the two processes. The comparisons he made are summarized in Exhibit II+5. 
EXHIBIT II-4 - SPS ENERGY RATIOS: HERENDEEN

(10 GW Satellite-1976-Silicon)

ENERGY RATIO ${ }^{1}$
$\begin{gathered}\text { (at } 3,413 \mathrm{Btu} / \text { Kwe) } \\ \text { Fuel } \\ \text { Included }\end{gathered}$

\begin{tabular}{|c|c|c|c|}
\hline $\begin{array}{l}\text { Coal Fired Power } \\
\text { Plant }{ }^{3}\end{array}$ & 0.31 & 7.7 & 23 \\
\hline $\begin{array}{l}\text { Light Water } \\
\text { Nuclear Plant }\end{array}$ & 0.24 & 4.8 & 14 \\
\hline $\begin{array}{l}\text { Combined } \\
\text { Coal Final } \\
\text { Plant }\end{array}$ & 0.38 & 14.0 & 42 \\
\hline \multicolumn{4}{|l|}{$\begin{array}{l}\text { SPS (Initial with } \\
\text { Maximum Range) }{ }^{4}\end{array}$} \\
\hline $\begin{array}{l}\text { Bes } \mathrm{i} \\
\text { Intermediate } \\
\text { Worst }\end{array}$ & $\begin{array}{l}3.0 \\
1.7 \\
0.5\end{array}$ & $\begin{array}{l}3.0 \\
1.7 \\
0.5\end{array}$ & $\begin{array}{l}\text { Not } \\
\text { Stated }\end{array}$ \\
\hline \multicolumn{4}{|c|}{$\begin{array}{l}\text { SPS (with Randomized } \\
\text { Uncertainty) }\end{array}$} \\
\hline $\begin{array}{l}\text { Best } \\
\text { Iritermediate }{ }^{5} \\
\text { Worst }\end{array}$ & $\begin{array}{l}3.9 \\
2.2 \\
0.7\end{array}$ & $\begin{array}{l}3.9 \\
2.2 \\
0.5\end{array}$ & $\begin{array}{r}11.7 \\
6.6 \\
2.1\end{array}$ \\
\hline
\end{tabular}

$1 \quad E R=\frac{\text { Electric Energy Del ivered over Lifetime }}{\text { Primary, }}$

2 Computed as per Note 1 with the electrical output (numerator) multiplied by three $(3 \times 3,413=10,239)$ to reflect the energy content of the fossil fuel required to generate the equivalent electricity at a nominal efficiency of $33 \%$.

Source: Reference 25

4 All extremes of range values assumed to occur simultaneously; subsequently modified by author in preseritation.

5 Calculated using arithmetical averages of all variables expressed as ranges.

6 Distribution of extremes for range variables assumed to be more random through use of Monte Carlo method.

SOURCE: References 12 and 13. 
Comparison of Selected Aspects of SPS and Gasohol:

\section{ASPECT}

1. Output

2. Solar conversion process

3. Relative size

4. Capital cost

5. Potential energy contribution

6. Regional suitability

7. Vested interests

8. Time scale to implement $30-50$ years

9. Uncertainties in data High
SOLAR POWER SATELLITE (48 10-GW Satellites-Silicon)

\section{Electricity}

Photovoltaic cells

Collector and Rectenna of order $100 \mathrm{~km}^{2}$ (10 GW output)

\$10-50 Billion

All U.S. electricity

NASA, aerospace contractors
GASOHOL

Liquid Fuel

Biomass

Typical distillery (of order $10^{4} \mathrm{M}^{2}$ ) producing of order $20 \times 10^{6} \mathrm{gal} / \mathrm{yr}$.

$\$ 10-20$ Million

$2 \%$ of present gasoline (crop surplus limitation)

Grain belt states

USDA, agriculture lobby

1-2 years

Low

Methodological problems in Energy Analysis:

EXAMPLES

1. Specification of sys tem boundary

2. Comparison of different energy types

3. Consideration of end use

4. Consideration of joint product

5. Confusion of energy payback with energy ratio

6. Inclusion of fuel in energy ratio

7. Dynamic effects (from ambitious building programs)

8. Question of negative costs vs. positive benefits ${ }^{*}$
Should research costs be included?

Electricity out vs. fossil fuel in.

Will electricity be used in heat pumps?

Complicated by SPS's expected decrease in output over lifetime
Should agricul tural energy be included?

Should process be evaluated as a petroleum-like fuel producer only?

Does gasohol get better milesper-gallon than gasoline?

How is energy "content" of feed by-product counted?

This is not a problem with these solar technologies but it is for competing fossil-based technologies (Potentially, always a problem)

*(This does not change balance but does change energy ratio.) Source: Reference 13. 
Item 7 on his list of methdological problems is of particular importance to the SPS. "Calculation of ER (energy ratios) masks the time evolution of energy output and input." (Reference 14). Although the author is referring primarily to the potential decrease in output associated with solar cell degradation, the issue he raises is of considerable importance even if constant output is assumed even through the annealing process. The point remains that the SPS program is an ambitious one in which additional units will be added yearly for thirty years. It may be some time, therefore, before the combined energy output of the operating SPS fully offsets the very substantial energy requirements associated with the on-going fabrication, launching and assembly of the units.

The energy intensities used by the author are not the result of process analysis or specific industry study. Instead, they are taken from the input-output analysis developed by the author and his associates at the Center for Advanced Computation of the University of Illinois. In subsequent discussions, the author stated that while he felt that the application of energy intensities per dollar of output in gross sectors was inappropriate, he did feel that the inputoutput approach with the energy corrections that have been applied to the 1967 data represented a sound working approximation of total energy requirements. He stressed that by using the input-output ratios related to physcial quantities rather than current dollars, it was possible to account for the indirect energies as well as the direct energies. He drew a careful distinction between this approach and additional process analysis which becomes extremely costly when used to estimate indirect as well as direct energy input.

Perhaps the best summary of the research embodied iii these twio references is provided by the conclusion to the paper submitted to Congress:

To sum up; (1) The SPS seems to be more efficient than conventional coal or nuclear technology in utilizing fossil fuel to produce electricity. We suggest that is should be compared with other solar technologies. (2) The SPS seems at least as susceptible and very likely more susceptible, as conventional coal or nuclear electricity to dynamic problems. (3) The uncertainties of actual materials requirements are so large and produce a large degree of uncertainty with regard to the energy ratio. For good comparison these uncertainties should be reduced. (Reference 14.)

The only observation that need be added to this summary is that an explicit policy determination should be made as to whether the performance parameters are to be subjected to uncertainty analysis or taken as given for ourposes of initial evaluation. 
A Different Materials-Energy Approach: The JPL "Resource Assessment"

The study of resource requirements of JPL (Reference 18) has many general features in common with Herendeen's analysis. It is based primarily on a conversion of material energy. In this instance, however, the question of indirect energy is treated quite differently.

The total energy expended for SPS...for various materials resources and fuels depends on the estimated value of specific energy consumption $(\mathrm{KWh} / \mathrm{Kg}$ ) of materials used as feed-stock in the various systems... the fundamental problem of ascertaining the specific energy consumption of a certain material is a proper definition of the boundaries. If they are too restrictive,...then the omission becomes very obvious. Less apparent, but certainly apparent, but certainly more significant, is the omission... of the energy consumed on transportation and storage, and most of all, facilities which include the capital equipment and their repair and maintenance as well as air conditioning, lighting, scrubbers and back-up. On the other hand, if the boundaries are too broad, the energy flows ...become multi-channeled with the same energy consumption being shared by several energy-using sectors in that society. Then the entries of energy-input-output table becomes fuzzy and it is easy to comit double bookkeeping.... the ECON study gives the ratio of overall energy consumption versus process energy requirement at 2.5 for the five materials 1 isted. If, according to a specific source, the specific energy consumption given, taking into account the process (or production) energy consumption only, this number will be multiplied by a factor of 2.5 to convert it to the overall energy consumption. Presumably, with boundaries covering all aspects of processing, transportation and storage, and facilities. (Reference 18.)

The JPL authors also treat the electrical-thermal unit conversion problem rather differently. First of all, they assume that all electricity used in the development of the SPS should be multiplied by a factor of four to arrive at the thermal energy content of fossil fuels consumed. They base this on an average thermal efficiency of power plants of 33 percent plus an additional adjustment factor for maintenance, operation, and supplies. A similar reverse adjustment is made in comparing the electrical output to the thermal input. In this case, electrical output is multiplied by three to reflect the average one-third efficiency of the fossil fuel fired plants that the SPS will replace. This technique does produce internally consistent estimates, but is not consistent with most other studies.

The specific energy estimates to which this study refers are engineering estimates. They are quoted as ranges reflecting the different estimates of specific energy available from different sources. For two materials in particular, aluminum and steel, high and low range values for the specific energy are used. 
The findings of this study are summarized in Exhibit II-6. The extended footnotes to this table state several of the underlying assumptions used and list all the individual component materials considered.

In summary, this study provides some elements of a useful model for how to approach the problem of SPS energy analysis. It is specifically modular in approach with separate analyses for space systems, propellants, rectenna systems, and launch sites. As previously noted in the critical materials analysis in this white paper, this study also represents an appropriate merging of materials and energy analysis.

The methodology used in the JPL paper may, however, significantly limit the comparison of SPS energy requirements to the energy requirements of competing power generation technologies. First of al1, the use of a 2.5 multiplier factor to derive total energy from direct process energy is by no means universally accepted. Secondiy, the admititediy arbitrary conversion of input and output electricity to thermal units by multiplying by factors of four and three, respectively, presents some comparability problems.

It remains to be determined whether or not the use of input-output energy coefficients can add meaningfully to the accuracy of accounting for indirect energy requirements, which may be quite substantial in the case of the SPS. Certainly, the 2.5 multiplier factor should not be adopted without further investigation.

Once again, the reader should be cautioned in interpreting the final results of this analysis in terms of the currently adopted reference concept for tine SPS. The nominal system used for the JPL study was a 1976 Johnson Space Center concept. It ignores completely the gallium option and is based on a larger (10gigawatt) satellite produced in significantly larger numbers (112 satellites scaled down to 48). It also does not incorporate several recent design changes. These and other issues of non-comparability are dealt with at somewhat greater length in the discussion of critical materials in this white paper.

Energy Requirements of Space Vehicles, Rice's PNL Paper

The literature search conducted as part of this effort was confined primarily to papers dealing explicitly with the SPS or studies depicting the general state of energy analysis. One notable exception to this was a recent paper by Eric Rice of Battelle's Columbus Laboratories entitled "Energy Impact Assessment of NASA's Past, Present, and Future Space Launch Vehicles" (Reference 26). In this paper, the author presents a detailed methodology for estimating the energy requirements of space launch vehicles.

This analysis is based primarily on consideration of specific energy in a manner somewhat similar to the analys is presented in the JPL paper on the SPS. In this instance, however, the author has gone further in estimating indirect energy and has actually identified many of the sources of indirect energy consumption associated with space launch vehicles. For example, he has developed functional 
EXHIBIT II-6 - ENERGY PAYBACK OF 48 10-GW SPS SATELLITES: JPL (1976 Silicon Concept)

\begin{tabular}{|c|c|c|c|c|}
\hline \multirow[b]{3}{*}{ SPS Sys tem Ca tegory } & \multicolumn{4}{|c|}{ Life Cycle Energy Expended } \\
\hline & \multicolumn{2}{|c|}{ Low/Low ${ }^{1}$} & \multicolumn{2}{|c|}{$\mathrm{High} / \mathrm{High}^{1}$} \\
\hline & $\begin{array}{c}\text { Energy } \\
\left(\mathrm{GW}_{\left.\mathrm{th}^{-y r}\right)}\right.\end{array}$ & $\begin{array}{l}\% \text { of } \\
\text { Total }\end{array}$ & $\begin{array}{l}\text { Energy } \\
\left(G W_{t h}^{-y r}\right)\end{array}$ & $\begin{array}{l}\% \text { of } \\
\text { Total }\end{array}$ \\
\hline Space Systems & 284.9 & 17.9 & 296.2 & 13.9 \\
\hline Propellants & 87.5 & 5.5 & 87.5 & 4.1 \\
\hline Rectenna Systems ${ }^{2}$ & $1,209.0^{3}$ & 75.9 & $1,738.0^{3}$ & 81.4 \\
\hline Launch Sites & 10.4 & 0.7 & 13.4 & 0.6 \\
\hline Total & $1,591.8$ & 100.0 & $2,135.1$ & 100.0 \\
\hline Divide by & $3 \bar{P}_{e}=13$ & $5 \mathrm{GW}_{\text {th }}$ & $3 \bar{P}_{e}=13$ & $\mathrm{GW}_{\text {th }}$ \\
\hline Energy payback time (yr) & 1.20 & & 1.61 & \\
\hline
\end{tabular}

1 High/High stands for high aluminum/high steel bounds of the specific energy consumption. Likewise, Low/Low.

2 Rectenna structure made of aluminium.

3 Output of 48 satellites each producing $92 \%$ of 10.0 gigawatt-years annually (multiplied by three to correspond to fossil equivalent) $\mathrm{P}_{\mathrm{e}}=10 \times 480 \times .92$
$=441.6$.

4 Analysis based on specific energies for the following materials or groups of materials:
Alumini um
Mechanical Sys tems Electronics
Stee ]
Black Paint
Concre te
Graphite
Silicon
Lique fied Hydrogen
Copper
Glass
Liquefied 0xygen
Inconel, Silver, Molybdenum
Insulation, Mylar, Glue Gold Kovar RP-1 (Rocket Propellant)

Source: Reference 18. 
relationships for energy expended in design, development and testing, quality control, and several other indirect energy costs associated with space launch vehicles.

What is particularly significant about this paper is that it provides a partial model for independent modular treatment of various components of the SPS. The importance of such modular treatment has already been noted. This paper by Rice, however, provides a specific example of how one element in the SPS energy requirements analys is can be dealt with somewhat independently of the others. His functional relationships specifically allow for payload capacity, number of reuses, and other factors which are potentially changing design parameters of the SPS. Given the high degree of interaction between satellite design changes and transportation requirements, it seems worthwhile to separate the energy requirements analys is into modules. In this separation, functional relationships to key "driving" variables such as number of launches, number of reuses, etc. should be explicitly identified. Subsequent changes in satellite design can then be factored into the energy requirements of space transportation in a very straightforward manner.

\section{Implications of Extant Research}

Several observations may be drawn from the review of this brief volume of existing research on the SPS energy requirements:

1. There is a need to establish a reference concept with fixed performance parameters over a sufficiently long period of time to complete a meaningful energy analysis without the concept being evaluated becoming obsoiete.

2. Policy decisions must be made with respect to the "immutability" of the performance parameters of the SPS and its input requirements. Are uncertainties to be treated at all? If so, then who is best qualified to specify the tolerances?

3. Any energy analysis of the SPS will be based to some significant degree on the energy intensity of major component materials: to this extent, there will be an element of process analysis.

4. Energy analysis of the SPS can be accomplished without recourse to input-output analys is but not apparently without some major problems in the treatment of indirect energy costs.

5. Certain conventions should be adopted with respect to the units to be used.

The International Federation of Institutes of Advanced Study (IFIAS) recently considered the issue of consistent units (Reference 16). They recommended the use of the joule as the measure of energy and the use of the "free energy" concept or enthalpy measurement for all the forms of energy. Whether this or some other convention should be adopted, it is clear that some rules should be established. 


\section{II-5. RECOMMENDED APPROACH TO ENERGY ANALYSIS FOR THE SPS}

\section{General Criteria for Selecting a Methodology}

A principal prerequisite for any methodology to be applied to SPS energy analys is is its applicability to other energy generation technologies. In the absence of this, the energy analysis of the SPS will become an empty exercise of little or no value to the policy makers who must deal with numerous competing technologies.

It may be argued that this requirement should be stated even more severely in that no methodology should be used which has not already been applied to other competing technologies. Only in this manner can two important subsidiary objectives be achieved: the assurance that the methodology selected is, in fact, applicable to other technologies; and the minimization of additional work in making such comparisons.

The methodology selected should lend itself to a modular approach. The different components or sub-systems of the overall SPS program should be susceptible to to separate analysis and expressible in functional terms in relation to a limited number of key parameters, e.g., number of tons to orbit, proportion of aluminum and/or concrete in rectenna sites, etc.

Another key criteria is that the methodology should be sufficiently straightforward and mechanistic to permit fairly rapid iteration. Whether or not the initial energy analys is is subjected to formal sensitivity analysis, it is inevitable that key design parameters will change and additional analyses will be required.

The presentation of energy requirements by type of energy, e.g., coal, oil and gas, nuclear, etc., should also be a major selection criterion. Many of the objections to energy analysis center around the use of a single figure of merit, e.g., a net energy ratio. The presentation of the amount and type of energy required to develop and operate a power generation system in sufficient detai 1 for the reader to draw his own conclusions may be considered to be the primary function of energy analysis. A major insight to emerge from the IGT symposium on energy modeling was that many of the analysts felt that any ratios were unreliable and that the key objective was to provide sound energy accounting in sufficient detail to permit the policy maker to formulate whatever ratios he felt were appropriate.

\section{A Recommended Mixed Methodology Approach}

If the foregoing criteria are rigorously applied, it is inevitable that some form of input-output analysis will be used. First of all, it is the only form of energy analysis that provides useful data on the different types of energy used, e.g., coal, oil, etc. without laborious process analysis. Secondly, it has many of the virtues of expediency. If necessary, it can be applied as early as the initial dollar level. It does reflect differences in the relationship of direct and indirect energies between sectors that simple multiplier approaches ignore. 
Several of the disadvantages of input-output analysis require that many of the key initial energy requirements of the SPS be established by process analysis. The preliminary analys is in the PRC survey clearly demonstrates the problem of inappropriate aggregation associated with the direct use of input-output analysis. Questions of timeliness are particularly meaningful insofar as any SPS energy requirements analys is is already an exercise in distant projection. This problem will only be compounded by basing analysis on 1967 or even 1972 data, no matter how well adjusted.

Process analysis must therefore be a critical element in any selected approach. In some cases, notably the fabrication of photovotaic cells, process analysis should be thorough, traditional engineering analysis, presumably involving some degree of primary research.

The use of material energy-intensities (an input-output concept) or specific energy requirements (a process engineering concept) can provide reasonable proxies for process analys is in many other instances. For example, there should be no reason to reinvent the energy requirements for aluminum, copper, steel, etc. Systematic evaluation of published data including, in particular, a determination of the extent to which indirect energies are accounted for, should suffice in lieu of additional primary process analysis.

Process analysis may also be the only way in which to deal with the problem of changing technology or fabrication. For example, the dollar cost of photovoltaic cells is projected to decrease by an order of magnitude as a function of SPS research and as a requirement of SPS feasibility. This cost reduction will inevitably be accompanied by a substantial, though not necessarily proportional, reduction in energy requirements. It may be possible to partiaiiy appruxinate the reduction in energy requirements by examining the components of total energy requirements in present technology and relating prospective changes in technology to these components. One example of this might be the rejection rate associated with present fabrication. Part of the cost reduction target might be a specified reduction in that rejection rate, i.e., better quality control. This is directly expressible as an energy savings. Other sources of cost savings and technology improvements that could be translated fairly directly into energy savings include reduced material quantities or thickness, reduced thermal requirements for processing, etc. While process analysis cannot be expected tn resolve the question of changing technology, it may provide the basis for at least a parametric treatment of reduced energy requirements.

The cumulative impact of indirect energy requirements otherwise unaccounted for is perhaps the most persuasive argument for using a hybrid methodology. Process analysis may be relied upon to identify and account for the major energy-intensive elements in the SPS. The simple assertion that these major energy-intensive elements account for a large enough majority of total energy requirements to warrant ignoring the remainder is indefensible without further investigation. The cumulative effect of small proportions of total energy requirements ignored at each step, in an otherwise process-dominated methodology, can be quite significant. It may not be significant but there will be no way to know that 
unless some attempt is made to account for these indirect energies.

The SPS draws on a wide range of highly heterogeneous economic sectors. This mitigates against the use of a single multiplier for a simple ratio of Btu's per dollar of GNP.

\section{Design and Policy Prerequisites}

Several of the policy decisions needed prior to any analysis of SPS energy requirements have already been noted. Presented below is a brief list of these and other policy decisions that are required:

1. The treatment of uncertainties in SPS materials requirements and specifications options include: ignoring uncertainty and taking the reference concept as is; designating technically qualified experts to provide error tolerance estimates for all non-trivial elements of the system; or using the contribution of each system element to the total energy requirements as a criteria for determining whether it is to be subject to such technically expert assignment of error tolerances.

2. Confirmation of the modular approach: if energy analys is is to be undertaken on a modular basis, these modules must correspond to the major system elements, as in the JPL study; and they must also be tied together by key interface variables which are defined in advance as the "drivers" of each module.

3. The identification, in advance, of which power generation technologies will be compared to the SPS in terms of energy requirements. Without such specification, the selection of appropriate methodologies and data bases may result in unforeseen lack of comparability at the conclusion of the analysis.

Confirmation and definition of the modular approach is an absolute necessity if both the gallium and silicon photocell options are to be pursued in a parallel manner without total duplication of effort. Only by isolating non-satellite components such as the rectenna and HLLV (Heavy Lift Launch Vehicles) from the satellite itself will it be possible to analyze both options without a total duplication of effort.

The policy issue with respect to uncertainty interacts directly with a similar issue raised in a section of this white paper on critical materials. In that discussion, the recommendation was made that error tolerances for all or most of the materials be specified as a substitute for detailed refinements of the estimates based on the current reference concept. To the extent that this recommendation is followed, it partially resolves the need for specifications of error margin in the case of the energy requirements.

One key interaction between energy and critical materials analys is is that energy intensity should become a criterion for specification of error tolerances on materials. This is not self-evident from the materials analysis itself since the initial screening process could simply discriminate on the basis of whether or not 
a material was likely to give rise to a supply problem. To these criteria must be added the extra criterion that the material qualifies for further investigation and error tolerance specification if it is highly energy-intensive.

\section{Recommended Procedural Sequence}

Presented below, in modified outline form, is an example sequence in which the analys is of energy requirements for the SPS can be undertaken:

\section{Task 1 - Module Definition}

1.1 Define modules, e.g., two alternative satellites, space assembly, space transportation (vehicles, launch, propellant), rectenna facilities. (For energy purposes it may also be useful to separate ground control systems.)

1.2 For each module, identify key "driver" parameters, e.g., solar cell thickness and composition for the satellite, payload and number of reuses for launch vehicles, etc.

1.3 Reconcile modulesused for energy analysis explicitly with modules used for critical materials analysis, and insofar as possible, with other existing analytic models of the SPS.

Task 2 - Prepare Materials List by Module

2.1 Identify major materials requirements for each module.

2.2 If materials are of significantly different specifications, e.g., different types of steel, disaggregate and specify. (Also needed for critical materials analysis.)

2.3 Identify materials which involve new and untested technologies and/or technologies to be drastically revised as part of the SPS effort. (For process analysis.)

2.4 Summarize materials requirements for the entire program and reconcile with materials list used for critical materials analysis.

2.5 Provide disaggregated budget for the modules, separating, if possible, the costs of items identified in Steps 1 and 2 above. (For inputoutput analysis.)

Task 3 - Identify Initial Candidates for Process Analysis

3.1 Major new technologies.

3.2 Major changes in scale of present technologies.

3.3 Materials and rrocesses so large in relation to total project that they should be considered even with stable technologies, e.g., concrete assemblies in the rectennas. 
Task 4 - Establish Base for Comparison to Other Technologies

4.1 Assemble up-to-date literature on energy requirements of competing technologies.

4.2 Review and evaluate to select not more than two methodologies or approaches already employed in evaluating competitive methodologies.

4.3 Review and identify data base used.

Task 5 - Assemble Key Energy Data Base Items

5.1 Obtain the most reliable current input-output energy analysis from CAC together with all adjustment tables and formulas.

5.2 For all materials on the materials list, assemble a data base of specific energies and/or energy intensities and examine each source for: (1) how recent it is; (2) the degree to which it includes indirect energies; and (3) the extent to which it is specifically applicable (or adaptable) to the materials specifications.

Task 6 - Perform First-Cut Prel iminary Analysis

6.1 Subject to process analysis only those initially defined candidates.

6.2 Employ materials energy intensities and input-output coefficients to complete energy analysis.

6.3 Perform uncertainty analysis on results by component. (May be 1 imited to uncertainties in energy intensities.)

6.4 Review findings to identify processes and materials requiring further in-depth evaluation.

Task 7 - Iterate and Refine Analys is

7.1 Obtain refined input data if needed (see Task 2).

7.2 Extend and/or refine process analyses as needed.

7.3 Reiterate input-output and materials energy intensities portion of the analysis to develop final estimates.

The foregoing list is only a partial one. It does not consider, for example, at what point a computer program should be evaluated and/or introduced. The first four steps are prerequisites to any final analysis. On the other hand, the detail in which materials specifications are given in Task 2 can, in part, be subject to the findings of Task 6 . If error tolerances on SPS performance specifications are to be considered, this would be incorporated in Step 3 of Task 6 . 
1. Bown, Robert W., U.S. Department of Energy, Office of Planning and Analysis, personal communications, July-August 1978.

2. Bullard, Clark W., III, Energy Costs and Benefits; Net Energy, Crane, Russak \& Company, Inc., 1976.

3. Bullard, Clark W. and Robert A. Herendeen, Energy Use in the Commercial and Industrial Sectors of the U.S. Economy, 1963, CAC Document No. 105, University of Illinois at Urbana-Champaign, Center for Advanced Computation, November 21, 1973.

4. Bullard, Clark W., Peter S. Penner, and David A. Pilati, Net Energy Analysis: Handbook for Combining Process and Input-Output Analys is, University of Illinois at Urbana-Champaign, Center for Advanced Computation, Energy Research Group, October 1976.

5. Common, Michael, "The Economics of Energy Analysis Reconsidered," Energy Policy, June 1976.

6. Development Sciences Inc., Application of Net Energy Analys is to Consumer Technologies, (report to U.S. Energy Research and Development Administrator, Office of the Assistant Administrator for Planning and Analysis), December 1976.

7. A Study to Develop Energy Estimates of Merit for Selected Fuel Technologies, (report to U.S. Department of the Interior, Office of Research and Development), September $\bar{i} \overline{\bar{T}} \overline{5}$.

8. The Utility of Energy Resource Accounting and Net Energy Analysis in Energy Technology Assessment, (Draft), (Sagamore, Massachusetts), February 14, 1978.

9. Frabetti, Alton J., Applied Resources Inc. (formerly Development Sciences Inc.), personal communications, July-August 1978.

10. Fraley, David W., Battelle Pacific Northwest Labs, "Issues in Net Energy Analysis," paper presented to the symposium on "Energy Modeling and Net Energy Analys is," Institute for Gas Technology, Colorado Springs, Colorado, August 21-25, 1978.

11. Fraley, D.W., C.L. McDonald, and N.E. Carter, A Review of Issues and Applications of Net Energy Analys is, Pacific Northwest Laboratory Toperated by Battelle Memorial Institute), May 1, 1978.

12. Herendeen, Robert, University of Illinois at Urbana-Champaign, Center for Advanced Computation, personal communications, August 1978. 
13. University of Illinois at Urbana-Champaign, "Two Technologies Near the Net Energy Limit: Gasohol and Solar Power Satellite Power Stations,: paper presented to the symposium on "Energy Modeling and Net Energy Analysis," Institute for Gas Technology, Colorado Springs, Colorado, August 21-25, 1978.

14. Herendeen, R., T. Kary, and J. Rebitzer, "Energy Analys is of Solar Satellite Power Station," Hearing Record, U.S. House of Representatives, Committee on Science and Technology, Hearings on H.R. 12505, a bill for "Establishment of a Solar Power Satellite Research, Development, and Demonstration Program." P. 429

15. Hill, K.M., and F.J. Walford, "Energy Analysis of a Power Generating System," Energy Policy, Vol. 3, No. 4, December 1975.

16. International Federation of Advanced Study (IFIAS), "The IFIAS Workshops Convened to Establish the Basic Ground Rules for Energy Analys is," summarized in "Conference Reports," Energy Policy, Vo1. 3, No. 4, December 1975.

17. Leach, Gerald, "Net Energy Analysis: Is It Any Use?" Energy Policy, Vol. 3, No. 4, December 1975.

18. Livingston, Floyd R., et al., Satellite Power System (SPS) Prel iminary Resource Assessment, 900-805, Rev. A., Jet Propulsion Laboratory, California Institute of Technology, Pasadena, California, August 7, 1978.

19. Long, Thomas Veach, II, The University of Chicago, "Comparing Methods of Energy Analys is in an Economic Framework," paper presented to the symposium on "Energy Modeling and Net Energy Analys is," Institute for Gas Technology, Colorado Springs, Colorado, August 21-25, 1978.

20. Maddox, Kenneth, Development Sciences Inc., "Energy Analys is and Resource Substitution," paper presented to the symposium on "Energy Modeling and Net Energy Analysis," Institute for Gas Technology, Colorado Springs, Colorado, August $21-25,1978$.

21. Development Sciences Inc., personal communications, August 1978.

22. Melcher, Albert G., Colorado Energy Research Institute, "Net Energy Analysis: An Energy-Balance Study of Fossil Fuel Resources," paper presented to the symposium on "Energy Modeling and Net Energy Anaiysis," Institute for Gas Technology, Colorado Springs, Colorado, August 21-25, 1978.

23. Colorado Energy Research Institute, personal communications, August 1978 .

24. Mitchiner, John L., et al., An Approach for Evaluating Alternative Future Energy Systems: A Dynamic Net Energy Analysis, (prepared for the U.S. Energy Research and Development Administration), SAND77-0439, Sandia Laboratories, Albuquerque, New Mexico and Livermore, California, May 1977. 
25. Pilati, David A., University of IIlinois at Urbana-Champaign, Center for Advanced Computation, Energy Analys is of Electricity Supply and Energy Conservation Options, Pergamon Press, New York, 1977. Reprinted from Energy, Vol. 2, No. 1, pp. 1-7.

26. Rice, Eric Edward, Battelle's Columbus Laboratories, "Energy Impact Assessment of NASA's Past, Present, and Future Space Launch Vehicles, "Journal of Energy, Vol. 21, No. 3, March 1978.

27. Sedlik, Barry, Teknekron, "An Investigation of the Theoretical Basis for Net Energy Analysis," paper presented to the symposium on "Energy Modeling and Net Energy Analysis," Institute for Gas Technology, Colorado Springs, Colorado, August 21-25, 1978.

28. Stanford University, The Institute for Energy Studies and TRW Systems Group, Report of the NSF-Stanford Workshop on Net Energy Analys is August 25-28, 1975, Dr. T.J. Connolly (Stanford) and Dr. J.R. Spraut (TRW Systems), editors, December 1975.

29. Waterman, Wende11 W., Institute for Gas Technology, "Net Energy Concepts Applied to Resource Utilization," paper presented to the symposium on "Energy Modeling and Net Energy Analys is," Institute for Gas Technology, Colorado Springs, Colorado, August 21-25, 1978.

30. Webb, Michael, and David Pearce, "The Economics of Energy Analysis," Enerýy fúlicy, Vol. 3, No. 4, nesember 1975. 
III-1. INTRODUCTION

Estimating the land use impacts of the SPS poses problems very different from the problems presented by critical materials and energy analysis. For these other two classes of resources there are two critical tasks: (1) to estimate the requirements of the SPS; and (2) to relate these requirements to sources of supply that tend to be both homogeneous and readily transportable. The aggregate land requirements of the SPS are, on the other hand, fairly easy to estimate with only a few inputs and assumptions. The resources available to meet these requirements are, however, neither homogeneous nor transportable. Land--or more accurately, the earth's surface, since sea and water sites may be considered--is geographically fixed and, in most respects, uniquely characterized by location.

The massive land (surface) area required for 60 rectenna sites presents a particularly complex problem due to the numerous constraints on rectenna locations. The key issues here are siting issues: What are the absolute constraints, if any, on such sites? What additional constraints are critical? What site characteristics are highly desirable? The answers to these questions are not at all self-evident and it may be many cannot be answered based on the current definition of the SPS reference concept.

One initial approach to land use impacts involves two preliminary steps. The first is to develop a comprehensive list of siting criteria that reflects the current state of knowledge (or assumptions) on the characteristics of rectenna sites. A second step is to apply as many as possible of these criteria to the land and inshnre area of the United States based on secondary research. Any such screening, based on published data is totally inadequate to quaiify evein a single site. Too many of the important siting constraints are purely local in nature and cannot be evaluated without field investigation. Nevertheless, a map-based screening exercise of this type should reveal the extent and distribution of "apparently eligible" areas for rectennas.

The land use-siting study effort summarized in this report has been closely coordinated with another study at the School of Architecture and Space Solar Power Research Program of Rice University. The focus of this parallel effort is on the initial identification of eligible areas within the U.S. for rectenna siting. This "eligibility" study corresponds to the map-based screening extrcise described above as the second of two critical preliminary steps and is summarized in a separate white paper (Reference 11). ${ }^{1}$

The balance of this section of the analysis is organized into seven subsections. The next subsection (III-2) attempts to provide an overview of the land use and siting issues connected with the SPS including: quantitative land requirements; objectives of the initial study; and certain generic issues in need of resolution. Section III-3 reviews the 1 imited body of past and present research on this problem. Recommended siting criteria are discussed in Section III-4, including

1 References identified with numbers only are listed at the end of this section. 
specific reference to those being considered in the Rice University eligibility study. Selected findings of that eligibility study are reviewed in Section III-5, along with implications for the tasks covered in this white paper. The concluding section deals with specific critical issues revealed by the research and a recommended sequence of further study.

\section{III-2. AN OVERVIEW OF SPS LAND USE AND SITING}

Estimated Land Area Requirements

At a latitude of approximately 34 degrees north, an SPS receiving antenna (rectenna) sized to generate five gigawatts of electricity at the busbar will occupy an elliptical land area extending approximately 13 kilometers ( 8.1 miles) northto-south and 9 kilometers ( 5.6 miles) east-to-west (Reference S15). ${ }^{2}$ The width of the rectenna area is essentially fixed, but the length, the north-to-south dimension, will vary with latitude. Because the satellite will be in orbit directly above the equator, the circular microwave beam will project an ellipse on the earth's surface anywhere except at the equator, directly under it. The further away from the equator, i.e., further north within the U.S., the more elongated the ellipse becomes. A figure showing both the projection and the rectenna dimension is shown in Exhibit III-1.

The land area occupied by the rectenna ellipse itself is approximately $92 \mathrm{~km}^{2}$ (36 square miles). A full rectangle of 13 by 9 kilometers will probably be required, at a minimum, to accommodate support facilities. The minimum land area with no buffer zone would therefore be $117 \mathrm{~km}^{2}$ (45 square miles).

Because of the intensity of microwave radiation at the edge of the rectenna, it is critical that there be a secure fenced buffer zone beyond the edge of the rectenna. Radiation densities at the edge of the rectenna are estimated to be 1 milliwatt per square centimeter $\left(\mathrm{mW} / \mathrm{cm}^{2}\right)$. To reduce maximum uncontrolled microwave exposure to approximately 10 percent of that 1 evel, or $0.1 \mathrm{~mW} / \mathrm{cm}^{2}$, will require an additional two kilometers ( 1.2 miles) on all sides of the rectenna. The nominal dimension of a rectenna site including the buffer zone would be 13 by $17 \mathrm{kilometers} \mathrm{(} 8.1$ by 10.6 miles). The land area occupied by the ellipse would be $174 \mathrm{~km}^{2}$ ( 67 square miles) and by the rectangle $221 \mathrm{~km}$ ( 85.3 square miles). Assuming an average of approximately $200 \mathrm{~km}^{2}$ ( 80 square miles), the total land area for 60 rectenna sites would be approximately $12,000 \mathrm{~km}^{2}$ (over 4,600 square miles). This total would represent somewhat less than .2 percent of the total land area of the continental United States.

The dimensions of the nominal rectenna site do not represent definitive specifications, even within the explicitly tentative context of the reference concept (Reference S15). They are to be considered only as highly tentative working assumptions. Some of the reasons for this include:

2 References prefaced by an "S" are general references to the SPS which are listed at the end of the entire report. 


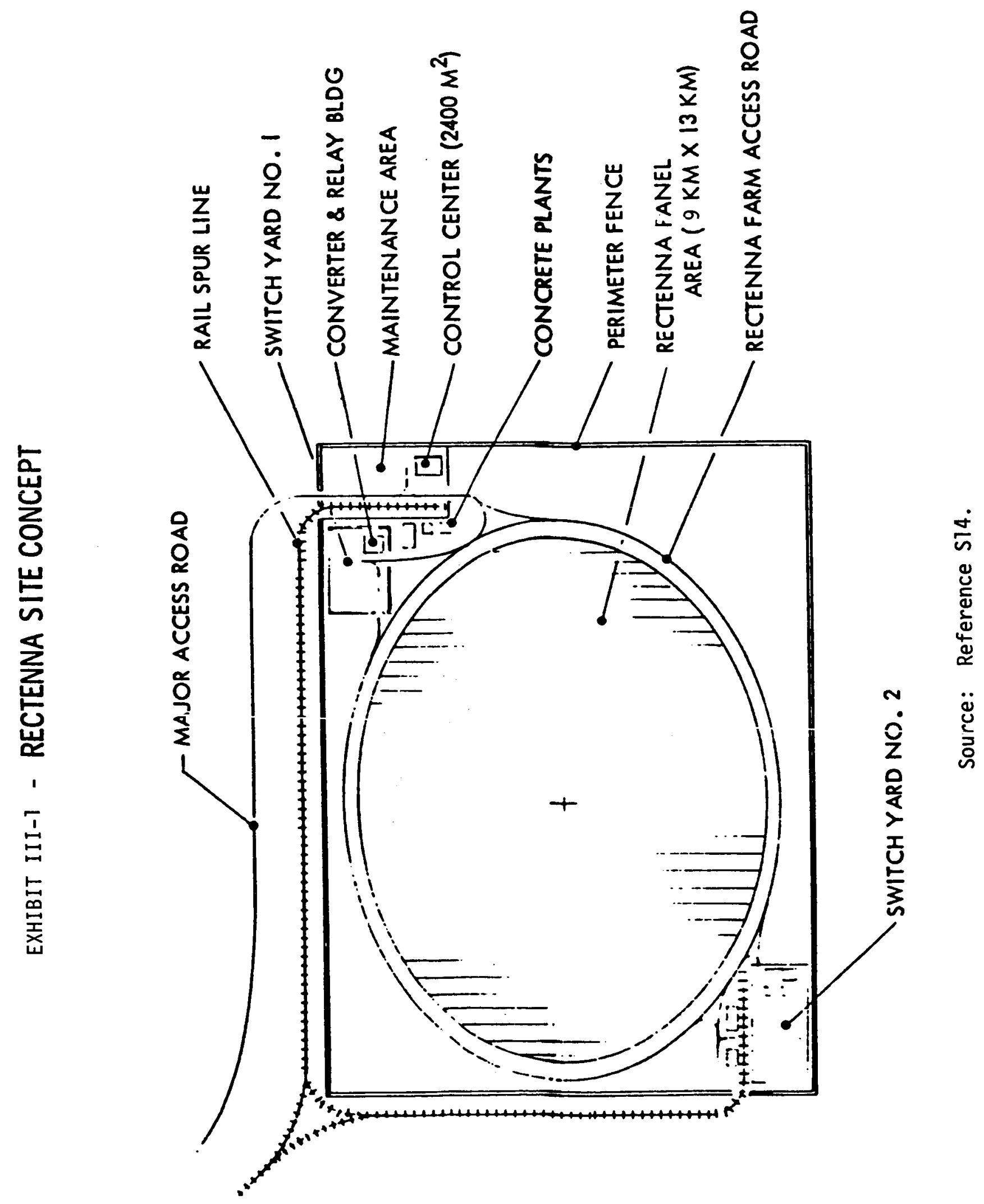


1. The long axis of the elliptical rectenna area itself has been estimated only for 34-35 north latitudes (approximately Los Angeles). This long (north-south) axis will vary measurably, though presumably not substantially, at different latitudes within the continental U.S.

2. Published briefing material on the SPS rectenna provides few specifications for the size of the buffer zone, presumably because the extent of buffering required cannot be determined until current research on microwave effects has progressed further. The two-kilometer estimate used in this and the Rice study was provided by the Marshall Space Flight Center verbally in response to the author's request and is admittedly based somewhat arbitrarily on a microwave density of 0.1 $\mathrm{mW} / \mathrm{cm}^{2}$ at the buffer's edge.

3. A maximum unrestricted exposure level of $0.01 \mathrm{~mW} / \mathrm{cm}^{2}$ is nominally in use in the Soviet Union and has been proposed, at least in the press, for the United States. (U.S. standard is currently $10 \mathrm{~mW} / \mathrm{cm}^{2}$ ).

According to the reference concept briefing (Reference S15), the lower density of $0.01 \mathrm{~mW} / \mathrm{cm}^{2}$ is at $20 \mathrm{~km}$ from the center of the rectenna.

This would imply a buffer zone extending more than $15 \mathrm{~km}$ from the edge of the rectenna and a total rectenna-buffer area of almost $1,700 \mathrm{~km}^{2}$ (650 square miles).

4. Pending the outcome of ongoing research on microwave effects on both humans and animals, it is not known whether any land in the buffer zone or, for that matter, under the rectenna, can be put to productive use, e.g., grazing or other agriculture. Such concurrent productive use of rectenna sites could tend to reduce the amount of land "effectively withdrawn" from other uses even if the nominal dimensions remained the same.

Operation of the SPS will require extensive launch facilities for space vehicles. The land area requirements for this purpose have been estimated at $20-850 \mathrm{~km}^{2}$ (8-328 square miles) (Reference S14). Land area requirements for launch facilities are not considered in this paper. The land area required is quite small in comparison to the 60 rectenna sites and the working assumption at NASA is that this requirement can be met by expansion of the Kennedy Space Flight facilities in Florida.

\section{The Problem of Inadequate Definition}

Stated in the simplest possible terms, the objective of any initial land use or siting study is to answer the question, "Where can we put rectenna sites?" or its corollary, "Are there 60 sites in the continental U.S. where rectennas can be located?" The core of the problem is that the reference concept design is, in many ways, only a "rough sketch." Most of the information on rectenna characteristics and impacts needed to determine what constitutes a qualified location is not available pending the outcome of ongoing or proposed evaluation and design refinement efforts. The initial land use and siting studies are themselves part of a "feedback" process to assist in design refinement. To oversimplify, the problem is that "We can't say where it can be located until we 
know what it is and we can't find out what it is unti] we can say more about where it can be located."

Obviously, the way to circumvent this problem is to adopt some working assumptions which, though admittedly arbitrary, will permit some initial investigation. The risk in this approach is that these working assumptions may be so "arbitrarily" constraining--or, conversely, so inappropriately liberal--that the results are not meaningful.

\section{III-3. PRIOR AND CURRENT RESEARCH ON RECTENNA SITING}

A careful reading of most of the NASA briefing materials on the SPS and a more superficial review of the voluminous backup data reveals little systematic treatment of siting criteria and only one published study dealing specifically with siting (Reference 6).2 The various briefing documents are nonetheless critical to establishing a working list of siting criteria.

The one NASA study that does deal specifically with siting is a technical memorandum entitled "Candidate Locations for SPS Rectifying Antennas," by Anne W. Eberhardt of the Marshall Space Flight Center (Reference 6).

Another much more ambitious study of siting is now under way. This study is being conducted by Arthur D. Little Inc. for NASA/Marshall under subcontract to ECON, Inc. Though no draft results are available, progress reports and briefing data indicate that this study will involve an extensive list of siting criteria.

\section{Indicated Siting Constraints: NÁS̄Ả B̈riefings}

Preliminary descriptions of rectenna sites are provided in the January 1978 "baseline" briefings by both space centers (References S2 and S14). The basic site specifications are quite similar.

With respect to the geographic limitations on rectenna siting, the initial presentation copy of the January Marshall briefing indicated a maximum latitude of 40 degrees north, which would exclude the northern third of the continental U.S. A later version of the same document had the number changed to 60 degrees north, which would include all 48 contiguous states. The 40-degree threshold has been retained for alternative eligibility analyses. No latitude limit is indicated in either the Johnson briefing or the joint July 13 briefing (Reference S15).

The January Johnson briefing does, however, imply that rectennas should be geographically distributed in relation to projected power loads, specifically that SPS power should not account for more than 20 percent of total electricity consumption in any region. The briefing includes a map of the regional electrical reliability councils in the U.S. with two illustrative distributions of 60 rectenna sites by region.

The Johnson briefing also refers to a buffer zone of "0.8 miles" $(1.3 \mathrm{~km})$ which is somewhat smaller than the two-kilometer buffer assumed in this study. With the 
smaller buffer zone, the total size of the recterna-buffer site is $200 \mathrm{~km}^{2}$ as compared to $221 \mathrm{~km}^{2}$ with the larger buffer zone.

"Candidate Locations" Study: NASA/Marshall

In November 1977, a technical memorandum identifying "candidate locations for SPS rectifying antennas" was published by the Marshall Space Flight Center

(Reference 6 ). The objective of this study was to identify candidate locations for 120 five-gigawatt rectennas, corresponding to 600 gigawatts of eventual SPS capacity. "For this analysis, the rectenna site, which contains the actual rectenna and a safety zone, (was) assumed to be a 15 mile diameter circle. In all cases, this is sufficient to contain the entire elliptical rectenna and some safety zone." (Reference 6. )

Preliminary analysis suggested to the author that rectenna distribution on land could not correspond to electrical energy usage distribution without major disruptive impacts. Electrical consumption is concentrated east of the Mississippi while most land is west of the Mississippi. As a compromise strategy, the study attempted to allocate two rectenna sites to each state (excepting Alaska) plus 22 added sites to achieve a better distribution with respect to demand. The study applied five classes of criteria. The first three were designed to minimize SPS impact on: (1) Tand intensively used; (2) population; and (3) transportation. Minimum elevation variations was a fourth criterion and maximum federal 1 and use was the fifth item.

For the most part, the various criteria were broken down into modestly detailed classifications, e.g., 15 types of land use, 3 dimensions of elevation classification, and 3 types of transportation.

The numeric data base for this analysis consisted primarily of U.S. Census publications. Maps were taken from Rand McNally or from the national atlas of the United States, except for special FPC maps of principal electrical facilities. The emphasis in this study was on the location of specific sites, apparently through map inspection and county outline maps are provided for all 48 states.

The results generally conform to the expected disproportionality between population and land area. Only a small number of sites, relative to population, could be located in either the Northeast or Mid-Atlantic areas. Those sites that could be identified were in fairly mountainous areas. For the most part, the Mid-West was somewhat in balance although certain parts were limited by virtue of high road density. The target of two sites per state was readily achieved in the Western states and was approached in the Southeast.

Given the limitation of two sites per state, only 69 sites could be located on land in this study. The remaining 51 sites were located offshore. Fourteen sites were located on the Pacific coast; another 15 on the Gulf coast; and the remaining 22 were distributed fairly continuously along the Atlantic coast from Maine to South Georgia.

This study clearly demonstrates some of the problems associated with a siting exercise designed to find specific sites. It is difficult to draw conclusions based on a two-site per state limitation. Furthermore, the criteria are 
somewhat limited in number and the data sources would appear to be somewhat general for refined examination. On the other hand, the study is explicitly preliminary and the author acknowledged the need for more detailed research and a more refined data base.

Ongoing Siting Study by Arthur D. Little Inc.

This current siting study is also being performed for the Marshall Space Flight Center under subcontract to ECON. It is similar in several ways to the "candidate locations study" described above. Once again, the emphas is is on identifying specific sites.

The list of criteria developed by Arthur D. Little as part of this study is considerably more ambitious than the list used in the "candidate locations" study. This list of criteria is reproduced in Exhibit III-2.

No published draft results are available from this study. According to Philip Chapman, project manager for Arthur D. Little, the initial cbjective of the study was to identify 200 potential sites using a subset of the criteria shown in Exhibit III-3. The "screening" subset of criteria deals primarily with considerations of land use, topography, and population density.

Once the initial list of 200 sites is assembled, each site will be examined in terms of all or most of the criteria 1isted. The object is to retain 60

"fully qualified" sites.

An acknowledged and possibly primary function of this study is to provide "feedback" to NASÁ/Marshail to aid in refining the design of the S̄PS. Une suich possible input to redesign would be the discovery that it was just as easy to find sites that would accommodate 10-gigawatt rectennas as to find sites adequate for 5-gigawatt rectennas. Presumably, the impetus to 5-gigawatt rectenna units is, in part, a function of a perceived problem in siting larger rectennas.

The project team at Arthur D. Little considered and rejected an approach in which all or most of the criteria would be examined for the country as a whole, possibly in a mapping exercise. They felt that too many of their criteria were not susceptible to secondary analys is. Local field investigation was required because the local or site-specific variation was more likely to be controlling.

Issues Revealed by Current Research

There are clearly two alternative approaches to an initial land use or siting study. In the first approach, the analysis proceeds from the specific to the general. A limited set of "screening" criteria are applied in what appears to be a map inspection exercise. The output from this process is a series of specific partially qualified sites which are then presumably subjected to more rigorous evaluation involving a more expanded set of criteria.

The output from this first approach to an initial siting study is a series of specific sites that have survived the second-stage screening and a large body of 
I. Mandatory (Site Must Not Encompass):

Designated Wilderness Areas

Designated Major National Monuments

Major State or Local Parks or

Recreation Areas

Major Scenic Areas ${ }^{2}$

II. Desirable

A. General

Low Population Density

Relatively Cheap Land ${ }^{2}$

Close to Major Load or Utility Tie-Point

Positive Local Economic/Demographic Effects ${ }^{2}$

Away from Federal Airways

B. Terrain and Engineering

Road/Railroad Access to Site ${ }^{3}$

Powerline Right of Way to Site ${ }^{2}$

Vehicular Access within Site ${ }^{2}$

Adequate Surface for Construction:

Minimum Earthmoving ${ }^{3}$

Minimum Sand ${ }^{2}$

Not Wetlands

Not Badlands ${ }^{2}$

C. Weather and Atmosphere

Not in Tornado Area ${ }^{3}$

Minimum Thunderstorms (Lightning)

Minimum Dusts torms

Minimum Freezing Rain ${ }^{3}$

Not in Acid Rain Area

Minimum Effect on Groundwater of Chemicals Leached from Rectenna ${ }^{3}$

D. Legal and Regulatory

Conformance to Federal Regulatory Constraints (EPA, OSHA, Etc.) 4

Eminent Domain Avoided if Possible ${ }^{2}$ No "National Grid"2
National Wildlife Refuges

Areas Essential to Endangered Species

Major Airports

$\mathrm{Hi-Density} \mathrm{Airways}$

Significant Towns

\begin{abstract}
In Aircraft Restricted Areas $^{3}$
Multiple Use Possibilities ${ }^{2}$

Room for 10 GW Rectenna ${ }^{2}$

Room for Several Rectennas

Isolated to Avoid Local RFI

Improved Local Aesthetics ${ }^{2}$

Federal Lands
\end{abstract}

Low Terrain Relief

Ridges East-West

Good Drainage ${ }^{3}$

Elevated Ground Plane For Safety ${ }^{2}$

Not Earthquake Area

Not Flood-Prone

Not Subject to Subsidence (Sinkholes, Mines, Etc.)

Not in Hurricane Track ${ }^{3}$

Reasonable Rainfall

Low Snowfall ${ }^{3}$

Weather Effects of Rectenna Heat Island ${ }^{2}$ Local Effects of Ozone from Corona

Discharge at Rectenna ${ }^{2}$

Variances Possible for Local Land Use Regulations ${ }^{4}$

Networking Rectennas ${ }^{2}$

1 Unless otherwise noted, criteria are incorporated in the same or similar form in the proposed siting criteria listed in Exhibit III-4.

2 Not considered in proposed criteria.

3 Considered only indirectly in proposed criteria.

4 Not considered in proposed criteria, but discussed under "Interaction with Regulation."

Source: Reference 5 
data on those factors which disqualified the remaining initially "eligible" sites. Summary tabulation of the characteristics of the surviving sites and the bases for disqualification should reveal a great deal about the siting problems that will be encountered by the SPS rectenna. Furthermore, this process should identify a variety of purely local problems that, in a more general or "global" process, would not be uncovered.

This first approach was employed by Marshall Space Flight Center in their "candidate locations" study and is currently being employed by Arthur D. Little Inc.

In contrast to this, the second approach used in the coordinated effort represented by this white paper and the Rice University study, proceeds from the general to the specific. Data is collected for some meaningful subset of siting criteria in a form suitable to mapping, and computer encoding for the continental U.S. as a whole. The data elements corresponding to constraints or criteria are independently mapped and encoded. This permits the successive application of constraints and the subsequent inspection and quantification of the remaining "eligible" area within the U.S.

This more general process inevitably excludes many siting criteria for which data is available only on a local level. It also tends to work better for "exclusion" criteria or constraints than for positive or beneficial characteristics of the land.

The major advantage of the second approach is that it permits successive simulation of different combinations of criteria to determine the generalized impact of each constraint. In the first and more specific approach, it wuiud be difficult if not impossible to quantify the impact of any one criteria on the amount of "eligible" area.

Both approaches lead by different paths to some preliminary conclusions as to which of the constraining criteria are most critical. What differentiates them is that the first and more specific approach probably provides significantly better insight into local or location-dependent variables. The second eligibility mapping approach provides explicitly quantitative output with respect to the impact of various criteria. Whether or not that output is uitimately meaningful is a function of whether the additional more location-specific criteria captured in the first approach are the more important ones. The relative merits of the two approaches cannot be determined in advance. There is, in fact, a distinct benefit to the simultaneous pursuit of both, at least to the point of some degree of general findings about which criteria are the most constraining. At the present stage of the analysis the two may be considered complementary although it may become apparent at some later date that one should be selected over the other.

Another critical issue raised by this literature review concerns sea sites. The findings of the "candidate locations" study suggest that even with a limited number of contraints it may be difficult to find an adequate number of land sites. At best this is a tentative conclusion since the study did locate 69 
sites. Also, it is not clear to what extent the site limitations were determined by the arbitrarily imposed limit of two sites per state.

High population densities, limited land availability, and high rates of power consumption in the New England and Middle Atlantic regions of the U.S. suggest that if these regions are to receive their "proportional" share of rectennas, sea sites will have to be considered.

This leads in turn to a question of "proportional" allocation. Both the Johnson briefing and the Marshall "candidate locations" study take as a starting point the assumption that rectennas should be distributed in proportion to demand. The Marsilall "candidate locations" study does suggest that population is a reasonable proxy for electricity consumption. Dr. Chapman of Arthur D. Little Inc. concurs in this view and is using population as a proxy for power consumption.

Preliminary projections suggest that 60 five-gigawatt antennas, when fully operational in 2030, will only constitute 20-25 percent of the national power supply. Except for reliability considerations, there would therefore seem to be no reason to distribute rectenna facilities evenly throughout the country or in proportion to power consumption.

The growing number of apparent constraints on rectenna sites suggests that the first order of business in land use and siting study should be to determine where rectennas can be built. At that point, the considerations of where they "should" be built should be added to the analysis. It seems premature to impose a demand-proportionality constraint on siting before the key physical limitations on site eligibility are identified.

\section{III-4. PROPOSED SITING CRITERIA}

The siting criteria proposed in this paper were developed from several sources. NASA briefings and other published reports on the SPS were used to establish physical constraints and to identify potentially adverse impacts (References S2, S3, S13, S14, S15, S16, and S17).

Various general lists of environmental impact criteria were reviewed to identify other considerations which were not treated in the SPS literature but which might bear on rectenna siting.

The criteria used in the other SPS siting studies (References 5 and 6) were incorporated into the preliminary list.

The initial and voluminous criteria list was then consolidated based on three major considerations:

1. Can the criterion be meaningfully applied to an area, i.e., map grid sector, or does it require the identification of a specific site? Examples of criteria discarded include presence of archaeological sites, current zoning, and potential for zoning variance. 
2. Is the criterion conceptually independent of other criteria or does it really refer to the same thing under a different name? Examples include: massive earthmoving and difficult topography; cheap land and minimum productive use of 7 and.

3. Is the criterion susceptible to more or less objective measurement? An example discarded criteria would be local aesthetics.

For the most part, data collection problems were not considered in discarding criteria. Considerations of data availability were, however, part of the selection process used by Rice University in their Initial Evaluation of Eligible Site study. The scope of that effort includes mapping and encoding all of the variables they consider. Consequently, several criteria proposed in this paper are omitted from their analys is due to the lack of a readily available and/or encodable data base.

Several criteria are included in the proposed list for which standards must still be established as a result of other ongoing SPS research. These include radio frequency interference effects, effects on migrating wildlife, maximum wind limits, groundwater leaching effects, and others.

\section{Categorization as Exclusion or Inclusion Criteria}

Exhibit III-3 lists the proposed criteria under a series of general headings. The exhibit also identifies for each criterion its proposed exclusion or inclusion application. This categorization reflects the logical treatment of the variable and the manner in which it will be treated in the Rice Initial Evaluation of Eligible Site study. The Rice study team has piotied ail of its vâriaties on a map of the continental U.S. on which has been superimposed a grid consisting of squares 26 kilometers (16.2 miles) on a side. Using a computer mapping routine the status of each variable in each grid square will be encoded so that the computer may generate maps showing the land area characterized by that condition or by any combination of encoded conditions.

The various exclusion and inclusion applications designated in Exhibit III-3 and the corresponding computer treatments are:

1. Exclusion-Universal: These are conditions which are assumed to completely preclude location of a rectenna site within the grid square.

2. Exclusion-Potential: These are conditions which are to be avoided if at all possible.

3. Inclusion-Potential: This category applies to desirable conditions rather than siting constraints. If a plot of these criteria were superimposed on the "non-excluded" area, the resulting map would show not only which areas are eligible but which are actually desirable. 


\section{Criterion}

\section{Land Characteristics}

\section{Federal Ownership}

National Recreation Areas

Indian Reservations

Military Reservations

National Forests

Bureau of Land Management

other

\section{Topography \\ Topography Unacceptable \\ South-facing slopes}

Wetlands

Currently Productive Use

\section{Local Government Ownership \\ State Recreation Facilities \\ Other State Land \\ Local Government Land \\ In Flood Area}

Poor Soils

Seismic Hazard

Water on Site

High Groundwater Table

North of $40^{\circ}$ Latitude

\section{Population}

Urbanized Metropolitan

Urbanized Non-metropolitan

Adjusted Population Density
Exclusion

Variable
Inclusion Variable
Treatment in Rice University Eligibility Study ${ }^{1}$
Universal

Potential

Potential

Potential

Universal

Potential

Universal

Potential

Universal

Universal

Potential

Potential

Potential

Potential

Adjacent

Potential

Potential
Mapped, encoded (5)

Mapped, encoded (5)

Potential Mapped, encoded (5)

Mapped, encoded (6)

Potential Mapped, encoded (5)

Potential Mapped, encoded (5)

Mapped, encoded (10), 3 levels

Potential Mapped, encoded (11), 3 levels

Mapped, encoded as Wetlands (9) and Marsh Vegetation (10)

Mapped, encoded as "Land in Cultivation" (15), and "Land Suitable for Cultivation" (16) each at 2 levels

Potential

Not treated

Not treated

Not treated

Not treated; Wetlands and navigable water ways are partial proxies

Not treated

Mapped, encoded (18)

Not treated

Not treated

Mapped, encoded (19), Design Consideration on all summary maps

Mapped, encoded (7)

Adjacent

Universal

Universal
Mapped, encoded (7):

Density $>50 / \mathrm{sq}$. mile

Mapped, encoded (7):

Density $>50 / \mathrm{sq}$. mile

IReference 11 
EXHIBIT III-3 - PROPOSED INITIAL SITING CRITERIA

(Continued)

Criterion

Transportation

Interstate Highway

Primary Local Roads to Site

Airport Nearby

Air Approach Corridors

Major Air Corridors

Railroad

Navigable Waterways

Climate

Winds Over 90 m.p.h.

Universal

Winds Over 50 Knots

Potential

Thunderstorm Area

Potential

Hail Area

Universal

High Total Precipitation

Potential

Acid Rain Area

Potential

Dust Storm Area

Environmental Concerns

Very Poor Air Quality

Endangered Species Habitat

Other Wildlife Habitat

Wildfowl Flyways

Utility Integration

Proximity to Grid

RFI Effects

Near Major/Numerous RF Sources Potential

Potential

Potential

Potential

Universal

Potential

Potential
Inclusion

Variable

Adjacent

Adjacent

Adjacent

Potential

Overlay map only; not encoded

Not treated; Population is partial proxy

\section{${ }^{1}$ Reference 11}

Source: Allan D. Kotin, Economic Consultants and Space Solar Power Research Program, Rice University. 
4. Inclusion-Adjacent: There are several conditions which would disqualify a site if they occurred on or immediately adjoining the proposed rectenna site, but would actually be desirable at a relatively nearby location, i.e., in the next grid square. This is particularly true of major transportation access which cannot pass through a rectenna site but which would be quite desirable to have nearby, particularly during construction.

In two cases, the same criterion is categorized as both an exclusion and inclusion variable. Military reservations may be "off limits" for rectennas, particularly if there is any weapons hazard or extensive radio transmission. On the other hand, some military reservations are so large and so remote that a distant corner of one might be an almost ideal rectenna site. Land and air access is probably already restricted, as it would have to be for a rectenna site. The land is federally owned, thereby minimizing zoning and acquisition problems.

The criterion "Topography Unacceptable-south facing slopes" is also classified as both a potential inclusion and potential exclusion variable. Theoretically, rectennas built on south facing slopes would be properly oriented to receive a beam originating at the equator and the land would, therefore, not have to be leveled. Practically speaking, however, it may be that level sites are preferable in all conditions to topographically difficult ones. For this reason, the more general criterion "Topography Unacceptable" is defined initially as excluding south facing slopes. In subsequent analvsis in the Rice studv, the south facing slope variable is added back in as another exclusion variable.

There are a total of 42 criteria 1 isted in Exhibit III-3. Of these exactly half, or 21 , are classified under the general heading "Land Characteristics." Two subsets of these criteria are of particular interest: (1) the universal exclusion criteria; and (2) potential exclusion criteria applied as "design considerations."

\section{Universal Exclusion Criteria}

Of the 42 total criteria, 12 have been tentatively classified as universal exclusion criteria. Due primarily to data 1 imitations, only 7 of these 12 are mapped and encoded in the Rice study as universal exclusion variables (see summary map 1 in Reference 11). These 7 are:

1. National recreation areas.

2. Topography unacceptable (excluding south-facing slopes).

3. Wetlands (as defined by marsh vegetation).

4. Urbanized metropolitan areas.

5. Urbanized non-metropolitan areas (population density over 50 persons per square mile). 
6. Adjusted population density (areas with population density over 50
persons per square mile as inferred from a population density map).

7. Navigable waterways.

The five "universal exclusion" variables which were not mapped or encoded due to data limitations include:

1. State recreation facilities.

2. Local government 1and.

3. Nearby airports.

4. Air approach corridors.

5. Winds over $90 \mathrm{~m} . \mathrm{p} . \mathrm{h}$.

In the case of the two airport related exclusion criteria, a partial proxy is provided by urbanization since most large airports exist near urbanized areas. Similarly, a partial proxy for "winds over $90 \mathrm{~m} . \mathrm{p.h} . "$ is provided by the variable "winds over 50 knots." The limitation of $90 \mathrm{~m} . \mathrm{p} . \mathrm{h}$. was set forth in the Johnson briefing (Reference S15) based on a preliminary engineering study. Data on winds of that speed are not readily available so the lower wind speed data was used as a proxy. No nationally published data is available on state recreation areas or local government land. Consequently, plotting and encoding of this information will have to await a iarger scale stuudy permitting additiona? primary research.

Variables Treated as "Design Considerations"

Many of the variables relating to climate were treated not as exclusion variables in the Rice analys is but rather as "design considerations." The significance of this is that when other exclusion variables are applied, the remaining eligible area is further classified as to whether or not it is characterized by the various climate conditions. A similar treatment is provided for federally owned land other than national recreation areas, national forests and Indian reservations. The remaining federal land, e.g. military reservations and "other federal lands", may be a potential inclusion variable since it may be desirable to site rectennas on federal land.

In summary, there are a total of eight variables treated as "design considerations":

1. Federal lands - military.

2. Federal lands - other.

3. Over 40 degree latitude. 

4. Wind storms (probability of winds over 50 knots).
5. Hail.
6. Thunderstorms.
7. Sheet rainfall.
8. Acid rainfall.

Gradient Treatment of Selected Criteria

Most of the criteria listed are treated, for purposes of mapping, as either present or not present. There are, however, several variables which are encoded at different levels, thereby providing a gradient of unacceptability. The criteria for which some gradient was established are listed below:

1. Topography unacceptable (3 levels).

2. Land in cultivation (2 levels).

3. Land suitable for cultivation (2 levels).

4. Seismic hazards (2 levels).

5. Windstorms (2 levels).

6. Acid rainfall (2 levels).

For the most part, these gradients are not reflected in the summary of the Rice study presented in this report. The information is there for those readers who wish to explore it in the maps and tables within the Rice study itself (Reference 11).

\section{Criteria Not Treated in Rice "Eligibility" Study}

Almost 40 percent of the variables listed are designated as "not treated" under the column "Rice Study, Current Status." In a few cases, this is a temporary condition to be resolved within the time frame of the current Rice effort. In most cases, however, formal mapping and encoding of these criteria will have to be deferred to a later task due to data limitations. Typically, there is one of two problems. Either national data is not available and state or regional sources must be assembled; or national data is available but not in a mapped form suitable to plotting and encoding without very extensive preprocessing.

RF I (radio frequency interference) effects may be one variable for which the relevant data set has to be defined. The recent work by the Institute for Telecommunications Sciences (ITS) suggests that RFI effects may be felt over a very wide area, such as the area covered by 1.5 degrees latitude and 1.0 degree longitude (Reference 7). Furthermore, the potentially adverse impacts of micro- 
wave transmission are a joint function of the number and sensitivity of radio transmission sources in the area. What is needed here is a list of categories of sensitive users together with some method for ascertaining their geographical distribution.

\section{III-5. PRELIMINARY FINDINGS OF RICE "ELIGIBILITY" STUDY}

Analysis of Individual Variables

The Rice "Eligibility" Study contains 19 maps describing the distribution of approximately 25 variables. In that study, the total area excluded within the contiguous 48 states is presented. A summary of these findings for all the variables is shown in Exhibit III-4. In this exhibit, the manner in which the variable was treated is noted under the column "variable treatment." The total amount of area excluded by the application of each of these variables individually is shown in three different ways: (1) number of grid cells of approximately 26 kilometers squared; (2) approximate size in both square kilometers and square miles; (3) and as a percentage of the total gridded area which corresponds closely to the total area of the 48 contiguous states.

Reviewing this map indicates that of the explicit exclusion variables, the most significant is probably topography unacceptable which excludes 3.8 percent of the total area.

Population variables are also significant sources of exclusion although in this case; the numbers alone are not particularly meaningful since there is a high degree of overlap among the three population variabies.

The other universal exclusion variables have generally minor effect in cerms of total land area.

Several of the potential exclusion variables are quite significant, however. Perhaps the most significant of these is "flyways of migratory waterfowl" which accounts for 46.5 percent of the total land area.

Land suitable for cultivation represents another powerful potential exclusion variable which accounts for almost 45 percent of the land area in the 48 states. The only other potential exclusion variables that significantiy constrain the total area are: interstate highways (18.5 percent excluded); land in cultivation (20.2 percent excluded); and seismic hazards, including both major and moderate damage potential ( 88.8 percent excluded).

Several of the "design consideration" variables also contribute substantially to restricting the eligible area. The two most important sources of constraint in this regard are windstorms, which eliminate approximately 55.4 percent of the area and thunderstorms, which eliminate approximately 52.3 percent. Close behind these two, is the constraint of building rectennas only below the 40 degree latitude. This variable eliminates 45.6 percent of the surface area considered in the study. 


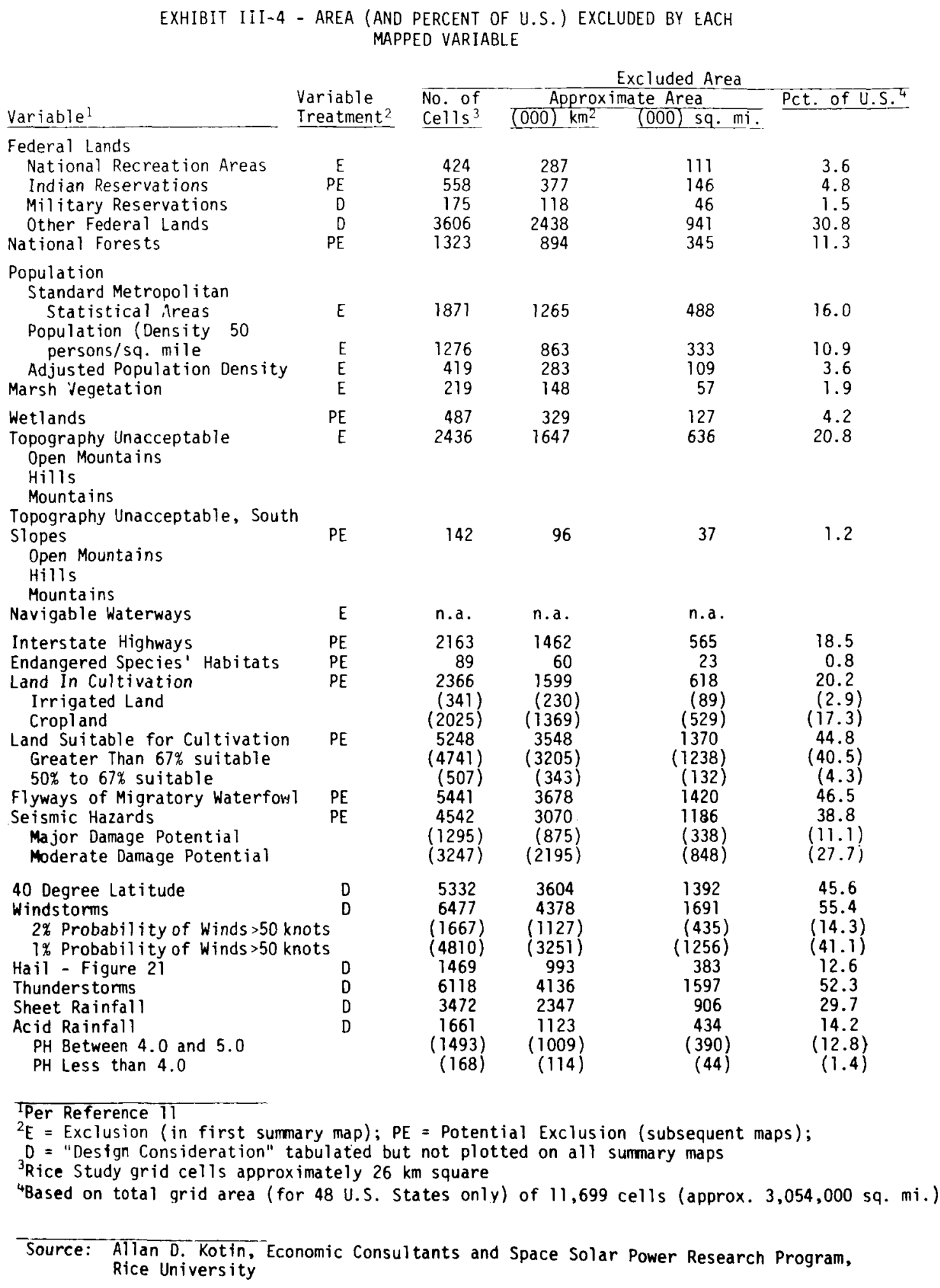


Other "design consideration" variables with some significant effect are:

sheet rainfall (29.7 percent) and hail (12.6 percent).

Combined Effects of Exclusion Criteria

The potential combinations of the various exclusion criteria represent a very large number. In the Rice study, eleven combinations of exclusion criteria were mapped (summary maps 1 through 11 in Reference 11). These represented examples of the type of "intersection" analysis that can reveal the incremental effect of adding additional exclusion variables.

The initial combined mapping exercise was restricted to the five "universal exclusion" criteria for which the Rice study was able to encode data: (1) National recreational areas; (2) population density; (3) topography unacceptable; (4) navigable waterways; and (5) marsh vegetation. Subsequent maps represent the application of successive additional exclusion criteria to the eligible area remaining in summary map 1 with the initial five exclusion criteria.

The results of these eleven analyses are summarized in Exhibit III-5. The upper part of this exhibit shows the variable values excluded in each of the eleven maps (as XXX in the appropriate columns). For each of the excluded variables, an initial percentage is given which indicates the amount of area within the 48 United States that would be excluded just by the application of this variable alone. For summary maps 2 through 11, two numbers are given at the foot of each column indicating the incremental effect of adding that exclusion variable to the preceding variahles in limiting the eligible area. The first number is the number of grid squares and the second number is the percentaye of tôtal araz represented by those grid squares. For example, wetlands, as distinguished from marsh vegetation, in total exclude 4.2 percent of the total area. Considered as an incremental effect, they exclude only 1.6 percent more than would be excluded by the first five variables.

An examination of this portion of the table indicates that the variables added in maps 2 through 6 have relatively minor impact on the total amount of exclusion. Neither wetlands, south slopes - unacceptable, national forests, Indian reservations, nor endangered species significantly reduce the eligible area or increase the excluded area. In the case of interstate highways (summary map 7), the reduction is potentially significant. The addition of this variable to the preceding variable increases the excluded area by 5.8 percent of the total. To some extent this is misleading, as noted in the Rice study, since the presence of an interstate highway in a grid cell does not necessarily disqualify the grid cel1. At this point, the analysis has not been refined to permit any better judgment than simply "preset" or "not present".

One interesting aspect of this analysis is to show that the incremental impacts can be much smaller than the total impacts. For example, national forests account for 11.3 percent of the total land area. Yet, when national forests are added to the map with 7 preceding exclusion variables, the incremental effect is only 2.2 percent. 


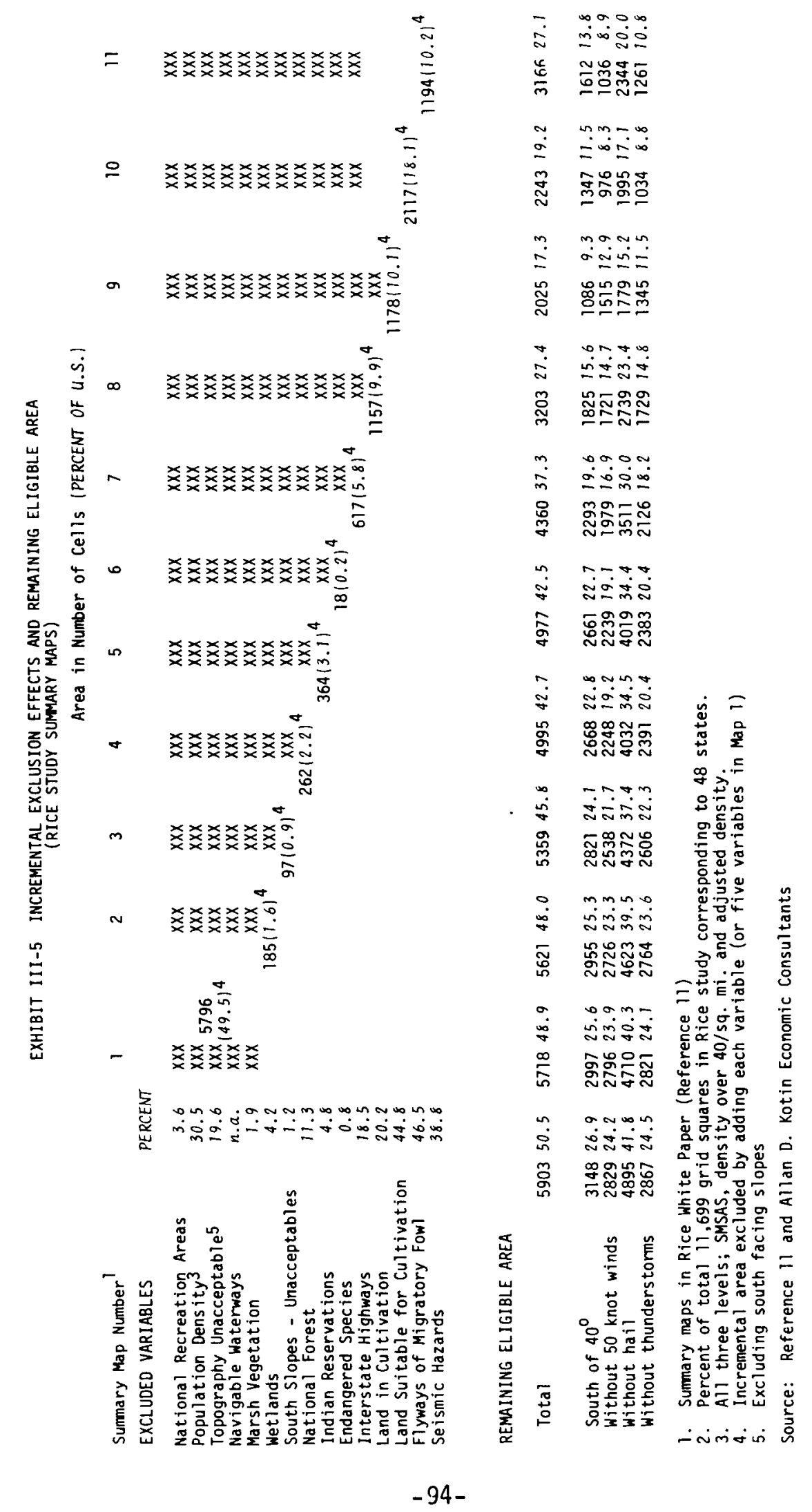


The treatment of land in cultivation or suitable for cultivation as a potential exclusion variable does appear to have a very significant effect on the amount of area excluded. Land in cultivation which accounts in total for approximately 20.2 percent of the land area, represents an incremental effect of 9.9 percent. Land suitable for cultivation ( 44.8 percent of the total land area) has an incremental effect of 10.1 percent.

Seismic hazards represent a similar incremental effect (10.2 percent). Obviously most of the seismic area has already been excluded by the variables used in map 7, since seismic hazards, in total, represent 38.8 percent of the total land area.

The exclusion variable with the largest incremental effect is "flyways of migratory fowl." As indicated by the left hand column, this criteria is the most significant of all the exclusion variables considered on both a total and incremental basis. The total land area excluded under this variable is 46.5 percent. The incremental effect is 18.1 percent. What this suggests is that, unlike some of the other variables, in this case the addition of this variable excludes substantial portions of the United States that are not excluded by combinations of other exclusion variables. Clearly, the imposition of this constraint on rectenna sitings will have a particularly bad effect on the amount of remaining eligible area for sites. This is of particular significance since the impact of microwave transmission on migratory wildfowl has not been established.

The lower part of Exhibit III-5 essentially presents the converse of the excluded areas shown in the upper part. In this case the remaining eligible area is tabuiaied for each summary map. Thị tabulation is presented both for the total area, and for the imposition of four of the so-called "design consideration: variables. The initial five exclusion variables (summary map 1) leave a remaining area of 50.5 percent of the total land area. If, in addition, areas north of 40 degree latitude are also excluded, the remaining area itself of 40 degrees is only 26.9 percent of the total land area. Alternatively, the removal of all areas with 50-knot winds reduces the total to 24.2 percent. Hail seems to have relatively little effect reducing the remaining eligible area only from 50.5 percent to 41.8 percent. The effect of thunderstorms in this instance is about the same as the effect of 50-knot winds, leaving 24.5 percent remaining eligible area.

The smallest remaining eligible area of all the summary maps is the one associated with map 9 in which both land in cultivation and land suitable for cultivation are excluded. Under these stringent conditions, only 17.3 percent of the total land area is in the remaining eligible category. If this is further reduced to only that land south of 40 degree latitude, the total is actually under 10 percent ( 9.3 percent). Almost equally dramatic is the independent addition migratory wildfowl flyways in summary map 10. In this case the total is reduced to 19.2 percent remaining eligible area. The imposition of further constraints for either 50-knot winds or thunderstorms reduces the remaining area to under 9 percent of the total.

One interesting characteristic of the lower part of Exhibit III-5 is that it shows the differential effects of the design considerations, e.g. south of 40 degrees, 
winds, hail and thunderstorms, on the remaining area under different summary map assumptions. For example, in summary map 11 the total remaining eligible area is 27.1 percent. This is cut by almost two-thirds to 10.8 percent if the design variable "without thunderstorms" is also considered. By way of contrast, the imposition of the thunderstorms criteria to summary map 1 or 2 reduces the available area only by approximately half (from 48.9-50.5 to 24.1-24.5 percent).

No final conclusions can be drawn from this admittedly limited sampling of the possible combinations. Nevertheless, it does appear that many of the variables which are potential constraints, do not have a substantial incremental effect. On the other hand, a few, notably land in cultivation, wildfowl flyways, and seismic hazards do have an important effect.

The Distribution of Eligible Areas - An Example Illustration

The total amount of eligible area remaining after the application of any combination of exclusion variables is perhaps less significant than the geographical distribution of that area. Substantial portions of the energy consumption of the United States seem to be concentrated in areas which appear to have little potential for providing rectenna sites. In order to measure this effect, it is necessary first to establish the distribution of "need" for additional electricity in the United States. A recent study performed for the Department of Energy at Oak Ridge National Laboratories (Reference 8) provides a useful starting point for this analysis. In that study, electrical consumption in the year 1985 was projected on a state-by-state basis for the entire United States. The same analys is contains a treatment of total energy imports. Electricity itself tends to be in balance within any region, though not always within individual states. The reason for this is that it is a relatively less transportable form of energy than either $0 i 1$, natural gas, or coal. Hence, regions will import sufficient energy in other fuel forms to provide the necessary electricity to keep them in balance. Consequently, the Oak Ridge report showed only trivial import-export balances for electricity in any region. The situation with respect to total energy imports was quite different. In the United States as a whole (48 states only) is a substantial net importer of energy and is projected to import 16,404 quads (Btu's $\times 10^{12}$ ) in 1985 .

Exhibit III- 6 provides a map showing the census regions and geographic divisions in the United States. This regional classification was selected primarily because of the fact that the energy consumption data base was developed based in part on census material. A second reason is that the most obvious alternative regional configuration for analys is would be the regional electric reliability councils (ERC'S). Unfortunately, energy data is only available on a state-bystate basis and ERC boundaries do not always correspond to state boundaries. The distribution of electrical consumption and total energy import by region and division is shown in Exhibit III-7. Of the four major regions of the United States, electricity consumption is most heavily concentrated in the South ( 38.5 percent) and least concentrated in the West (16.2 percent). 


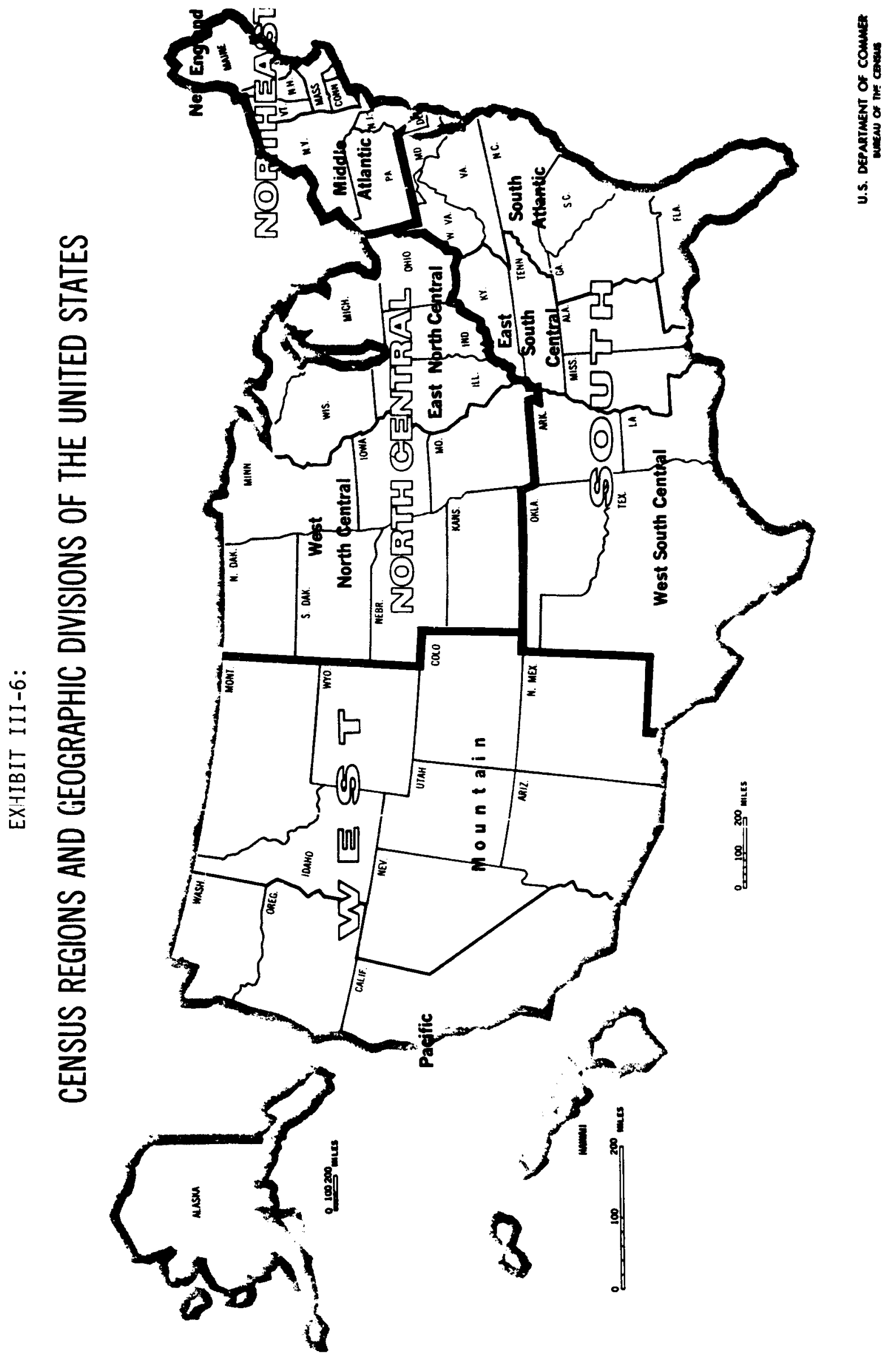




\section{EXHIBIT III-7 - PROJECTED REGIONAL ELECTRICITY CONSUMPTION}

AND TOTAL ENERGY IMPORTS, 1985

Geographic Division Region

\section{East}

New England

Middle Atlantic

North Central

East North Central West North Central

South

South Atlantic

East South Central

West South Central

West

Mountain

Pacific (excluding

Alaska and Hawaii)

TOTAL 48 STATES
Electrical Consumption ${ }^{1}$ kwh $\times 10$ Pct. of U.S. 2

\begin{tabular}{|c|c|c|c|c|}
\hline$\underline{626}$ & 19.6 & 14,713 & 89.7 & 33.6 \\
\hline $\begin{array}{l}129 \\
497\end{array}$ & $\begin{array}{r}4.1 \\
15.5\end{array}$ & $\begin{array}{r}3,742 \\
10,971\end{array}$ & $\begin{array}{l}22.8 \\
66.9\end{array}$ & $\begin{array}{r}8.6 \\
25.1\end{array}$ \\
\hline$\underline{824}$ & 25.7 & 16,240 & 99.0 & 37.0 \\
\hline $\begin{array}{l}589 \\
235\end{array}$ & $\begin{array}{r}18.4 \\
7.3\end{array}$ & $\begin{array}{r}13,012 \\
3,228\end{array}$ & $\begin{array}{l}79.3 \\
19.7\end{array}$ & $\begin{array}{r}29.7 \\
7.3\end{array}$ \\
\hline 1,231 & 38.5 & $-12,026$ & -73.3 & -- \\
\hline $\begin{array}{l}585 \\
306 \\
340\end{array}$ & $\begin{array}{r}18.3 \\
9.6 \\
10.6\end{array}$ & $\begin{array}{r}7,475 \\
928 \\
-20,429\end{array}$ & $\begin{array}{r}45.6 \\
5.6 \\
-124.5\end{array}$ & $\begin{array}{c}17.1 \\
2.1 \\
--\end{array}$ \\
\hline$\underline{520}$ & 16.2 & $-2,523$ & -15.4 & -- \\
\hline $\begin{array}{l}162 \\
358\end{array}$ & $\begin{array}{r}5.0 \\
11.2\end{array}$ & $\begin{array}{r}-7,001 \\
4,478\end{array}$ & $\begin{array}{r}-42.7 \\
27.3\end{array}$ & $\overline{10.2}$ \\
\hline 3,201 & 100.0 & 16,404 & 100.0 & $100.0^{4}$ \\
\hline
\end{tabular}

Total Energy Imports

Total Energy Imports
btu's $\times 10^{12}$
Pct. of U.S. 3 Pct. of Gross

${ }^{1}$ Converted, in accordance with source, at $3213 \mathrm{btu} / \mathrm{kwh}$

${ }^{2}$ Excluding Alaska and Hawaii

${ }^{3}$ Percentage of net total imports; minus numbers indicate exporting regions

4Percentage of gross regional imports of $43,834 \times 10^{12} \mathrm{btu}$ 's not offset by interregional expor

Source: Reference 8 and Allan D. Kotin, Economic Consultants 
The situation with respect to total energy imports is, however, quite different. If the net energy imports of the United States are divided among the four regions, the Northeast (New England-Middle Atlantic) accounts for almost 90 percent and the North Central (Midwest) accounts for 99 percent. The reason for this is that the other two major regions, the South and the West, are net exporters of energy. The West South Central region (Texas, Oklahoma, Louisiana and Arkansas). by itself accounts for energy exports larger than the net energy imports of the entire country. In order to adjust for this, the last column on the exhibit expresses the regional share of the gross energy imports without offsetting negatives. In this case, the Mountain and West South Central region are not included since they are the net energy exporters. The percentages assigned to the remaining regions are predicated on their share of a revised "gross" total energy import. By this measure, the East accounts for 33.6 percent of imports, the North Central for 37 percent, and the South Atlantic region for an additional 17.1 percent. In the West, only the Pacific region (excluding Alaska and Hawaii) has net energy imports, accounting for 10.2 percent of the gross energy imported.

The suggestion is often made that rectenna sites should, in theory, be distributed in accordance with electricity demand or some other index of energy need. The percentages presented in Exhibit III-7 can be used to provide tentative example distributions of rectenna sites that would meet these objectives. In Exhibit III-8, a hypothetical distribution of sites is presented based first on electricity consumption in 1985 and then on total energy deficit or imports in 1985 . As shown in the exhibit, the South would account for the largest number of sites (23) if sites were to be theoretically distributed on the bas is of electririty consumption. The Northeast and lest would have the lowest number of sites ( 12 and 10 respectively).

The situation is quite different if the distribution of sites is based on total energy deficit. In this case, over two-thirds of the sites would be concentrated in the Northeast and North Central (20 and 22 sites respectively). The Middle Atlantic would account by itself for one-quarter of the sites (15). Both the West and the South would have disproportionately small number of rectenna sites.

Using these highly tentative bases for the distribution of sites, it is possible to re-examine the information on eligible areas in terms of the suitability of distribution of the eligible area. Based on summary map 1 (the five initial exclusion variables), an illustrative analys is of this type is summarized in Exhibit III-9.

The upper portion of this exhibit shows the regional distribution of eligible area, first for the five basic exclusion criteria, and then with various additional exclusions for design considerations.

Ignoring any design considerations, it would appear that the five basic exclusion criteria (summary map 1) leave a remaining eligible area heavily concentrated in the South and West. Forty percent of the eligible area is in the West, with most of that in the Mountain states. Thirty-one percent is in the North Central, with most of that in the less populated West North Central region. The Northeast 
EXHIBIT III-8 - HYPOTHETICAL DISTRIBUTION OF SITES

\begin{tabular}{|c|c|c|}
\hline $\begin{array}{l}\text { Geographic Division } \\
\text { Region }\end{array}$ & $\begin{array}{l}\text { Based on } 1985 \\
\text { Electricity Usage }\end{array}$ & $\begin{array}{l}\text { Based on } 1985 \\
\text { Total Energy Deficit } 2\end{array}$ \\
\hline East & 12 & $\underline{20}$ \\
\hline $\begin{array}{l}\text { New England } \\
\text { Middle Atlantic }\end{array}$ & $\begin{array}{r}2 \\
10\end{array}$ & $\begin{array}{r}5 \\
15\end{array}$ \\
\hline North Central & $\underline{15}$ & $\underline{22}$ \\
\hline $\begin{array}{l}\text { East North Central } \\
\text { West North Central }\end{array}$ & $\begin{array}{r}11 \\
4\end{array}$ & $\begin{array}{r}18 \\
4\end{array}$ \\
\hline South & $\underline{23}$ & $\underline{12}$ \\
\hline $\begin{array}{l}\text { South Atlantic } \\
\text { East South Central } \\
\text { West South Central }\end{array}$ & $\begin{array}{r}11 \\
6 \\
6\end{array}$ & $\begin{array}{r}11 \\
1 \\
--\end{array}$ \\
\hline West & $\underline{10}$ & $\underline{6}$ \\
\hline $\begin{array}{l}\text { Mountain } \\
\text { Pacific }\end{array}$ & $\begin{array}{l}3 \\
7\end{array}$ & -- \\
\hline TOTAL U.S. (48 STATES) & 60 & 60 \\
\hline
\end{tabular}

Source: Allan D. Kotin Economic Consultants 
EXHIBIT III-9: REGIONAL DISTRIBUTION AND AREA PER SITE FOR

FIVE BASIC EXCLUSIONS WITH LATITUDE CLIMATE VARIATIONS

Eligible Area (in Number of Map Grid Cells)

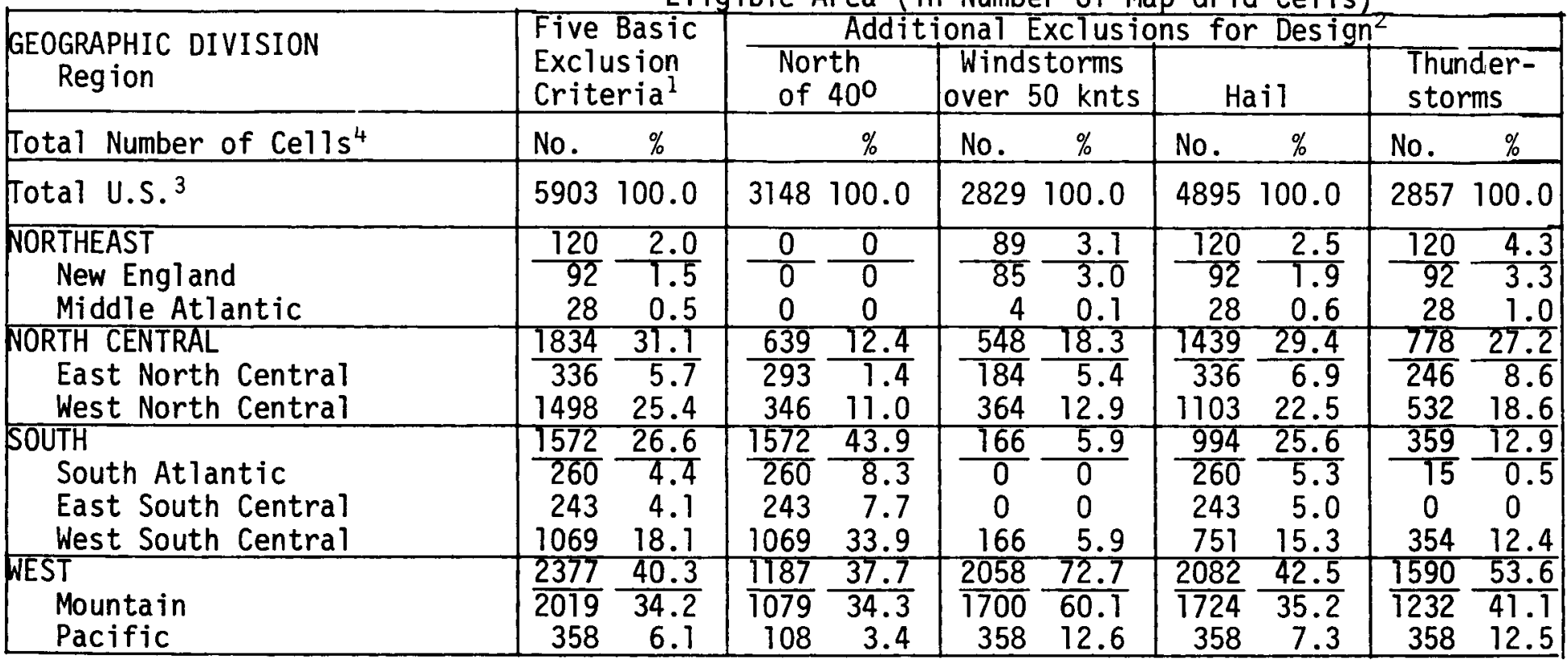

\begin{tabular}{|c|c|c|c|c|c|c|c|c|c|c|}
\hline Ratio of Cells per Site ${ }^{4}$ & $E C^{5}$ & $\mathrm{SOI}^{6}$ & $E^{5}$ & $\mathrm{SOI}^{6}$ & $E C^{5}$ & $\mathrm{SOI}^{6}$ & $E C$ & $\mathrm{SOI}^{6}$ & $E C^{5}$ & $\mathrm{SOI}^{6}$ \\
\hline TOTAL U.S. $(60)^{7}$ & 98 & 98 & 52 & 52 & 47 & 47 & 8 & 82 & 48 & 48 \\
\hline $\begin{array}{l}\text { NORTHEAST }(12,20) \\
\text { New Engl and }(2,5) \\
\text { Middle Atlantic }(10,15)\end{array}$ & $\begin{array}{r}10 \\
46 \\
3\end{array}$ & $\begin{array}{r}6 \\
18 \\
2\end{array}$ & $\begin{array}{l}0 \\
0 \\
c\end{array}$ & $\begin{array}{l}0 \\
0 \\
0\end{array}$ & $\begin{array}{r}7 \\
43 \\
<1\end{array}$ & $\begin{array}{r}4 \\
17 \\
<1\end{array}$ & $\begin{array}{l}7 \\
4\end{array}$ & $\begin{array}{r}6 \\
18 \\
2\end{array}$ & $\begin{array}{r}10 \\
46 \\
3\end{array}$ & $\begin{array}{r}6 \\
18 \\
2\end{array}$ \\
\hline $\begin{array}{l}\text { NORTH CENTRL (15,22) } \\
\text { East North Central }(11,18)\end{array}$ & $\begin{array}{r}122 \\
31 \\
375\end{array}$ & $\begin{array}{r}83 \\
19 \\
375\end{array}$ & $\begin{aligned} 43 \\
27 \\
87\end{aligned}$ & $\begin{array}{l}29 \\
16 \\
87\end{array}$ & $\begin{array}{l}37 \\
17 \\
97\end{array}$ & $\begin{array}{l}25 \\
10 \\
91\end{array}$ & $\begin{array}{r}9 \\
3 \\
27\end{array}$ & $\begin{array}{l}65 \\
65 \\
19\end{array}$ & $\begin{array}{r}52 \\
22 \\
22\end{array}$ & $\begin{array}{l}2 \\
35 \\
14\end{array}$ \\
\hline $\begin{array}{l}\text { SOUTH }(23,12) \\
\text { South Atlantic }(11,11) \\
\text { East South Central }(6,1)\end{array}$ & $\begin{aligned} 68 \\
24 \\
41\end{aligned}$ & $\begin{array}{r}137 \\
24 \\
243\end{array}$ & $\begin{aligned} 68 \\
24 \\
41\end{aligned}$ & $\begin{array}{r}137 \\
24 \\
243\end{array}$ & $\begin{aligned} 3 \\
0 \\
0 \\
0\end{aligned}$ & $\begin{array}{r}14 \\
0 \\
0\end{array}$ & $\begin{array}{r}4 \\
2 \\
4 \\
\end{array}$ & $\begin{array}{r}83 \\
24 \\
243\end{array}$ & $\begin{array}{r}16 \\
1 \\
0\end{array}$ & $\begin{array}{r}30 \\
1 \\
0\end{array}$ \\
\hline \begin{tabular}{|l} 
West South Centr \\
WEST $(10,6)$ \\
Mounta in $(3,0)$ \\
Pacific $(7,6)$
\end{tabular} & $\begin{array}{r}178 \\
238 \\
673 \\
51\end{array}$ & $\begin{array}{c}- \\
\overline{396} \\
\overline{60}\end{array}$ & $\begin{array}{r}178 \\
110 \\
360 \\
15\end{array}$ & $\frac{-}{198}$ & $\begin{array}{r}28 \\
206 \\
567 \\
51\end{array}$ & $\frac{-}{343}$ & $\begin{array}{r}12 \\
-20 \\
57 \\
5\end{array}$ & $\begin{array}{c}- \\
347 \\
- \\
60\end{array}$ & $\begin{array}{r}59 \\
159 \\
411 \\
51\end{array}$ & $\begin{array}{c}265 \\
- \\
60\end{array}$ \\
\hline
\end{tabular}

1 Unacceptable topography, population density, national recreation areas, and navigable waterways.

2 See Exhibit III-4

348 contiguous states only

$426 \mathrm{~km}$ square map grid cell $\mathrm{s}$

$5 \mathrm{EC}=$ sites distribted based on 1985 electricity use

6 SOI=sites distributed based on 1985 share of imports of total energy (See Exhibit III-8)

7 Number of sites each region "should" have (EC, SOI)

Source: Reference 11 and Allan D. Kotin Economic Consultants 
which accounts for 20 percent of electrical consumption and almost 34 percent of gross energy imports, has only 2 percent of the eligible area. The Middle Atlantic, which by itself accounts for 15 percent of electricity consumption and 25 percent of projected total energy imports, has less than one-half of one percent of the area.

The imposition of the various climatological design exclusion criteria does tend to change both the distribution of the area as well as the amount of eligible area remaining. For example, if all areas with windstorms over 50 knots are excluded, there is virtually no remaining area in any region except the West which accounts for almost 73 percent of the area. The Northeast and South have negligible remaining areas.

Any attempt at evaluating the appropriateness of the distribution of eligible area must consider not only the percentage of area in various regions but the amount. One way to reflect both the distribution of eligible area and the amount of eligible area is to use a ratio of the number of grid cells of eligible area per theoretical site. This cell/site ratio gives effect to the total amount of area and also shows on a comparative bas is the maldistribution associated with different exclusion variables. Such an analys is is included at the bottom of Exhibit III-9. The U.S. as a whole (48 states) contains 5,903 eligible grid cells under the five basic exclusion criteria. It also shall contain 60 sites. The cell/site ratio is, therefore, 98 cells per site. By itself this is a quite comfortable ratio since each cell could nominally accommodate more than three rectenna sites and there would, therefore, be a 300:1 ratio or better for the U.S. as a whole. Looking at the cell/site ratios for individual regions shows wide variations. The Western United States and specifically the Mountain region are extremely well endowed with eligible areas per site required. In the "EC" column which represents the number of sites distributed according to electrical consumption, the mountain states have the highest ration at 673 cells per required site. The Middle Atlantic has the lowest ratio at 3 cells per required site, a difference by a factor of over 200 between these two regions.

If rectenna sites are to be distributed based on the share of imports (SOI), then the second column in each pair should be used. In this instance, the most generously endowed region is the West North Central which requires four sites and has a total available area of 1,498 grid squares for a ratio of 375 grid squares per site. Again, the Middle Atlantic is the worst region with a ratio of only 2 cells per site (28 cells total to accommodate 15 sites). As this part of the table clearly shows, under any assumption the Northeast is consistently underendowed with eligible areas. On the assumption of windstorms, the South is also largely undersupplied with eligible area as it is with thunderstorms. In most instances, there is more than an adequate number of sites in the West and a generally adequate number in the North Central area. The statistics on the North Central are somewhat misleading since most of the eligible area is in the West North Central (Northern Plains states) rather than the East North Central (highly urbanized industrial Midwestern states).

The foregoing analysis of distribution is intended merely to illustrate one approach to examining the distribution of eligible areas as well as the total 
magnitude. Obviously, any consideration of land use requirements must consider both the total and the distribution not only for this one example, but for all the various combinations of exclusion criteria that appear to be meaningful. This is a key task for subsequent analysis.

\section{III-6. CRITICAL UNRESOLVED ISSUES}

\section{General Issues}

Several physical characteristics of the SPS rectenna would seem to impose importrestrictions on the type of sites that may be selected. One example of this is the requirement for generally level sites so as to minimize the problems in erecting a massive series of presumably level and parallel receiving panels (billboards). Another example is wind resistance which at one point was nominally set, in a highly preliminary analysis, at 90 miles per hour. In the course of trying to confirm these limitations on rectenna sites, the following response was frequently encountered, "We1l, it's just a matter of money. If we spend a little more we can level a mountain. If we spend a little more we can build a rectenna to resist 150 miles per hour winds." This type of response is not necessarily specious. The dollar commitments involved in rectenna construction are huge ( $\$ 2.5$ billion each). At the same time, however, this type of reasoning can remove too many constraints and make the initial evaluation effort an empty exercise. Some type of policy decision with respect to the frame of evaluation is needed. One option would be, as mentioned in the energy anaiys is section, to freeze the reference concept and not to permit any variations as a function of "spending a little more money."

An alternative would be to pursue further the analysis in the Rice study to identify which parameters would have the greatest impact on expanding tne eligible area. Once identified, estimates of revised costs could be requested from the design-cost team. These could be in the form of additional "options" just as the silicon and gallium arsenide photocells represent options. Whatever approach is selected, ground rules or policies relating to this nominal cost flexibility should be set prior to the next round of land use and siting study. The inclusion or exclusion of rectenna sites on the sea is another critical general issue requiring resolution. It relates specifically to the increasing cost issue discussed above. It is frequently stated that there are no inherent technological problems in building a rectenna offshore and that it is "only a matter of money." Unfortunately, there exists no reference concept or preliminary design to confirm this widely held belief. Furthermore, it is not clear "how much more money" an offshore site would cost. It may be argued that the cost increment is not critical. The same does not apply to the need for some sort of design. Constructing a rectenna offshore would create a variety of new parameters to be considered. For example, does wave action become a siting criteria? What about the relationship to shipping lanes and shipping communications? Are there different kinds of problems associated with high voltage transmission over water than over land? How deep can the water be at a location where a rectenna site is to be erected? Is there a problem of corrosion for both the metallic and the electronic components in the rectenna? 
The briefing literature on the reference concept does not discuss sea sites specifically. Without some discussion and even the coarsest of design parameters, any attempt to evaluate sites in the next round of site evaluation will be a largely empty exercise.

A third and final general issue to be considered concerns the joint use of rectenna sites. Various references to potential joint agricultural uses of rectenna sites are sprinkled throughout the literature. The Arthur D. Little study, for example, has two such related criteria in its siting criteria list. A brief review of the SPS literature provides no general description much less any specific ireatment of such joint beneficial uses. What few references are found are explicitly speculative in nature. A minor policy decision is required with respect to the inclusion of such joint uses in any siting evaluation. If they are to be included, some 1 imited independent study is required to indicate their scope and requirements.

\section{Specific Issues}

The creation of a criteria list and its application to the computer-mapping exercise undertaken at Rice revealed a variety of specific issues involved in siting which have not been resolved. The briefing documents which support the SPS reference concept do not contain sufficient information to establish standards for many of these criteria. In part this is because the basis for establishing standards is to emerge from parallel white papers or subsequent study efforts.

Exhibit III-10 provides a brief list of these specific issues, together with perceived sources of resolution. In some cases, the source of resolution is an interface with another white paper effort. The obvious implication is that subsequent investigations should be more closely coordinated in those areas.

\section{7 . RECOMMENDATIONS FOR FURTHER STUDY AND INVESTIGATION}

Before undertaking the next round of evaluation on land use and siting, several steps should be taken to assure substantive results:

\section{Resolve or Initiate Resolution of General Issues}

For the most part, these are issues that will not go away. The sea siting problem and the degree of adherence to the reference concept in the face of the "just a little more money" syndrome will continue to plague all future siting efforts. If resolution cannot be effected prior to initiation of the next round of evaluation, then milestones and schedules should be set so that answers are available to the consultants well before the final reports are due.

\section{Revier Rice Study Findings and Extend Analysis}

The summarization and extension of the Rice analysis presented in this paper is largely illustrative in nature. First of all, the number of combinations tested 


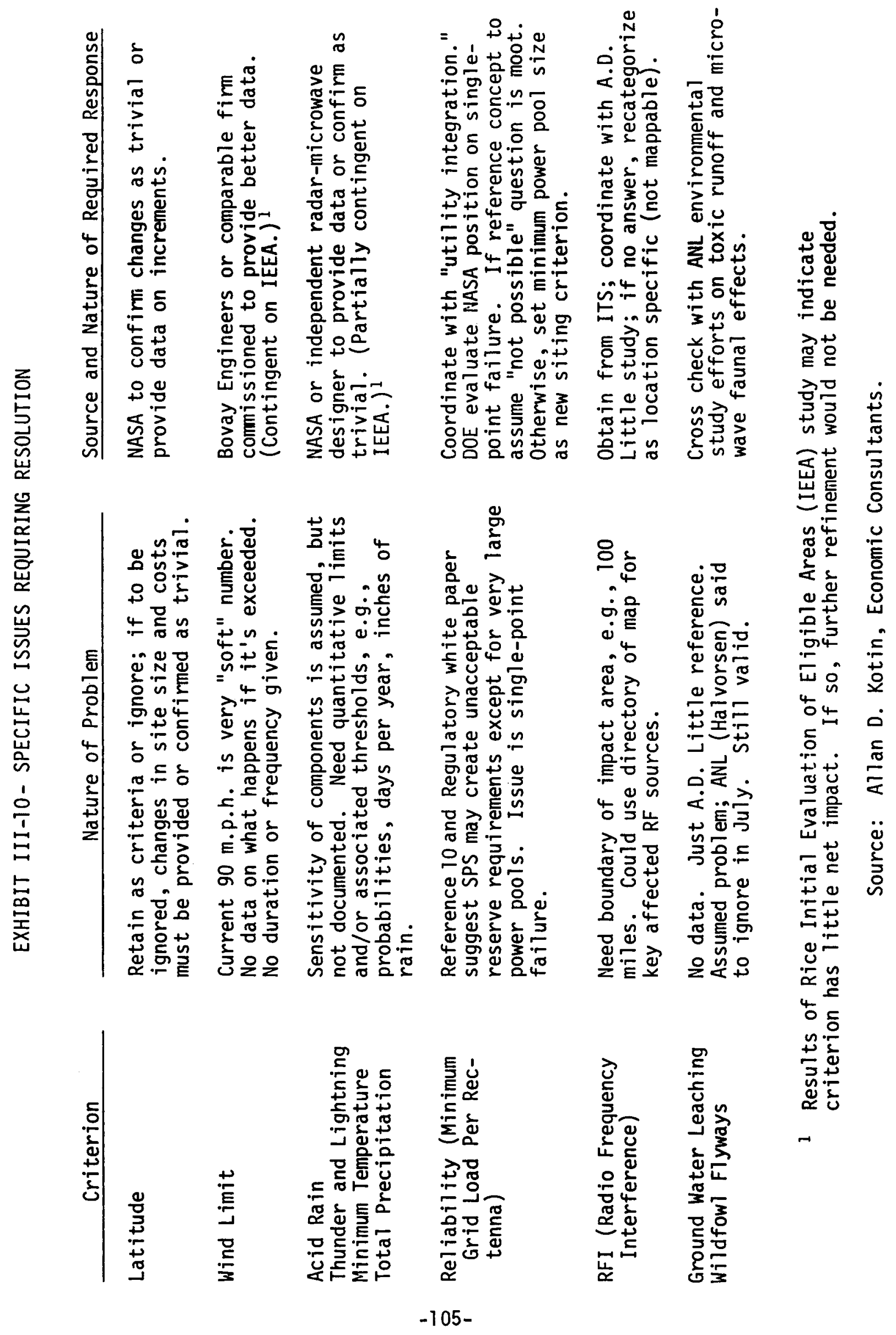


by Rice was itself arbitrarily limited. Secondly, there are numerous questions of data reliability and additional data gathering raised in the Rice report itself which should be resolved before further extensive quantitative analysis is applied to their findings.

It is clear that an extension of the computer analysis model to perform a distributive analysis as well as a simple quantitative derivation of total eligible areas is in order. This should probably be one of the first priorities since even the existing data base could yield much more sensitive information on the distributive effect of various exclusion variables.

At this point, the Rice analysis is largely illustrative rather than conclusive. The addition of gradients and their analys is of the separable gradient effect could be of significant value in those areas which are particularly sensitive. For example, further refinement in both the data base and the analytic framework for migratory fowl flyways is clearly indicated by the drastic effect of this variable on the eligible areas.

Similarly, key excluded variables should be introduced into the analysis. Most notable among these are some more explicit treatment of microwave effects on radio frequency interference and air transportation. Conceptually, both these problems can be mapped and encoded. The key prerequisites are better information about the potential impacts of the SPS microwave transmissions and further data search.

Clearly, one further extension of the Rice analysis which might be fruitful would be to exercise the alternative permutations more systematically. In the example selected by Rice, each variable was added to the preceding variables in most cases. This masks, to some degree, the isolatable incremental impact of each variable which might be of some value. Obviously, the number of permutations is too large to consider exhaustively. Nevertheless, even the limited data available provides indications of which ones should be examined more closely, e.g. national forests, land in cultivation, and the climatological variables.

\section{Integrate and Compare Findings of Arthur D. Little Study}

Even though the study of eligible areas in the Rice analys is is not complete, it does provide a useful bas is for comparison with the findings of the ongoing $A$. $D$. Little, Inc. siting study. The extent to which the conclusions to be drawn from these studies reinforce each other is itself a matter of considerable importance to future siting research. Similarly, a superimposition of the sites selected in the A. D. Little study over the various exclusion areas defined in the Rice study should prove of considerable value.

\section{Resolve Specific Criteria Issues}

Some of the questions regarding specific criteria may become moot as a result of the Rice study. If a variable has little effect on the availability of sites, additional refinement effort is not justified. Many issues will remain, including at least some of the climatological issues, e.g., wind, thunderstorms, etc. 
Another round of evaluation without some parameters to attach to these and other unresolved criteria will be inevitably wasteful.

5. Specify Level of Integration of Further Siting Studies With Other Evaluation Efforts

This step is particularly important with regard to further studies in the area of utility integration and state and local regulation. Locational factors and siting criteria are intrinsic to all three evaluation efforts and much data collection overlaps. Reliability and regionalization are both key issues which may exert a profound effect on siting. The reliability issue in particular may be a "showstopper" if the SPS is explicitly subject to single-point failure. While both siting and state and local regulation efforts must be concerned with this, any resolution must come from the interaction of the utility integration effort with NASA design. 
1. Chapman, Philip, Arthur D. Little Inc., perscnal communications, July 1978.

2. ECON, Inc., Political and Legal Implications of Developing and Operating a Satellite Power System, 77-195-1, August 1977.

3. Glaser, Peter, Arthur D. Little Inc., personal communications, July 1978.

4. Gregory, D.L., The Boeing Aerospace Company, Space Solar Power and Our Energy/Economic Crisis, undated.

5. Little, Arthur D., Inc., "Rectenna Siting Requirements," briefing prepared for NASA/MSFC, 1978 (undated chart).

6. NASA/MSFC, Candidate Locations for SPS Rectifying Antennas, (prepared by Anne W. Eberhardt), NASA TM-73 146, November 1977.

7. U.S. Department of Commerce, Office of Telecommunications, and Institute for Telecommunication Sciences, Applied Electromagnetic Science Division, Congested Region Performance Predictions and Model Development Group, Electromagnetic Compatibility, Tropospheric and Ionospheric Aspects of SPS MPTS Operations, (Preliminary Study), (prepared for Pacific Northwest Laboratory (Batte11e), PNL-2616, UC-97a, March 1978.

8. Vogt, D.P., P.L. Rice, and V.P. Pai, Energy Availabilities for State and Local Development: Projected Energy Patterns for 1980 and 1985, ORNL/ TM-5890/S4, Oak Ridge National Laboratory, Oak Ridge, Tennessee, June 1978.

9. The Western Interstate Nuclear Board, Regional Factors in Planning and Siting Electrical Energy Facilities in the Western States, (prepared for the U.S. Nuclear Regulatory Commission, Office of Standards Development), (49-24)-0249, (Lakewood, Colorado), April 5, 1977.

10. Winer, B., Arthur D. Little, Inc., Impacts and Benefits of a Satellite Power System on the Electric Utility Industry, Final Report, July 1977.

11. Blackburn, James B. Jr., and Bavinger, Bill A., Satellite Power System Receiving Antenna Siting Study, Mapping of Exclusion Areas, Rice University School of Architecture and Space Solar Power Research Program, Houston, Texas, October 1, 1978. 
Presented below, in alphabetical order, is a brief discussion of some of the problems encountered with some of the specific materials. In the interest of brevity, the body of the text did not present fully the process by which production and capacity estimates were derived and some aspects of the definitional problems. On the other hand, this information is clearly relevant if the preliminary classification scheme is to be understood and appreciated. Consequently, brief discussion of this type are presented below for selected types of materials.

\section{Aluminum and Bauxite}

A large proportion of the bauxite ore is imported. Major sources are Jamaica and Australia which are considered reliable. (References 5, 9, and 21.)

Arsenic

The arsenic required for solar cell purpcses would be a high purity grade. Domestic production capacity shown in the table is basically that of a by-product in the smelting and refining of ores for other metals, in which arsenic would be considered an impurity. Data is not available for the capacities or production of high purity arsenic. Because of the limited number of products in the United States, production data are withheld in order to protect company confidentiality. Also, environmental pressure groups are contributing to some restriction of the expansion of capacity. A recently published research study projects high purity arsenic production in the year 2000 to be 23 metric tons. (References 10 and 22.)

\section{Gallium}

Gallium production results entirely as a by-product of the processing of other metals, particularly aluminum and zinc. It is found in minute proportions in bauxite and zinc ores. Its recovery ratio from bauxite may range from 0.002 to 0.004 percent. Thus, based on known bauxite reserves in the U.S., a total of 2,000 metric tons may be obtained from them. The Bureauof Mines also estimates that known U.S. zinc resources may contain an additonal 700 metric tons. World reserves of both are estimated to contain approximately 112,000 metric tons. System requirements over a 30-year period for the SPS program in its present concept would require 65,580 metric tons or 59\% of all presently known world reserves.

Actual production data is not available. There are only two producers in the United States and probably about 10 more scattered throughout the non-communist world. Total world production in 1974 is estimated to have been about 15 metric tons. U.S. supplies have been augmented by imports from Canadian and Swiss sources who are reported to have produced approximately 10 metric tons in 1973. U.S. consumption of the metal during the four-year period 1972-1976 is estimated to have grown at an average annual rate of about 12.04 percent. The rest of the world is estimated to have used about 5.5 tons in 1973 and if its consumption rate grew at a comparable rate until 1976, total world consumption in that year 
is estimated to have been about 15.75 tons.

Gallium is used largely in the instrumentation industry as a superconductor. Other users are in the dental industry as a substitute for mercury and as mirror coating in the optical industry. These uses for gallium are expected to continue. In a forecast prepared in 1974 by the Bureau of Mines, world demand was estimated for the year 2000 at a probable level of 47 metric tons per year and high level of 63 metric tons. Comparable U.S. demand was forecast to be 32 metric tons and 43 metric tons. Obviously, SPS requirements would be additional. Supply problems could be exacerbated if refining processes are developed to permit economic use of kaolin as a substitute for bauxite in aluminum production. Then the bulk material for gallium production would decline in availability. (References 9, 10, 22, and 23).

\section{Glass}

The glass manufacturing industry in the United States is quite immense and probably has no particular shortages of domestic source materials for any type of glass. However, the type of glass planned for this application is borosilicate glass of high purity. Current levels of production for this product have not been identified. Available production projects for the year 2000 for this product is 29,000 metric tons per year. SPS needs will far exceed that level. Therefore added capacity to produce borosilicate glass will be needed. It is expected that there will be no shortage of raw or bulk materials. (Reference 10.)

\section{Graphite and Graphite Epoxy}

Graphite epoxy estimated to be approximately 75 percent graphite plus epoxy resin as a binding compound. Personal interviews with space scientists indicate that the graphite in graphite epoxy is a synthetic material produced from rayon fibers rather than natural graphite. Those fibers are baked. The process also permits them to align in the same direction. The synthetic fiber may permit better control of grain regularity than would a natural graphite fiber. Data are not available on its manufacture. The technology is relatively new. It may be assumed, however, that there would be no shortages of this basic forest product fiber. If, however, natural graphite fibers are intended for use in the SPS, the situation would be quite different. Domestic resources of graphite are reported as "insignificant" by the Bureau of Mines' graphite specialists. In 1977 the United States imported a total of 79,400 metric tons of graphite from all sources. Of this total, 54,900 metric tons of amorphous graphite originated in Mexico; approximately 4,000 metric tons of crystalline flake was from Malagasy; and 2,168 metric tons of artificial graphite came from Japan. If fibers from those products are suitable for SPS structures' design, in particular, the Mexican product, adequate future supply is not expected to be jeopardized. Known resources are described as "very large to huge" and sufficient for SPS levels of incremental demand for more than 30 years. (References 7, 10, and 12.) 


\section{Hydrogen}

There are only four plants in the United States which currently produce hydrogen. Those operate at approximately 66.7 percent load factor. Also, there are other facilities, now out of operation, which could be restored to production with minimal refurbishing. It would probably need about five years of lead time to expand industrial capacity to the levels of demand indicated by incremental purchases for SPS needs. That is not a problem and the added facilities would be able to operate at substantially higher levels of efficiency. The only problem may be reduced supplies of natural gas (methane) as a raw material. Given the methane, hydrogen supply is not a problem. (References 2 and 25.)

\section{Mercury}

The United States, for many years, has been a substantial net importer of mercury. In 1977 imports represented 48.4 percent of total supply. In 1974 imports were as high as 96.8 percent of total supply notwithstanding the fact that average prices for the metal were more than twice as high in the earlier year. The recent reduction in net imports may possibly be explained by the opening of a new deposit in Nevada. This deposit claims reserves amounting to 89 percent of total known U.S. reserves $(15,525$ metric tons in 1974). Total U.S. consumption of mercury during the 10-year period (1968-1977) was 21,034 metric tons or 35.5 percent greater than known 1974 reserves. Thus, at recent average annual consumption levels, total domestic reserves might satisfy slightly more than seven years' consumption levels, not including SPS needs. Domestic resources are only twice the known reserves. Other known North American reserves and resources in 1974 amounted to 12,765 metric tons and 37,950 metric tons respectively. In the past, Canada has been a prime import source for mercury. This country reduced shipments in 1976 to less than 9 percent of imports. Other exporting countries also reduced shipments because of declining prices during the past two years. Other import sources in 1976 were Algeria (18 percent), Spain and Yugoslavia (12 percent each), and the People's Republic of China (10 percent). Spain continues to hold the largest share of world reserves with 68,900 metric tons or 38 percent of all reserves. (References 5 , 6,22 , and 23.)

\section{Oxygen}

Raw material source is unlimited in the atmosphere. Industry, now operating substantially below capacity. If additional capacity is needed, this should not pose any problem beyond the lead time for construction.

Silicon, Metallurgical and High Purity Grades

The materials needed to produce silicon are abundantly available. Any problems which might occur will more likely result from the high purity content requirement. The production figures in Exhibit $1-2$ represent metallurgical grade silicon refined in 1977. In addition to that, about 800,000 tons of ferrosilicon was produced. Ferrosilicon requires some added refining to be converted to 
metallurgical grade. High purity silicon (electronic grade) needs even inore processing. Current solar cell quality silicon is not as pure as that needed for integrated circuitsswhich sometimes use rejected electronic-grade product. 1977 production of high purity silicon was 800 metric tons. Capacity for this grade is approximately 1,200 metric tons per year, and current supply is excessive. The process is both capital and energy intensive. Bringing a new plant on-stream takes about three years. Given sufficient lead time added high purity production will not be a problem from the materials availability viewpoint. Also, exploration is now being intensified for higher purity ores which would require less refining. Capacity to produce metallurgical grade silicon is expected to increase to about 200,000 metric tons per year by the year 2000 . This represents a capacity increase of about 80 percent over existing levels. (References 10, 18, and 21.)

\section{Silver}

The data for domestic production capacity is that for U.S. mines in 1974. This may have been expanded as a result of silver commodity price increases from $\$ 3.00-\$ 4.00$ per ounce to recent prices of $\$ 5.00-\$ 6.00$. Refinery capacity in the United States in 1974 was 3,266 metric tons and was expected to increase to 4,977 metric tons by 1980. Additional supplies of domestic silver may also be price sensitive and probably exists in unknown substantial quantities in privately owned hoards and collections. World production of silver in 1976 was 9,481 metric tons, which is only about three times annual demand in the gallium option $(3,112$ metric tons $)$.

The 30-year proposed program would consume approximately half of the known U.S. mine resources in 1974 and twice the known reserves. U.S. reserves and resources are estimated to be about 25 percent of world supplies.

\section{Teflon}

Teflon is a proprietary synthetic resin product and probably is manufactured to volumes large enough to satisfy currently anticipated demands. Raw material contents such as coal, fluorspar, natural gas, salt, sulphur, and 1 imestone are abundantly available. As demand for this product becomes confirmed it should be quite feasible for industry to expand its production capacity in order to satisfy SPS incremental needs. (References 9 and 10.)

\section{Tungsten}

The United States consumed nearly two and one-half times its domestic production of tungsten concentrates in 1977. Imports, however, were only about the same as production $(3,105$ metric tons). Differences between consumption and net imports plus production were made up by releases from the Federal stockpile, now in the process of reduction. If not for this process of stockpile release, import requirements might have amounted to 4,580 metric tons. This would have equalled 5.76 percent of world production outside the U.S. (79,500 metric tons). Nearly half of that production occurred in three communist-ruled countries: 


\begin{tabular}{ll} 
USSR & 16,326 M.T. \\
China & 17,959 \\
North korea & 4,299 \\
\hline Total & 38,584 M.T.
\end{tabular}

Major sources of imported concentrate in 1976 were: Canada, 22\%; Peru, 18\%; Bolivia, 12\%; Thailand, 10\%; Portugal, $9 \%$; Mexico, $9 \%$; China, $8 \%$; South Korea, $5 \%$; and Australia, $4 \%$.

Using 1975 as a base year, the last year for which production data for all countries is available, total for all countries, excluding the three communist countries and the United States, was (in equivalent terms to values published at 60 percent $\mathrm{WO}_{3}$ metal content) 37,921 metric tons. The production totals for 1975 for those countries from which the U.S. had imported (not including China) were 23,656 metric tons. The 1977 production deficit in the United States amounted to 12.1 percent $(4,580: 37,921)$ and 19.4 percent $(4,580: 23,656)$, respectively. If incremental quantities required by the SPS (1,220 metric tons) are included, those ratios would be increased to 15.3 percent and 24.5 percent of the total production from our current non-communist trading partners.

Thus, it is conceivable that unless new resources are identified in stable and reliable supply countries, a real potential problem may be encountered. (References $5,6,16,20,21,22$, and 23.) 


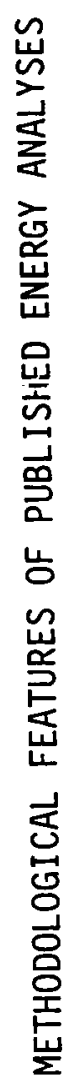

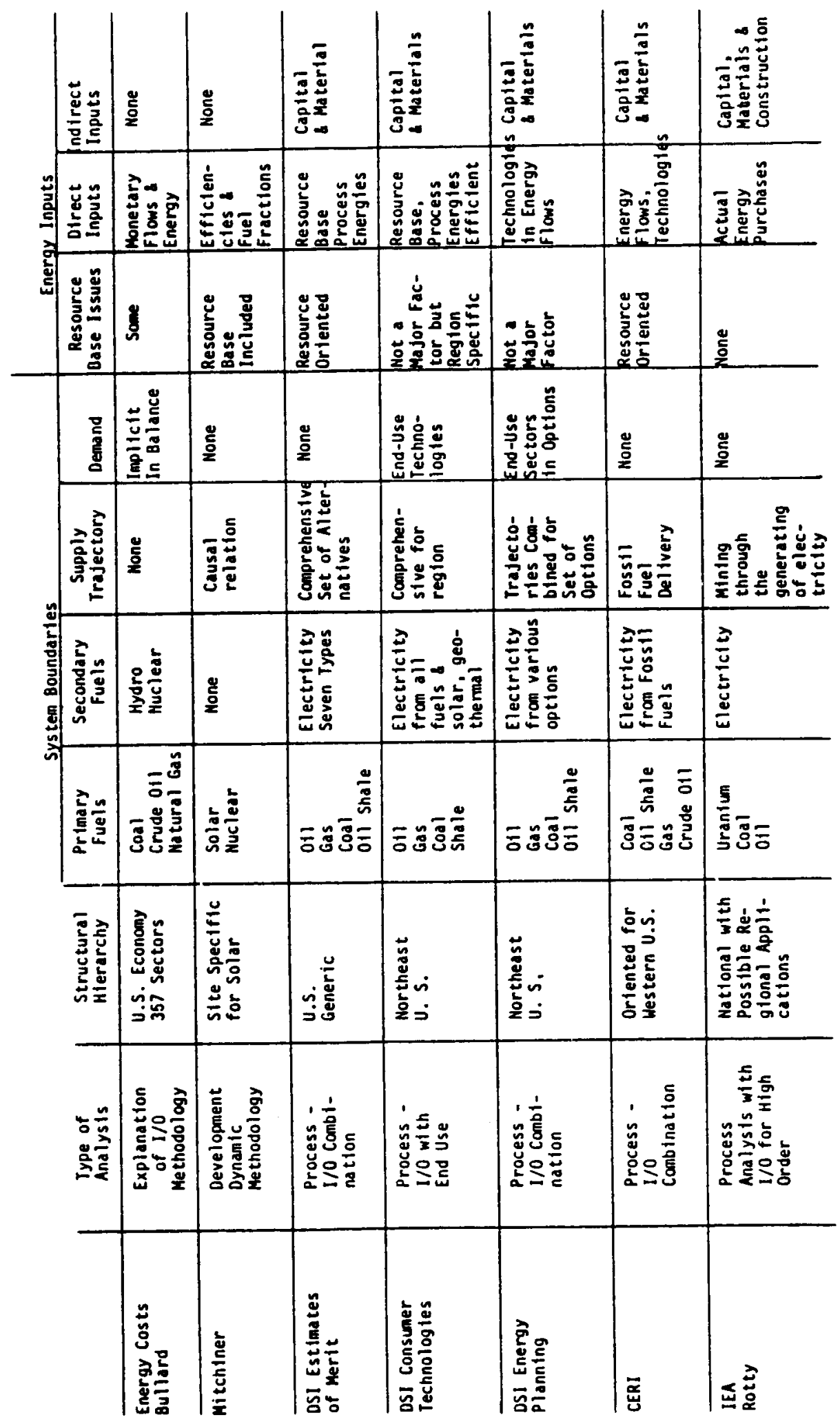




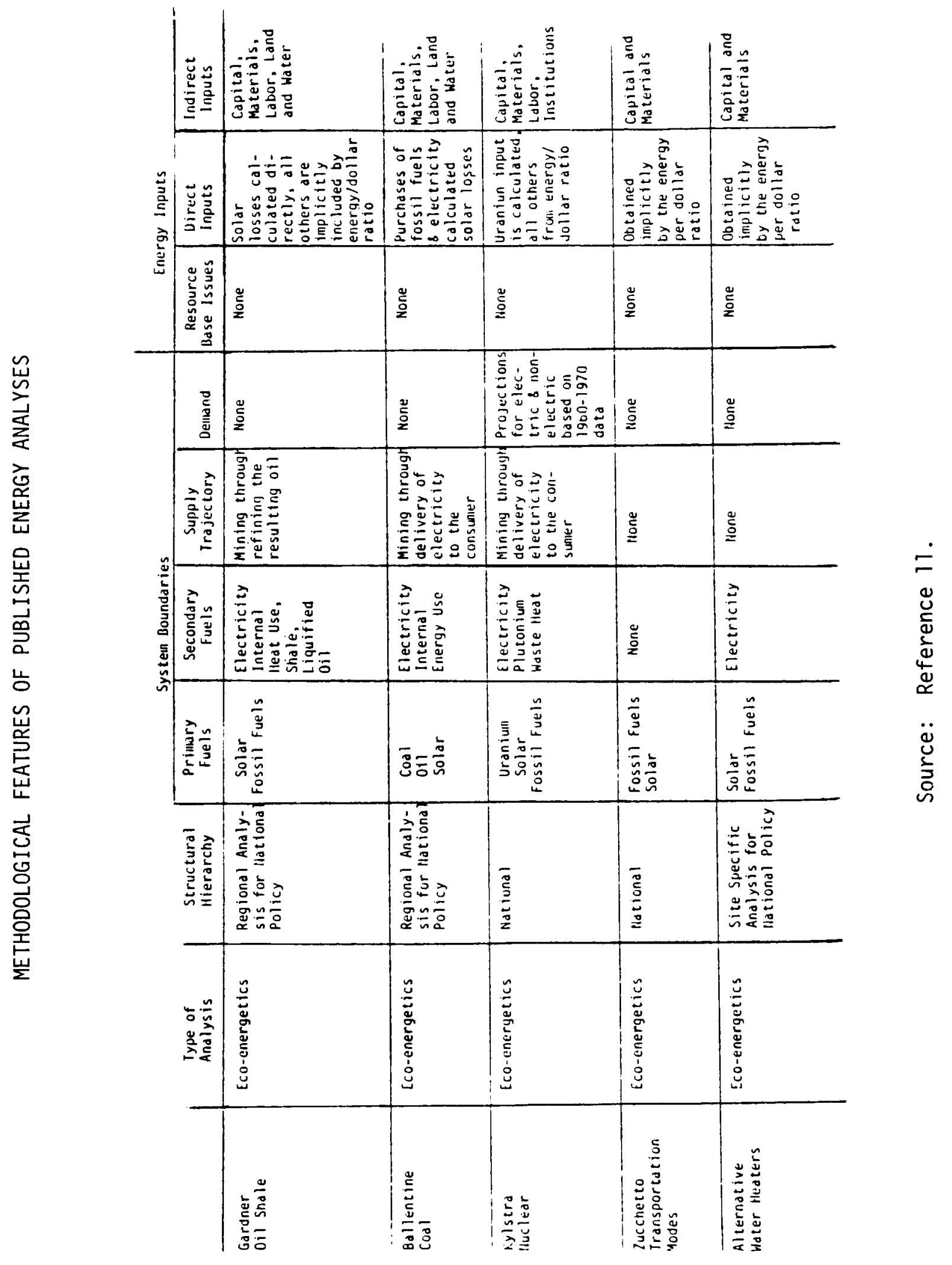


S1. Boeing Aerospace Company, Solar Power Satellite, System Definition Study, Parts I and II, Vols. II-VI, December 1977, $(\mathrm{I}-256)^{\star}$.

S2. Boeing Aerospace Company and NASA/JSC, SPS Concept Evaluation Program, January 25, 1978, (I-28.3).

S3. Boeing/G.E., SPS System Definition Study (Part III); Preferred Concept Definition, March 1978, (I-28).

S4. SPS System Definition Study (Part III); Final Briefing, March 7, 1978, (I-28.3).

55. Clark, Wilson, Energy for Survival, The Alternative to Extinction, Anchor Books, Garden City, New York, 1974.

S6. DOE/ET, SPS Concept Development and Evaluation Program Plan (July 1977 August 1980), D0E/ET-0034, February 1978.

S7. DOE/NASA, SPS Concept Evaluation Program Plan (July 1977-August 1980), MSFC-76-PA-4000-491, January 1978.

S8. FASST News, "The Issues Behind Solar Power Satellites," Vol. 7, Nos. 1 \& 2 , Winter-Spring 1978.

S9. Glaser, Peter, Arthur D. Little Inc., personal communications, July 1978.

510. International Technical Services, Inc., An Overview of Prospective Organizational Structures in the Solar Power Satellite Field, Draft repcrts for Task I, Subtask 3, and Task II, Subtask 3, (prepared for Argonne National Laboratory, Argonne, Ill inois, Contract No. 31-109-38-4387), Arlington, Virginia, June 30 and July 3, 1978.

S11. Jet Propulsion Laboratory, Satellite Power System. (SPS) Microwave Subsystem Impacts and Benefits, (prepared by Richard M. Dickinson, Radio Frequency and Microwave Subsystems Section, Telecommunications Science and Engineering Division), California Institute of Technology, Pasadena, California, September 28, 1977.

S12. Library of Congress, Congressional Research Service, Solar Energy From Space: Sateliite Power Stations, (prepared by Marcia S. Smith, Science Policy Research Division), Issue Brief Number 1B78012, Update 06/23/78, Originated $02 / 14 / 78$.

513. NASA/JPL, Satellite Power System Environmental Impacts -- Preliminary Assessment, (prepared by Floyd R. Livingston), May 12, 1978, (I-24).

* Reference codes used in PRC/ANL bibliography distributed June 1978. 
S14. NASA/MSFC, Prel iminary Basel ine SPS Concept Recommendations to DOE/NASA, January $24,1978,(1-43)$.

515. NASA, MSFC-JSC, Solar Power Satellite Baseline Review (Preliminary), July 13, 1978.

S16. Planning Research Corporation, Charles E. Bloomquist, A Survey of Satellite Power Stations, DSE/2071-1, September 1976, (I-161).

517. PRC Energy Analys is Company, Interim Environmental Guidel ines for Satellite Power System (SPS) Concept Development and Evaluation - Iteration 2, Tprepared for the Department of Energy, Office of Energy Research, Associate Director for Research Policy, SPS Project Office), June 1978, $(I-41)$.

S18. Rockwell International, Satellite Power Systems (SPS) Concept Definition Study, SPS System Requirements, Final Report, Vols. II-VII, April 1978.

S19. Smith, Marcia S., Research Analyst, Library of Congress, Congressional Research Service, personal communications, July 1978.

S20. U.S. House of Representatives, Solar Satellite Power System Concepts, Hearings before the Subcomittee on Space Science and Application and the Subcomittee on Energy Research, Development and Demonstration of the Committee on Science and Technology, 94 th Congress, Second Session No. 67, February 20, 1976.

S21. Universities Space Research Association, Report of the Solar-Power Satellite Task Group, (Houston, Texas), March 1978. 